University of South Florida

DIGITAL COMMONS

Digital Commons @ University of

@ UNIVERSITY OF SOUTH FLORIDA

South Florida

USF Tampa Graduate Theses and Dissertations

USF Graduate Theses and Dissertations

3-1-2005

\title{
Giving Voice To Parents Of Young Children With Challenging Behavior
}

Jonathan Worcester

University of South Florida

Follow this and additional works at: https://digitalcommons.usf.edu/etd

Part of the American Studies Commons

\section{Scholar Commons Citation}

Worcester, Jonathan, "Giving Voice To Parents Of Young Children With Challenging Behavior" (2005). USF Tampa Graduate Theses and Dissertations.

https://digitalcommons.usf.edu/etd/920

This Dissertation is brought to you for free and open access by the USF Graduate Theses and Dissertations at Digital Commons @ University of South Florida. It has been accepted for inclusion in USF Tampa Graduate Theses and Dissertations by an authorized administrator of Digital Commons @ University of South Florida. For more information, please contact digitalcommons@usf.edu. 
Giving Voice To Parents Of Young Children With Challenging Behavior

by

\author{
Jonathan Worcester
}

A dissertation submitted in partial fulfillment

of the requirements for the degree of

Doctor of Philosophy

Department of Psychological and Social Foundations

College of Education

University of South Florida

Co-Major Professor: Harold Keller, Ph.D.

Co-Major Professor: Linda Raffaele Mendez, Ph.D.

Kathleen Armstrong, Ph.D.

Teresa Nesman, Ph.D.

Date of Approval:

March 1, 2005

Keywords: families, ecological, system of care, early childhood, qualitative

(C) Copyright 2005 , Jonathan Worcester 
Table of Contents

Abstract $\quad$ V

Chapter One. Introduction 1

Building a Rationale for Early Intervention Services 2

Bronfenbrenner's Ecological Model of Child Development 5

$\begin{array}{lr}\text { Purpose } & 8\end{array}$

$\begin{array}{lr}\text { Research Questions } & 10\end{array}$

Definitions 11

Challenging behavior $\quad 11$

IDEA Part-C: The Infants and Toddlers With Disabilities Program 11

$\begin{array}{ll}\text { Young Children } & 12\end{array}$

Chapter Two. Literature Review 13

The Ecological Theoretical Framework 13

Prevalence and Significance of Children Birth to Three With

$\begin{array}{ll}\text { Challenging Behavior } & 15\end{array}$

Medication and the Long-Term Course of Challenging Behavior 20

National Systems of Care for Children Birth to Three With

$\begin{array}{ll}\text { Challenging Behavior } & 22\end{array}$

The Social Security Act $\quad 24$

Medicaid 24

Rationale and Purpose. $\quad 24$

The Strengths of Medicaid. 25

The Weaknesses of Medicaid. 26

The Individuals with Disabilities Education Act (IDEA) 27

Part C: The Early Intervention Program 27

Rationale and Purpose. $\quad 27$

The Role of Early Intervention Services 31

Serving the National Population of

Children Birth to Three 33

Strengths of the Early Intervention Model 34

Weaknesses of the Early Intervention Model 37

Local Level Systems of Care for Children Birth to Three With

Challenging Behavior

Parent Perceptions and Experiences Associated With Their Child's

Disability

The Concepts of “Disability” and "Stigma” 42 
The Experiences and Perceptions of Parents of Young Children

With Disabilities

Promoting Parent Involvement and Collaboration $\quad 49$

Summary

Qualitative Research Methods

Chapter Three. Methodology 59

Purpose $\quad 59$

$\begin{array}{ll}\text { Theoretical Framework } & 60\end{array}$

$\begin{array}{ll}\text { Measurement } & 60\end{array}$

$\begin{array}{ll}\text { Procedure } & 61\end{array}$

Step 1: Participant Recruitment and Sampling 61

Written Contact 63

Telephone Contact 63

Participant Stipends $\quad 65$

Step 2: Bracketing Interview 66

Step 3: Interview Data Collection 67

$\begin{array}{ll}\text { Consent } & 67\end{array}$

Interviews 67

Step 4: Credibility $\quad 69$

Pilot study $\quad 69$

Saturation $\quad 71$

Step 5: Data Analysis $\quad 72$

Chapter Four. Results $\quad 75$

Participant Demographic Information $\quad 75$

$\begin{array}{ll}\text { Participant Descriptions } & 77\end{array}$

Participant One: Bri $\quad 77$

$\begin{array}{ll}\text { Participant Two: Grace } & 79\end{array}$

Participant Three: Darnell $\quad 81$

Participant Four: DJ

Participant Five: Andrew $\quad 84$

$\begin{array}{ll}\text { Participant Six: Lenny } & 87\end{array}$

Participant Seven: Tank $\quad 89$

Research Questions $\quad 90$

Question One: What are the experiences of parents obtaining

Services for young children with challenging behavior

living in Hillsborough County, Florida?

90

Assumption One: Parents of young children with challenging behavior will report difficulties obtaining accurate and useful information regarding their child's challenging behavior 
Assumption Two: Parents of young children with challenging behavior will report difficulties obtaining services and supports designed to reduce their child's rate of challenging behavior

Assumption Three: Parents of young children with challenging behavior will report that their child's challenging behavior created financial stress

Assumption Four: Parents of young children with challenging behavior will report experiencing stress among members of their family

Assumption Five: Parents of young children with challenging behavior will report that they experience community isolation as a result of their child's challenging behavior

Question Two: What types of protective factors

(i.e., microsystemic, mesosystemic, exosystemic, macrosystemic, chronosystemic) are perceived by parents to positively influence the experiences of young children with challenging behavior living within Hillsborough County, Florida?

Individual Level

Microsystem Level

Exosystem Level

Chronosystem Level

Question Three: What types of risk factors

(i.e., microsystemic, mesosystemic, exosystemic, macrosystemic, chronosystemic) are perceived by parents to negatively influence the experiences of young children with challenging behavior living in Hillsborough County, Florida?

Individual Level

Microsystem Level

Exosystem Level

Chronosystem Level

Summary of Questions Two and Three

Chapter Five. Discussion

Review of Research Questions

Question One: What are the experiences of parents obtaining

Services for young children with challenging behavior living in Hillsborough County, Florida?

Obtaining information about challenging behavior

Obtaining services and supports 
Strained family relationships

Question Two: What types of protective factors

(i.e., microsystemic, mesosystemic, exosystemic, macrosystemic, chronosystemic) are perceived by parents to positively influence the experiences of young children with challenging behavior living within Hillsborough County, Florida?

Question Three: What types of risk factors

(i.e., microsystemic, mesosystemic, exosystemic, macrosystemic, chronosystemic) are perceived by parents to positively influence the experiences of young children with challenging behavior living within Hillsborough County, Florida?

Limitations

Implications for Future Research and Practice

Appendix A: Interview Protocol 
Giving Voice to Parents of Young Children with Challenging Behavior

Jonathan Worcester

\begin{abstract}
In recent years, there has been increased interest in the science of child development, particularly relative to early childhood (i.e., birth to 5 years) and children with challenging behavior. A broad interest in brain-behavior relationships and prevention services for young children has led to a renewed interest in the developmental significance of early life experiences (National Research Council \& Institute of Medicine, 2000). Armed with an increasingly large body of neuroscience research, researchers have begun to examine the efficacy of prevention services and supports for young children and families, particularly those with challenging behavior (i.e., behaviors that interfere with optimal learning or engagement in prosocial interactions with peers and adults; Powell, Fixsen, \& Dunlap, 2003). In light of such a research agenda, the voices of parents are often left unheard, despite widespread acknowledgment that "parents are the child's first and most important teacher” (Ferrell, 1985).

A sizable body of interdisciplinary research has evolved in support of a system of care designed to both improve children's growth and development and to prevent occurrences of challenging behavior in young children. While qualitative studies in early intervention and early childhood special education are presently lacking (Sandall, Smith, McLean, \& Ramsey, 2002), local efforts have begun to investigate the impact of services
\end{abstract}


for young children with special needs in Hillsborough County, Florida (Raffaele Mendez \& Hess, 2003). However, detailed reports of parent experiences were not possible, nor did the study focus on challenging behavior. Consequently, the purpose of this qualitative study was to obtain detailed parent reports of experiences raising young children with challenging behavior. Analyzed within an ecological framework relative to emergent themes and reported patterns of risk and protective factors, participating parents were afforded an opportunity to share their stories and provide illustrations of experiences raising young children with challenging behavior. Results indicated that parents not only shared many similar experiences (e.g., difficulties obtaining accurate information, obtaining services and supports, financial stress, stress within the family, and community isolation), but also reported comparable ecological risk and protective factors impacting their child's behavior. Implications for research and practice are discussed. 


\section{Chapter One}

Introduction

In recent years, there has been an increased interest in the science of child development, particularly within the early childhood years (i.e., birth to 5 years) and specifically pertaining to children who exhibit challenging behavior. A broad interest in brain-behavior relationships and prevention services for young children has led to a renewed interest in the developmental significance of early life experiences (National Research Council \& Institute of Medicine, 2000) as well as the "nature versus nurture” argument. Armed with an increasingly large body of neuroscience research (Cadoret, Winokur, Langbehn, Troughton, Yates, \& Stewart, 1996; O’Connor, Deater-Deckard, Fulker, Rutter, \& Plomin, 1998; Plomin, Fulker, Corley, \& DeFries, 1997; Rutter, Dunn, Plomin, Simonoff, Pickes, Maughan, Ormel, Meyer, \& Eaves, 1997; Rutter, Silberg, O’Connor, \& Simonoff, 1999), researchers have begun to ask questions about the efficacy of prevention services and supports for young children, particularly those with challenging behavior (i.e., behaviors that interfere with optimal learning or engagement in prosocial interactions with peers and adults; Powell, Fixsen, \& Dunlap, 2003). In light of such a research agenda, the voices of parents have been often left unheard, regardless of widespread acknowledgment that "parents are the child's first and most important teacher” (Ferrell, 1985). Not only are parents teachers, but they are also experts, with 
stories to share that can shed new light on what is known about the science of child development. While additional qualitative research studies are needed within the fields of early intervention/early childhood special education (EI/ECSE; Sandall, Smith, McLean, \& Ramsey, 2002), national organizations have begun to assess the political, social, and economic impacts of child development.

\section{Building a Rationale for Early Intervention Services}

One of the seminal research efforts conducted in this area was commissioned by the National Research Council and the Institute of Medicine (2000) with the dual purpose of synthesizing the existing body of research in this area, as well as providing an analysis of its corresponding social, economic, and political implications. Emerging from this project were 10 core concepts of development:

1. Human development is shaped by a dynamic and continuous interaction between biology and experience;

2. Culture influences every aspect of human development and is reflected in childrearing beliefs and practices designed to promote health adaptation;

3. The growth of self-regulation is a cornerstone of early childhood development that cuts across all domains of behavior;

4. Children are active participants in their own development, reflecting the intrinsic human drive to explore and master one’s environment;

5. Human relationships, and the effects of relationships on relationships, are the building blocks of health development; 
6. The broad range of individual differences among young children often makes it difficult to distinguish normal variations and maturational delays from transient disorders and persistent impairments;

7. The development of children unfolds along individual pathways whose trajectories are characterized by continuities and discontinuities, as well as by a series of significant transitions;

8. Human development is shaped by the ongoing interplay among sources of vulnerability and sources of resilience;

9. The timing of early experiences can matter, but more often than not, the developing child remains vulnerable to risks and open to protective influences throughout the early years of life and into childhood; and

10. The course of development can be altered in early childhood by effective interventions that change the balance between risk and protection, thereby shifting the odds in favor of more adaptive outcomes (pp. 3-4).

Though the findings of this project provided strong theoretical and anecdotal empirical support for the support the provision of comprehensive services and supports at an early age in order to prevent more serious, long-term outcomes, rigorous empirical replications of meaningful outcomes remain in need (Bailey, 2000, 2001; Bailey, McWilliam, Darkes, Hebbeler, Simeonsson, Spiker, \& Wagner, 1998; Carta, 2002; Guralnick, 2000; Turnbull \& Turnbull, 2000). Given the fact that over 200,000 children and families receive Part C early intervention services and supports in the United States (Hebbeler, Spiker, Mallik, Scarborough, \& Simeonsson, 2003; U.S. Department of Education, 2000), documentation 
of meaningful system level as well as child and family level outcomes has become an issue of national significance and critical need.

Among the many research efforts presently investigating outcomes of children receiving early intervention services is the National Longitudinal Early Intervention Study (NEILS; Bailey, Scarborough, \& Hebbeler, 2003; Hebbeler et al., 2003; Hebbeler, Spiker, Mallik, Scarborough, Simeonsson, \& Collier, 2001; Hebbeler, Spiker, Wagner, Cameto, \& McKenna, 1999), a longitudinal study of over 3,000 children who were either disabled or at-risk of disability and were followed beyond preschool into the elementary school years. The purpose of this study was to not only identify patterns of demographic characteristics of children and families but to also document the types of services and child and family outcomes that were experienced.

Among the study's initial demographic findings was a bimodal distribution of the ages in months of children at the time of their initial eligibility for early intervention services (Hebbeler et al., 2001). Relative to this distribution, the authors found greater proportions of children between the ages of 2 to 10 months and 24 to 32 months, concluding that the corresponding age clusters were attributable to greater numbers of children diagnosed with medical conditions in the first year of life and greater numbers of children with identified developmental delays as they reached age three (pp. 9-10). Likewise, subsequent reports of the NEILS study indicated that "children who entered early intervention at younger ages also had more demographic risk factors than children who entered at later ages” (Hebbeler et al., 2003). 


\section{Bronfenbrenner's Ecological Model of Child Development}

Although conclusions regarding differences between the two age clusters were drawn on the basis of available demographic characteristics, it is important to consider the findings relative to a theoretical framework of early childhood development. One of the most widely accepted and supported frameworks is Bronfenbrenner's ecological theory of child development (Bronfenbrenner, 1979; 1986; 1999), which considers a child's development within “a complex system of relationships affected by multiple levels of the surrounding environment” (Berk, 2002). Bronfenbrenner's model is comprised of five different systems. The microsystem is defined as a child's direct interactions with immediate family members and his or her surroundings. The mesosystem refers to a child's connections to individual microsystems (e.g., home, preschool, hospital, peer group, local neighborhood). The exosystem describes the social environment that indirectly impact the child's experiences (e.g., maternal and paternal places of employment, parental support networks). The macrosystem is defined as a culture's overarching laws, values, and customs, while the chronosystem refers to the sequence or pattern of events that impact a child's development (Berk, 2002). Within Bronfenbrenner's model, the five systems interact dynamically; that is, each system has the potential to impact the other, and all of them affect the child's individual developmental trajectory.

Since its original articulation in 1979, Bronfenbrenner's model has received considerable support and endorsement, particularly from proponents who argue that child development is mediated by environmental variables. In fact, many of the core concepts identified by Shonkoff and Phillips (2000) embody the ecological framework (e.g., 
human development is shaped by a dynamic and continuous interaction between biology and experience; culture influences every aspect of human development; human relationships are the building blocks of health development; the timing of early experiences can matter, but more often than not, the developing child remains vulnerable to risks and open to protective influences throughout the early years of life and into childhood; pp. 3-4). These core concepts not only support the ecological model but provide specific examples of the "patterning of environmental events and transitions over the life course,” that impact familial functioning (Bronfenbrenner, 1986).

Another central advantage to conducting research using ecological theory as a theoretical framework of early childhood development is its fit within a prevention model, where issues are considered relative to their impact upon a regional system of care for young children and their families (SOC; Stroul \& Friedman, 1986). Defined as “a comprehensive spectrum of mental health and other necessary services which are organized into a coordinated network to meet the multiple and changing needs of children and adolescents" (Stroul \& Friedman, 1986), the SOC is an exosystem designed with the intention of playing a significant role in positively influencing the lives of children and families in need of support. Using the ecological framework, professionals within the SOC are able to identify patterns of variables that either positively or negatively impact the children and families they support. When used in this fashion, the ecological model not only helps explain the process of development but also contributes to the evaluation of the SOC in which it is applied.

In an example of such an evaluation, Raffaele Mendez and Hess (2003) conducted an analysis of community-based services and supports for children and families within 
Hillsborough County, Florida. Using a mixed methods design, the researchers sought to estimate the number of children in the county who were identified with special needs and identify both the challenges faced by their families and gaps in local service delivery. Among the children aged birth to three, several challenges were identified: 1) arriving at a proper diagnosis; 2) the child’s primary care pediatrician was not always helpful; 3) entering and navigating the system of care; 4) balancing work and child care; and 5) obtaining parent support (Raffaele Mendez \& Hess, 2003). Likewise, the authors identified a number of service gaps for children birth to 3 , including a lack of adequate developmental screening and assessment, limited access to information, deficiencies in public school education, care coordination, childcare, access to social opportunities, accessible mental health, limited employment, transition, and transportation (pp. 5-9). Relative to the local SOC, the authors offered several suggestions for changing exosystemic variables within the community, including creating a comprehensive community resource directory, organizing a coordinating council to disseminating information to parents and providers, and strengthening linkages between the medical community, schools, and other providers (p. 9). Outlining a set of coordinated, multi-step action plans linked to their research findings, the authors' recommendations were designed to directly strengthen the Hillsborough County SOC, thus indirectly benefiting every recipient within the county.

Based on applications such as those described above, Bronfenbrenner's ecological framework appears to be a useful tool for evaluating the system level effectiveness of a local SOC, as it affords the opportunity to assess the patterns of variables that either strengthen or weaken the system over time. The ecological model has helped parents and 
professionals recognize and influence the broad array of external influences affecting the capacities of families, organizations, and communities to support young children with disabilities (Bronfenbrenner, 1986). While this model has directly enhanced the accountability and efficacy of all services and supports, the use of such an approach has been particularly important for young children with challenging behavior, who often require high levels of service and have inconsistent or poor outcomes.

Unfortunately, there has been an increasing trend in the number of young children with challenging behavior. Estimates may be as high as $12 \%$ or $16 \%$ of the total population aged birth to three (Campbell, 1994; American Academy of Pediatrics, 2001). In light of sharp increases in federal appropriations for Part C services from 1992 to 2002, services and supports were provided to only $2.14 \%$ of the national population of children birth to three in 2002 (Danaher, 2002). Consequently, federal legislators and policy makers have sought to develop, implement, and evaluate strong prevention programs for young children in order to minimize the prevalence and impact of child psychopathology over time, particularly with respect to challenging behavior.

\section{Purpose}

A sizable body of interdisciplinary research has evolved in support of a system of care designed to both improve children's growth and development and to prevent the occurrence of challenging behavior in young children. In lieu of strong theoretical support (e.g., Dunlap \& Fox, 1996; National Research Council \& Institute of Medicine, 2000), there is a great need to demonstrate the Part C program's accountability for both children and their families. Studies are needed to document the program's overall efficacy, as well as its impact on young children and their families. While the need for 
objective, empirical studies is clear, they are not a panacea. Qualitative studies in EI/ECSE are presently lacking (Sandall, Smith, McLean, \& Ramsey, 2002), despite the fact that quantitative studies may not adequately measure family-related outcomes. Such a position has been supported by Bailey and his colleagues (1998), who suggested the following:

Measurement strategies typically call for "objective” assessment by an individual who has no personal investment in whether the outcomes are attained. However in the case of family assessment, the attainment of most family outcomes (e.g., hope, perceived control) is a personal experience that can only be reported by family members themselves (p. 315).

Consistent with this rationale, Fox, Vaughn, Wyatte, and Dunlap (2002) conducted a qualitative study with 20 family members who participated in positive behavior support (PBS) interventions for children aged three to 12 with challenging behavior. Using an open-ended interview format, the authors identified three themes: 1) the difficulties of coming to terms with a child's disability; 2) the importance of having support from others; and 3) the pervasive impact that challenging behavior exerts on all aspects of family functioning (p. 437). Over the course of their investigation, the authors also shared their impression that the families interviewed "felt a need to describe the onset of their journey and felt that those difficult beginnings were relevant to their present-day circumstances” (p. 448). Likewise, the authors reported that such information had provided them with a greater understanding and appreciation for the magnitude of impact their child’s challenging behavior had upon the entire family system. 
Locally, an effort has been made to learn more about the impact of services and supports for young children with special needs in Hillsborough County, Florida (Raffaele Mendez \& Hess, 2003). Though the study addressed the concerns of families with children aged birth to three, detailed reports of parent experiences were not possible, nor did the study focus on young children with challenging behavior. Consequently, the purpose of this study was to obtain detailed parent reports of experiences raising young children with challenging behavior. Analyzed within an ecological framework and relative to reported patterns of ecological risk and protective factors, emergent themes not only offered participating parents an opportunity to share their stories but also provided an illustration of the experiences of parents of young children with challenging behavior living in the Hillsborough County region.

\section{Research Questions}

The following research questions were addressed in this study:

1. What are the experiences of parents obtaining services for young children with challenging behavior living in Hillsborough County, Florida?

2. What types of protective factors (i.e., microsystemic, mesosystemic, exosystemic, macrosystemic, chronosystemic) are perceived by parents to positively influence the experiences of young children with challenging behavior living in Hillsborough County, Florida?

3. What types of risk factors (i.e., microsystemic, mesosystemic, exosystemic, macrosystemic, chronosystemic) are perceived by parents to negatively influence the experiences of young children with challenging behavior living in Hillsborough County, Florida? 


\section{Definitions}

\section{Challenging Behavior}

For the purpose of this study, the term "challenging behavior” was defined as “any repeated pattern of behavior, or perception of behavior, that interferes with or is at risk of interfering with optimal learning or engagement in prosocial interactions with peers and adults” (Powell, Fixsen, \& Dunlap, 2003). Examples of challenging behaviors include prolonged tantrums, physical and verbal aggression, noncompliance, property destruction, stereotopy, self-injury, withdrawal, and screaming (Powell, Fixsen, \& Dunlap, 2003). Regardless of its topography, challenging behaviors all result to some degree in a functional impairment in some aspect of the child's daily functioning (e.g., social, academic, communicative, or adaptive functioning).

IDEA Part-C: The Infants and Toddlers with Disabilities Program

Prior to the advent of PL 99-457, The Education for the Handicapped Act Amendments of 1986, children were generally unable to receive support services until they were old enough to enter school. Through the advent of funding for special education and related services for preschoolers (Part B) and children under age 3 (Part C), benefits granted by the Individuals with Disabilities Education Act (Office of Special Education and Rehabilitation Services, 1997) became available to all children. Relative to Part C, the program was established with three purposes in mind: 1) to enhance the development of infants and toddlers and minimize the potential for developmental delays; 2) to control costly special education services provided in elementary and secondary schools; 3) to strengthen and enhance the ability of families to address the needs of their 
children, particularly those from underrepresented and disadvantaged populations (Powell, Fixsen, \& Dunlap, 2003).

Being national legislation, the Part $\mathrm{C}$ program is responsible for establishing and maintaining statewide systems of early intervention across each of the 50 states and federal territories. While Part C mandates specific components of statewide programs, each state and territory must define the population of children considered "at-risk" and in need of service delivery, identify appropriate diagnostic instruments, procedures, and set criteria to be used when determining eligibility (NECTAC, 2004). As a result, the federal mandate (i.e., Part C) authorizes the role and function of comprehensive state- and regional-level early intervention programs (EIPs) charged with its implementation.

\section{Young Children}

For the purpose of this study, young children were defined as children aged birth to three years of age (i.e., three years, 11 months, 30 days). 


\section{Chapter Two}

\section{Literature Review}

The purpose of this chapter was to provide the reader with a review of the relevant literature pertaining to this study. Specifically, six areas were addressed: 1) the ecological theoretical framework; 2) the prevalence and significance of children birth to three with challenging behavior; 3) national-level systems of care for children birth to three with challenging behavior; 4) local-level systems of care for children birth to three with challenging behavior; 5) parent perceptions and experiences associated with their child's disability; and 6) the qualitative research methodology used in this study.

\section{The Ecological Theoretical Framework}

In order to further understand the theoretical perspective of this researcher, it is necessary to present and discuss the ecological theory (Bronfenbrenner, 1979; 1986; 1999), which served as a framework for understanding and interpreting information obtained from this study.

Built upon the basic premise that "ecosystems consist of the family and its interaction with the environment,” (Bubolz \& Sontag, 1993) human ecology or ecological theory adheres to a number of central premises, including: 1) as human groups, families are part of the total life system, interdependent with other forms of life and the nonliving 
environment; 2) all parts of the environment are interrelated and influence each other; 3) interactions between families and environments are guided by both biological laws of nature and human-derived rules; 4) families have varying degrees of control and freedom with respect to environmental interactions; and 5) decision making is a central control process in families that directs actions for attaining individual and family goals” (Bubolz \& Sontag, 1993). Practically speaking, ecological theory offers a means for understanding the external influences upon an individual and his/her subsequent development.

The most significant contribution of human ecological theory to the social sciences was developed by Urie Bronfenbrenner, who created a four-tier model of family ecosystems. Using the four-tier model of micro-, meso-, exo-, and macro-systems, Bronfenbrenner's model provides a framework for understanding the impact of familial behavior as it is influenced by extra-familial conditions and environments. Relative to children and families, the ecological perspective promotes understanding of "the external influences that can affect the capacity of families to foster the healthy development of their children” (p. 723). Bronfenbrenner presents four levels of influence, each serving as a unique context for a child's development. The microsystem is comprised of the family unit, such as the individual child, parents, siblings, and extended family. The mesosystem refers to interactions, relationships, and the degree of match or mismatch among various microsystems and between microsystems and exo-systems. The exosystem is comprised of those external settings where the child has indirect contact (e.g., parent's work environment), and finally, the macro-system is described as "the broad ideological values, norms, and institutional patterns of a particular culture that make up 
the 'blueprints' for the culture’s ecology of human development” (Bubolz \& Sontag, 1993).

A unique feature of the ecological model is that it is not a static model; the model serves as a dynamic framework for understanding the ways by which different systems within the environment influence an individual's development. In this regard, the ecological model offers a greater understanding of the context in which the child lives. Given the fact that the purpose of this study was to obtain a greater understanding of the context of families of young children with challenging behavior, this theory appeared not only well suited, but an optimal foundation from which to build.

\section{Prevalence and Significance of Children Birth to Three with Challenging Behavior}

In recent years, children’s mental health has been increasingly recognized as an issue of national significance. Children's mental health continues to be one of America's most pressing public health concerns (National Research Council \& Institute of Medicine, 2000; New Freedom Commission on Mental Health, 2003; U.S. Department of Health and Human Services, 2000). Efforts to improve the social and emotional health of young children have become a national priority, as evidenced by the President's New Freedom Commission on Mental Health (2003), the Surgeon General’s National Action Agenda for Children’s Mental Health (U.S. Public Health Service, 2000), and Healthy People 2010 (U.S. Department of Health and Human Services, 2000). Seeking to reduce the mounting stress placed upon the nation's systems of education and public health, federal legislators and policy makers have sought to develop and implement strong prevention programs designed to both supplement existing treatment programs and minimize the prevalence and manifestation of child psychopathology over time. For 
example, the New Freedom Commission on Mental Health identified "early mental health screening, assessment, and referral to services” as one of its top six goals (p. 5). Specific to young children, the Commission articulated objectives designed to promote the mental health of young children, improve and expand school mental health programs, and link primary health care to treatment and supports within the community (p. 57). Likewise, the U.S. Public Health Service's top three goals included an interest in “improving the assessment and recognition of mental health needs in children” (p. 4). Additionally, one of the goals of Healthy People 2010 is to "improve mental health and ensure access to appropriate, quality mental health services” (p. 17), with supplemental objectives recommending an increase in the number of children receiving mental health screening and assessment (goal 18-6) and treatment (goal 18-7) (p. 58). Though the population of children aged birth to three comprises only a portion of the total pediatric population, it is clear that the nation's health and public health agendas have included an interest in reducing rates of challenging behavior in young children.

Relative to these goals, the increased prevalence of challenging behavior in young children has been among the most striking of research findings driving recent policy efforts (Division of Early Childhood, 1999; Campbell, 1994; Zito et al., 2000). Overall, the most frequently reported prevalence rate of challenging behavior was the one reported by Campbell (1994), who concluded "roughly 10\% to 15\% of preschool children (ages two to six years) have mild to moderate problems” (p. 117). However, Campbell’s estimate, as well as others, should be interpreted with caution: prevalence rates for disorders in samples of children under age two were absent from the literature (Powell, Fixsen, \& Dunlap, 2003). Likewise, it is also important to recognize that prevalence rates 
have been highly dependent upon a number of factors, including sample, age, gender, methodology, and instrumentation (Powell, Fixsen, \& Dunlap, 2003). Therefore, it is not surprising that prevalence estimates ranged from 3\% to 6\% (Achenbach \& Edelbrock, 1981; Hebbeler et al., 2001) to as high as $19 \%$ to $21 \%$ among different populations (American Academy of Pediatrics, 2001; Kaiser, Hancock, Cai, Foster, \& Hester, 2000; Navon, Nelson, Pagano, \& Murphy, 2001). Similarly, the finding that boys tended to demonstrate challenging behavior more often than girls may also be explained as a possible artifact of different factors (Campbell, 1994; Kaiser, Hancock, Cai, Foster, \& Hester, 2000; Qi \& Kaiser, 2003; Zeanah, Boris, \& Larrieu, 1997).

In addition to these studies, a wealth of evidence supports the notion that prevalence rates of challenging behavior varied depending upon the presence of risk or protective factors. For example, Qi and Kaiser (2003) reported that while estimates of challenging behavior vary somewhat within the general population, estimates are reported at a higher rate among families with a lower socioeconomic status (SES; p. 188). Specifically, rates of challenging behavior were greater for children of families with a lower SES who experience single or multiple risk factors at either the individual (e.g., low birth weight, difficult temperament), microsystem (e.g., maternal education, maternal depression, parental substance abuse, poor parenting practices), or exosystem (e.g., financial macrosystem) levels (Campbell, 1994; Huffman, Mehlinger, Kerivan, Cavanaugh, Lippitt, \& Moyo, 2001; Ingoldsby, Shaw, Owens, \& Winslow, 1999; Landy, 2002; Nuttall, Romero, \& Kalesnik, 1999; Qi \& Kaiser, 2003; Zigler \& Freeman, 1987; Zill, Collins, West, \& Hausken, 1995). Regardless of the specific rate of challenging behavior each study reported, the most valuable contribution of these studies was that 
they consistently illustrated a direct relationship between increased rates of challenging behavior and the presence of risk factors. This supported the rationale for the provision of comprehensive supports to young children with challenging behavior. Likewise, the presence or absence of risk and protective factors has provided professionals with information about which individual children may be at risk for developing internalizing and externalizing behavior disorders, low academic achievement, poor social interactions, and poor peer relationships (Campbell \& Ewing, 1990; Huffman, Mehlinger, \& Kerivan, 2000; Moffit, 1990; Stormont, 2000).

Research has also shown a relationship among rates of challenging behavior and diagnosis of chronic pediatric conditions. Certain disorders and conditions (e.g., asthma, sickle cell anemia, diabetes, fetal alcohol syndrome, prenatal drug exposure, HIV/AIDS, otitis media) also have increased in recent years, and many of these conditions have psychological components and sequelae (Donenberg, 2001; Mangione, Landau, \& Pryor, 1998; Roberts, 1995; Sexon \& Madan-Swain, 1995). Such findings further substantiate the pervasive impact of challenging behavior among a greater proportion of young children.

Given the evidence available within the empirical literature base, it is not surprising that there has been an increase in the number of children in need of mental health services, particularly among young children. For example, the United States Department of Education estimates that the number of children served in the national early intervention system has increased by approximately 32\% between 1988 and 1998 (Hebbeler et al., 2001; U.S. Census Bureau, 1999). Within this population, the majority of children who demonstrated needs for service were boys (61\%) and children from a 
cultural minority group (44\%; Hebbeler et al., 2001). With respect to the specific concerns and needs demonstrated by this population of children, data from the National Early Intervention Longitudinal Study (Hebbeler et al., 2001) indicated that $58 \%$ of all children were deemed eligible for services due to the presence of a developmental delay, $28 \%$ due to a diagnosed medical/developmental condition, and another $13 \%$ due to circumstances placing them at-risk for delayed growth and development (p. 5). The most frequently reported concern was a speech/communication impairment or delay (41\%), followed by prenatal/perinatal problems (19\%), gross or fine motor delays (17\%), and global developmental delays (12\%) (Hebbeler et al., 2001).

While reports of challenging behavior were not explicitly reported, it is reasonable to assume that challenging behavior was a prominent concern among families reporting delayed growth and development. The reason for this concern was that young children experiencing frustration or difficulty performing a specific skill or participating in a particular routine often expressed their frustration through challenging behavior (Dunlap \& Fox, 1996; Hart \& Risley, 1975; 1999). Such patterns were particularly evident among children with speech and language difficulties, the most frequently reported concern in the National Early Intervention Longitudinal Study (Hebbeler et al., 2001). Given the fact that children who are not able to express themselves verbally were forced to attempt to express themselves through nonverbal communication (e.g., pointing, leading, gesturing), challenging behavior often resulted due to frustration. There also was a well-defined relationship between hearing concerns (e.g., congenital hearing impairments, otitis media), difficulties understanding and producing intelligible language, and rates of challenging behavior (American Psychiatric Association, 1994; Creps \& 
Vernon-Feagans, 2001; Vernon-Feagans, Manlove, \& Volling, 1996). Children who are unable to hear language were less likely to develop age-appropriate receptive and expressive language skills. Likewise, challenging behavior also is represented among children with diagnosed medical/developmental conditions, many of which include challenging or atypical behavior as part of their diagnostic criteria (e.g., autism spectrum disorders, adjustment reactions, attachment disorders; American Psychiatric Association, 1994).

\section{Medication and the Long-term Course of Challenging Behavior}

While national and statewide rates of young children with challenging behavior have increased, trends for prescribing medications to treat challenging behavior in young children have increased as well, particularly in the last 15 years (Zito et al., 2000; Kennedy \& Meyer, 1998). Prescription rates have increased for the three major psychotropic drug classes of stimulants, antidepressants, and neuroleptics. Though pediatric clinical trials for these medications have often been lacking (Zito et al., 2000), many young children are prescribed psychotropic medication. The annual rate of stimulant prescriptions for children two to four years of age increased from 3.57 prescriptions to 8.77 prescriptions per 1,000 children (Zito et al., 2000). Similar increases were reported in the other two drug classes. Together, these data suggest that as the prevalence of challenging behavior exhibited by young children appears to have increased, many parents and professionals have resorted to medication in order to suppress the child's behavior before their behaviors become more severe.

A growing body of research has indicated that challenging behaviors exhibited by young children are often not outgrown, and in fact, have been known to worsen over time 
(Ingoldsby, Shaw, Owens, \& Winslow, 1999; Keenan \&Wakschlag, 2000; McEvoy \& Reichle, 1995). Young children with challenging behavior problems are frequently diagnosed and labeled with externalizing disorders (e.g., Oppositional Defiant Disorder, Attention-Deficit Hyperactivity Disorder, Conduct Disorder) upon enrollment in elementary school, and are often placed in special education programs and/or receive costly individualized supports within the home, school, and community (Kaiser \& Hester, 1997; Keenan \& Wakschlag, 2000; Pierce, Ewing, \& Campbell, 1999).

Research has also supported the impression that externalizing disorders exist along a continuum or developmental trajectory, where patterns of behavior meeting a set of diagnostic criteria (i.e., ODD, ADHD) frequently escalated into conduct disorder (CD), one of the most serious forms of childhood psychopathology (American Psychiatric Association, 1994; Hinshaw \& Anderson, 1996; Loeber \& Coie, 2001). Following this continuum, aggression exhibited by young children may predict future episodes of aggression in childhood and adolescence, as well as a possible diagnosis of psychopathology such as ADHD, ODD, or adult antisocial behavior (Broidy, Nagin, Tremblay, Bates, Brame, Dodge, Fergusson, Horwood, Loeber, Laird, Lynam, Moffitt, Pettit, \& Vitaro, 2003; Campbell \& Ewing, 1990; Campbell, Pierce, Moore, Marakovitz, \& Newby, 1996; Keenan \& Wakschlag, 2000; Lahey \& Loeber, 1997; Moffit, 1990; Stormont, 2000; Tolan Guerra, \& Kendall, 1995). While diagnosis of ODD may not always be a developmental precursor of CD (Lahey, McBurnett, \& Loeber, 2000), research indicated that chronic disruptive and aggressive behaviors, especially among young boys, tend to be predictive of more severe adolescent and adult psychopathology (e.g., Antisocial Personality Disorder, Conduct Disorder). Furthermore, research 
indicated that many juvenile boys who become serious offenders had first demonstrated such behavior prior to age 12, the majority of which had been doing so for a period of at least five years prior to turning 12 (Stouthamer-Loeber \& Loeber, 2002).

Challenging behavior exhibited by young children appears to be part of a model of antisocial development that has been substantiated with research, including exposure to coercive and inconsistent discipline, academic failure, and peer rejection (Patterson, DeBaryshe, \& Ramsey, 1989). Together, these variables have snowballed into a number of dangerous and destructive social problems for children with antisocial development, including school bullying, gang related activity and association with antisocial peers, substance abuse, high school drop out, juvenile offenses, and acts of violence, including violence in schools and weapons use (Batsche, \& Knoff, 1994; Broidy, Nagin, Tremblay, Bates, Brame, Dodge, Fergusson, Horwood, Loeber, Laird, Lynam, Moffitt, Pettit, \& Vitaro, 2003; Lahey \& Loeber, 1997; Moffit, 1990; Patterson, DeBaryshe, \& Ramsey, 1989; Tolan, Guerra, \& Kendall, 1995). Considering the fact that these outcomes have been found to act as accelerators and predictors for adult violence and criminal behavior (American Psychological Association, 1994), a strong rationale exists for intervention during the preschool and elementary school years so that subsequent developmental outcomes (e.g., externalizing childhood psychopathology, adolescent/adult antisocial behavior) may be prevented.

\section{National Systems of Care for Children Birth to Three with Challenging Behavior}

It has been estimated that nearly two thirds of all children in need of comprehensive mental health services and supports do not receive the services they need (Joint Commission on the Mental Health of Children, 1969; Knitzer, 1982; 2000). In 
support of such a large-scale need, the federal government has primarily relied on the Departments of Health and Education in order to establish and maintain a comprehensive system of care for all children and families. Defined by Stroul and Friedman (1986), a system of care is "a comprehensive spectrum of mental health and other necessary services which are organized into a coordinated network to meet the multiple and changing needs of children and adolescents” (p. 3). Articulating a set of core values inherent to an effective system of care, the authors asserted that the system of care should be: 1) child-centered and family-focused, driven by the needs and values of the child and family; 2) community-based, with services and supports administered and managed locally; and 3) culturally-competent, respecting cultural, racial, and ethnic differences (p.18). In simpler terms, the system of care is a framework designed such that services and supports have been maximally individualized and customized to directly target the specific skill deficits impacting a child and family's quality of life (e.g., Hughes, Hwang, Kim, Eisenman, \& Killian, 1995; Schalock, 1994; Turnbull, Turnbull, Wehmeyer, \& Park, 2003).

Originally conceptualized as a multi-component model targeting children and adolescents with severe emotional handicaps, the system of care model has served as a model or framework for the administration and provision of services and supports for infants, toddlers, and their families. Relative to young children with challenging behavior, two federal agencies have served prominent roles: the Department of Health and the Department of Education. The Department of Health oversees, the Medicaid program, which is authorized through Title XIX of the Social Security Act (Agency for Health Care Administration, 2003a) and has been governed by the Agency for Health 
Care Administration (AHCA). In contrast, the Part C early intervention program, a component of the Individuals with Disabilities Education Act (IDEA; Office of Special Education and Rehabilitative Services, 1997), has served as the central service delivery model administered by the Department of Education. In the following sections, both the Medicaid and Part C programs have been presented, with their respective rationales, strengths, and weaknesses articulated.

The Social Security Act

The Social Security Act is a combined federal/state entitlement program that provides financial support for children and families whose low SES prevents them from receiving proper medical care (Centers for Medicare and Medicaid Services, 2003a; Social Security Administration, 2003). Originally enacted into law in 1965, the Social Security Act funds Medicaid, the largest provider of funding for medical and healthrelated services and supports for individuals living in poverty or severe financial distress. Though a federal program, the Social Security Act has allowed states to establish their own eligibility standards, as well as rates of payment, and the scope of services (Centers for Medicare and Medicaid Services, 2003b).

\section{Medicaid}

Rationale and purpose. Medicaid provides financial support for children and families with low incomes who require services related to the assessment and treatment of medical and developmental conditions (Berson, Vargo, Dailey, Zheng, \& Powell, 2003; Centers for Medicare and Medicaid Services, 2003b). Administered by AHCA (Agency for Health Care Administration, 2003b), Medicaid has historically covered a wide array of services, including inpatient and outpatient hospitalization, pediatric and 
nursing services, vaccinations, rural health clinic services, home health care, and early and periodic screening for young children through the Early and Periodic Screening, Diagnostic, and Treatment Program (EPSDT; Wishmann, Kates, \& Kaufman, 2001). In addition to these services, some states have also approved additional services and supports on an optional basis, including diagnostic and clinic services, optometry services, rehabilitation/physical therapy, and home/community-based care to persons with chronic impairments (Centers for Medicare and Medicaid Services, 2003b).

Within the state of Florida, Medicaid has served as a major funding source for children and families with special needs. For example, Berson and colleagues (2003b) reported that during FY2000, 10,190 children birth to three received Medicaid-funded services (p. 8). Though the total expenditure for FY2000 exceeded \$10 million, only 2\% of the total population of children under age 3 in Florida were served ( $N=563,068$; p. 8). Increasing slightly to 11,420 children in FY2001, the total expenditure rose to exceed \$11 million, while providing services to roughly the same proportion of the state's population of young children (Berson et al., 2003b).

The strengths of Medicaid. There are a number of important strengths inherent to the Medicaid model. First, Medicaid has offered a wide variety of services to children and families living in poverty, for which they might not otherwise have access. Second, Medicaid has played an important role in the integration of services for young children and families. For example, there is a well-documented overlap in services provided for children enrolled in both Part C and Medicaid (Berson, Vargo, Dailey, Lemrow, \& Armstrong, 2003b). What this implied is that instances exist where children receiving Part C services also receive payment for the same services under Medicaid. While efforts 
have been undertaken to better separate and clearly identify both Medicaid and Part C funding streams, it is encouraging to know that there has been a recognized need for comprehensive assessment-based interventions and supports at the federal- and statelevels.

The weaknesses of Medicaid. Although Medicaid has served thousands of children and families across the nation, the program faces a number of limitations in its present form. The most significant limitation of the Medicaid program is its theoretical orientation toward the use of a medical model (Berson et al., 2003b). Driven by diagnoses and expert opinion, Medicaid has been generally incompatible with the familyoriented, comprehensive supports provided in the child's natural environment that are now recognized to reflect best practices (Berson et al., 2003b; Bredekamp, 1991; Koegel, Koegel, \& Dunlap, 1996).

A second limitation of Medicaid has been its funding stream. In order to secure financial reimbursement, Medicaid required that providers hold professional licensure. This becomes a problem in the case that a provider may be qualified to provide a specific intervention but does not have a professional license that allows for Medicaid reimbursement (e.g., Department of Education educator certification). Such a limitation has not only impacted a provider's ability to secure reimbursement but also has the potential to impact the overall quality of services available under the auspices of the program.

While the Medicaid program has played a central role in the health and well being of many children and families, it appears that the degree to which the program is tapped by families has depended upon a number of factors. For example, Chen (2003) 
conducted a survey of Medicaid recipients with the intention of examining their relationship between the perceived quality of their relationships with health care providers, service utilization, and health care costs. The author found that an individual's trust in a health care provider was an important factor in the use of services. This was particularly true for children, where parents of younger children were more likely to report trusting their health care provider than parents of older children (Chen, 2003). Such findings illustrate the value of establishing rapport and earning the trust of children and families, two frequent criticisms of the medical model of consultation (Brown, Pryzwansky, \& Schulte, 1998).

The Individuals with Disabilities Education Act (IDEA)

Theories about the impact of services and supports provided during the preschool years led to legislation that made early intervention a reality. In recent decades, children of all ages were guaranteed the legal right to both a free and appropriate public education under the Education of All Handicapped Children Act of 1975, now the Individuals with Disabilities Education Act or IDEA (Office of Special Education and Rehabilitative Services, 1997). This groundbreaking legislation provided all children enrolled in elementary or secondary school with the opportunity to receive an education, regardless of disability or handicapping condition.

Part C: The Early Intervention Program

Rationale and purpose. In 1986, IDEA was amended to include preschool children. Under Pub. L. No. 99-457, also known as Part C, the federal government authorized the provision of grants designed to support the development and implementation of a comprehensive system of early intervention for young children and 
their families (Office of Special Education and Rehabilitative Services, 1997). Early intervention was defined under Part C as "developmental services that are provided under public supervision, provided at no cost except where federal or state law provides for a system of payments by families, and are designed to meet the developmental needs of an infant or toddler with a disability” (Jacob-Timm \& Hartshorne, 1998). The consensus argument was that "providing appropriate services early is of potentially greater impact than beginning services later. Accordingly, an important policy goal has been to identify and get children with developmental problems into programs as early as possible” (Hebbeler, Spiker, Mallik, Scarborough, Simeonsson, \& Collier, 2001; National Research Council \& Institute of Medicine, 2000). In support of this goal, the law has had five specific purposes: 1) enhance the development of young children and to maximize their potential for overcoming developmental delays; 2) reduce the education costs to our society, including our nation's schools by minimizing the need for special education and related services after young children with disabilities reach school age; 3) minimize the risk of institutionalization in adulthood in favor of independent living; 4) enhance the capacity of families to meet the needs of their children; and 5) enhance the capacity of state and local agencies and service providers to identify, evaluate, and meet the needs of historically underrepresented populations, particularly minority, low-income, inner-city and rural populations (Jacob-Timm \& Hartshorne, 1998; Office of Special Education and Rehabilitation Services, 1997).

For years, professionals across a wide array of disciplines (e.g., medicine, psychology, education, communication sciences) have argued that the preschool years (i.e., birth to five years of age) are the most significant period of a child's development 
(Berk, 2002; Guralnick \& Bennett, 1987; National Research Council \& Institute of Medicine, 2000; Shonkoff \& Meisels, 2000). As Bijou (1975) noted, “It is unquestionably the period during which the foundation is laid for the complex behavioral structures that are built in a child’s lifetime” (p. 829). Similarly, Caldwell (1970) commented that, "If the environment can be presumed to have its greatest impact during roughly the first four years of life, careful attention to the development of growth fostering environments during this early period is essential” (p. 721). Similar endorsements can be found relative to social, language, and cognitive development. Experts have agreed that the communicative behavior of young children serves as a foundation for later social and language development (Bricker, 1992). Others have asserted that "the first five years of life are a 'critical period,' during which intervention is likely to be effective in raising intelligence, after which intelligence may be considered fixed” (Scarr \& Arnett, 1987; Zigler \& Freeman, 1987). Consequently, the rationale and intent of early intervention has been clear: Supports and services enhancing skill development at an early age have the potential to increase rates of child development and thus minimize subsequent delays experienced later in life (Dunlap \& Fox, 1996). Sharing this perspective, Shonkoff and Phillips (2000) asserted, "The course of development can be altered in early childhood by effective intervention that changes the balance between risk and protection, thereby shifting the odds in favor of more adaptive outcomes” (p 32). Although there is consensus that intervening early in a child's life is likely to lead to positive outcomes, Dunlap and Fox (1996) highlighted another important point central to the rationale of early intervention. They suggested that service delivery at an early age is particularly helpful because "the early years of development offer a window of 
opportunity to significantly affect serious problem behavior because young children have brief learning histories, and their problem behavior is less likely to be associated with a string of varied and complex interventions" (p. 34). In other words, intervention efforts geared toward preschool children with challenging behavior have a greater potential to be successful because the children have had little time to learn or practice behaviors inhibiting the acquisition of age-appropriate replacement behaviors. Thus, supports targeting preschool children make sense not only from the standpoint that they may have a greater impact over time, but that they may be generally easier to implement as well.

In support of the rationale for early intervention, Bailey and his colleagues (1998) discussed three themes regarding the families of young children with mental health needs that contributed to the emergence of the early intervention model. First, the authors observed that families varied relative to their resources, priorities, concerns, and culture. In other words, no two families are alike in their capacity to support their children, as well as the values and beliefs guiding them in their lives. Second, both families and professionals have acknowledged the need and right to respect families to act as partners in planning and implementing service delivery. Finally, Bailey and colleagues recognized that families are the ultimate decision makers and caregivers of their children, and to include them in treatment planning is to improve the likelihood of positive outcomes in the future (p. 314). As a result of this logic and interest in forming collaborative partnerships with families, a strong consensus emerged among mental health professionals that providing supports early in the lives of children in need was one of the best ways to reduce the overall amount of mental health needs within the nation's population of children (Caldwell, 1970). 
The role of early intervention services. Although the rationale and legal precedent for early intervention has been made quite clear, it is equally important to recognize that early intervention has never referred to a solitary intervention procedure implemented by one type of professional. Rather, early intervention is much more broad, constituting any form of treatment designed to enhance any aspect of the child's development (e.g., cognitive, social, motor, adaptive, communicative), and as a result, the type of professional providing early intervention has depended upon the needs of the child (e.g., pediatrician, psychologist, educator, nurse, behavior analyst, speech and language pathologist, occupational or physical therapist, social worker). Within such a model, professionals have had the opportunity to work collaboratively in multidisciplinary teams, using their expertise to directly target and create comprehensive supports relative to both a child's strengths and identified areas of concern.

Under the auspices of Part C, Jacob-Timm and Hartshorne (1998) noted that each state is responsible to identify a lead agency responsible for the administration, supervision, coordination, and monitoring of programs and activities in the state. In some states, such as Florida, the supervising organization has been the state department of health. In others, the department of education or social welfare has managed the program. Through the supervising agency, the early intervention model is comprised of four components. The first component is Child Find, a comprehensive public awareness program designed to screen and identify all children eligible for early intervention services within a specified catchment area (e.g., the greater Tampa Bay or Jacksonville regions). Once screened, children judged to be in need of additional evaluation receive a multidisciplinary assessment and developmental evaluation. This second component of 
the early intervention model is used to assess the child's development and special needs, as well as the family's capacity to provide effective supports. If the child's skills (e.g., cognitive, adaptive, social, communicative, motor) are significantly delayed or impaired, the evaluation team may determine eligibility for services funded through Part C.

The third component, a comprehensive individualized family support plan (IFSP), is written once eligibility is determined and parental consent for services is obtained. Evaluated at least once annually, the IFSP provides: 1) a statement of the child's current levels of functioning along with a statement of family resources; 2) a statement of anticipated outcomes resulting from funded services; 3) a statement describing the specific services to be provided; 4) a statement of the level and intensity of service provision deemed necessary; 5) a statement describing the environment in which services will be provided; 6) the range of time in which services will be provided; 7) identification of a service coordinator who will serve as a direct liaison between parents and the early intervention system; and finally, 8) a statement describing the specific steps needed to ensure successful transition of the child to preschool or Head Start (Barnett, Bell, \& Carey, 1999; Florida Department of Education, 1998). Once agreed upon by the child's parents and the early intervention program, the signed IFSP serves as a legal contract protecting the child. In addition to guaranteeing the need-specific supports to be provided, parents are guaranteed rights to confidentiality, access to records, mediation, the right to consent or decline services, and the right to written notification prior to any changes are made to the child's IFSP (Jacob-Timm \& Hartshorne, 1998).

The fourth and final component of the early intervention model involves the actual services provided to children. Using the IFSP as a guideline, need-specific 
supports are provided (e.g., speech and language therapy, physical therapy) according to the specified setting and indicated level of intensity/frequency (e.g., therapy two times per week for 30 minutes). Data are collected to document the child's progress and are used to make decisions about changes in the child's IFSP at annual reviews.

Serving the national population of children birth to three. Since the inception of Part C of the Individuals with Disabilities Education Act in 1997, percentages of children birth to three receiving services and appropriations have increased significantly. The average number of children served nationally under Part $C$ has increased by approximately 67\% from FY 1992 to 2002 and by \$242 million, reflecting a 138\% increase in spending over a decade (Danaher \& Armijo, 2003). Though appropriation estimates reflected an increase in spending per child from \$1050 in 1992 to \$1686 in 2002, even more alarming is the fact that only $1.41 \%$ of the national population of children birth to three were served in 1992, and only $2.14 \%$ of the national population of children birth to three were served in 2002 (Danaher \& Armijo, 2003). In some states, recent estimates of the number of young children found eligible for Part C services over the past six years (including those with challenging behaviors) far exceeded the national average. For example, the state of Florida's number of young children found eligible for Part C services over the past six years has increased by approximately $389 \%$ according to reported rates of program eligibility and referrals for service (University of Florida College of Medicine Perinatal/Research Center, 2000). Together, these data support the goals of national public policy efforts calling for improvements in the identification and treatment of children with mental health needs, including preschool-aged children at-risk 
of delayed growth and development (New Freedom Commission on Mental Health, 2003; U.S. Public Health Service, 2000).

Strengths of the early intervention model. After a consideration of the rationale and different strategies available under the early intervention model of service delivery, it is clear that there are a number of distinct advantages in employing such a model to support young children and their families. A primary advantage is that through its attempts to maximize development and minimize developmental delays, Part $\mathrm{C}$ has exemplified the application of primary prevention, a foundational concept reflective of best practices and care. Second, Part C has been organized and administered with consideration for cost and efficiency. Indexing both accountability and practicality, Part $\mathrm{C}$ is a statewide, multidisciplinary, interagency public health program designed to contain costs associated with maintaining more costly special education placements and out-ofschool placements (e.g., in- and out-patient hospitalization, private school, additional resources and treatments). Although the systems vary considerably from state to state, the Part C program was designed to coordinate resources, services, and supports through a combination of local, state, federal, and/or private resources (Hebbeler et al., 2001; Powell, Fixsen, \& Dunlap, 2003; Smith \& Fox, 2003). Third, Part C has embodied an ecological perspective and aims to improve the quality of life of children and families. Through an emphasis of fostering independence and community integration, Part $\mathrm{C}$ has been geared to help empower individuals to pursue their own destinies, as well as to enhance the abilities of family members working to support children in need of services.

Another important strength to the Part $\mathrm{C}$ program is that it has become more inclusive, more antecedent- and ecologically-based (i.e., less emphasis on problems 
within the child and more consideration on variables in the environment that may be changed to promote success), and more outcomes-based. Early intervention was originally designed with the intention of maintaining a child-centered focus and providing services from a wide array of disciplines, and studies suggest that the integrity of this assumption has been maintained. Finally, both parents and professionals have expressed satisfaction with the model and its efficacy (English, Goldstein, Shafer, \& Kaczmarek, 1997; Guralnick, Kiser, Eaton, \& Bennett, 1998; National Research Council \& Institute of Medicine, 2000). In this regard, the Part C model of early intervention incorporates a social validity standard. That is, parents and professionals have acknowledged the importance of the model, the need for its use, and its value as a resource to enhance children’s growth and development.

In addition to these strengths, Bricker (1992) studied the efficacy of the Part C system and its impact upon young children and their families. Through a review of the research literature, she identified the following ten trends:

1. There have been increased efforts to place a range of children who are disabled into community-based programs developed primarily for nondisabled children.

2. There have been increased efforts to study the effects of integration on children and families using more scientifically defensible approaches than have been employed in earlier studies.

3. There has been a move from examining more general effects toward examining more specific outcomes. 
4. Much of the early work used group designs, while current work frequently makes use of a single-subject approach.

5. The early work used almost exclusively quantitative methodologies and work now is either more qualitative or merges both methodologies.

6. There has been a move from focusing primarily upon the effects of integration on children with disabilities to examining the effects on nondisabled children and on the families involved in integration.

7. There is an increased effort to examine more closely the various effects of integration on the parents of preschool children.

8. There is a trend toward manipulating the physical and social environment in order to produce specific outcomes.

9. There is a movement to redefine the areas deemed worthy of intervention.

10. There is a shift in the settings in which integrated programs are conducted (Bricker, 1992).

Bricker's comments suggested that while the early intervention model of service delivery has become increasingly sophisticated, it has remained in its infancy at the same time. It is clear that much work remains in honing the early intervention model of service delivery to better meet the needs of young children in need of mental health services, including conducting and implementing cost-benefit analyses, cost-containment strategies, and documenting ways in which IFSPs can be maintained and generalized to additional settings. However, in light of these concerns, it is clear that early intervention has become more than a legitimate model of mental health service deliverypractitioners, researchers, and parents have attested to the model's value and/or efficacy, 
though empirical demonstrations remain elusive (Bailey et al., 1998; Odom \& Strain, 2002). While we know science has yet to find a cure for mental illness, we do know that it is possible to reduce and inoculate children and families from its devastating effects over time by treating it early and comprehensively.

Weaknesses of the early intervention model. Although its strengths are considerable, Part $\mathrm{C}$ has also had its share of weaknesses and limitations. Indeed, one of its strengths, cost effectiveness, is also a weakness. Proponents of the model suggested that it is cost effective. In other words, the supports and services were effective, thereby alleviating more costly treatment and rehabilitation in the future. To date, much of the research has provided only anecdotal support in favor of statements suggesting that early intervention is truly cost effective. Though studies of a national scale are being conducted (e.g., Hebbeler et al., 2001; Hebbeler, Spiker, Wagner, Cameto, \& McKenna, 1999), additional data is necessary in order to provide a definitive conclusion supporting the program's efficacy. However, one must carefully consider the fact that relative to early intervention, costs pertain to both the financial (e.g., expenses, salaries, materials) and human resources (e.g., hours of labor, number of persons required to achieve a goal) required to support the child within the time frame allocated by the IFSP. While most studies on Part C have failed to directly address cost-benefit analyses, many of the studies were cost-effective in the long-term although costly in the short-term. The reason for this was that early intervention studies may have initially resulted in financial and human labor costs whose impact were reduced over time when the developmental gains of children receiving services were taken into account (Barnett, Pepiton, Bell, Gilkey, 
Smith, Stone, Nelson, Maples, Helenbrook, \& Vogel, 1999; Dunlap \& Fox, 1999;

English, Goldstein, Shafer, \& Kaczmarek, 1997).

In addition to cost-benefit concerns, Barnett, Bell, \& Carey (1999) also noted that there are debates regarding who should be served under Part-C, how needs should be determined, and how children should be served (pp. 1-2). By virtue of its own design, Part C has been open to interpretation - the federal government stipulates the necessary components to include within the system but otherwise allows flexibility in the way that states organize, implement, and administer the program (Hebbeler et al., 1999; Powell, Fixsen, \& Dunlap, 2003). Others, such as Fox, Hanline, Vail, and Galant (1994) noted the debate among professionals using the model, identifying a high degree of disagreement between early intervention providers and educators in elementary schools with regard to their philosophical approach to educating young children. In contrast to professionals in early intervention who endorse developmentally appropriate practices (DAP), professionals in early childhood and elementary education adhere to a model that tends to rely on direct instruction rather than ecological or antecedent-based approaches (Carta, Schwartz, Atwater, \& McConnell, 1991; Fox, Hanline, Vail, \& Galant, 1994).

Finally, it should be noted that the broad scope of the early intervention model has been a limitation in some ways. Although its broad scope has allowed for the provision of a wide array of prevention and intervention services, resulting problems have included both the practical difficulty in successfully coordinating a wide range of services as well as the increasingly difficult task of defining “early intervention” outside of the legal terminology stated in its legislation (Jacob-Hartshorne \& Timm, 1998). Because the 
terminology has defined the model relative to its benefits and purposes, a clearly operationalized definition remains elusive.

Local Level Systems of Care for Children Birth to Three with Challenging Behavior Within Hillsborough County, Florida, the Children's Board of Hillsborough County (CBHC) has served as a central agency in the local system of care for children and families with challenging behavior. Hillsborough County's system of care is in its developmental stages, working to provide comprehensive services and supports to the community with the eventual goal of emphasizing best practices for children from birth to the elementary school years (Children’s Board of Hillsborough County, 2002). In support of this goal, the CBHC articulated five emphases in its 2012 Plan:

1. Funding for prevention services for the very young of the community;

2. The use of proven practices that have been successful;

3. Improving the capability of existing service providers;

4. Effecting practice and systems improvements in the community; and

5. Advocating for policy and funding strategies to maximize the impact of limited resources (Children’s Board of Hillsborough County, 2002).

Such focus is similar to that at the national level, where a greater emphasis has been placed on prevention in the preschool and early elementary years, as well as on evidencebased practices (U.S. Department of Education, 2001). A recent study of children birth to three found that over 1,600 children residing in Hillsborough County were identified with significant developmental delays warranting federally-funded support (Children’s Board of Hillsborough County, 2002). Similarly, a committee of parents and professionals conducted a study confirming such a finding, noting that several problems impacted the 
county's capacity to provide supports to young children with challenging behavior, including lack of adequate, family-friendly information; lack of consistently-provided services; lack of capacity of existing service systems; lack of family-centered services; and lack of services that employ evidence-based practices (Grosz, Behal, Fernandez, Ureta-Mazilli, Graven, Boothby, \& Marfo, 2000; Powell, 2002).

In response to this concern, the $\mathrm{CBHC}$ embarked on two separate initiatives to address the needs of children and families with challenging behavior in the community. First, match-dollar funding was provided for the Early Intervention Positive Behavior Support project (EIPBS; Fox \& Dunlap, 2002), a model demonstration program providing comprehensive services and supports using the positive behavior support model (PBS; Koegel, Koegel, \& Dunlap, 1996). Designed with the intention of serving 200 young children with challenging behavior and their families, the EIPBS program has provided an array of services to residents of Hillsborough County, ranging from developmental screening and parent support groups to intensive home-based intervention and training for community providers.

Second, a coalition called the "Hillsborough Coalition for Children and Youth with Special Needs” was formed with the intention of conducting a comprehensive analysis of the county's community-based services and supports for children and young adults with special needs. Comprised of a diverse committee of parents, professionals, and community leaders, the Coalition collected a wealth of information using mixed methods, including mail surveys, focus groups, interviews, and GIS mapping techniques. Analyses yielded a number of important conclusions specified by age range, including young children birth to three. Relative to this age group, the Coalition found that parents experienced difficulty with the following: 
1. Obtaining proper diagnosis from a pediatrician who was helpful;

2. Acquiring accurate medical information;

3. Entering and navigating the system of care, with specific difficulties in learning about the system of care and obtaining necessary services;

4. Coordinating and scheduling their child's care;

5. Balancing work and care for their child, including transportation to therapies; and

6. Obtaining support for themselves” (Raffaele Mendez \& Hess, 2003).

Although the authors executed a comprehensive study of the needs of children and young adults with special needs in the community, additional research is necessary, particularly with young children with challenging behavior. The study yielded six trends identified specifically for children birth to three. Each trend deserves further investigation in order to further elucidate and articulate what types of programmatic responses are required. In this regard, each of the identified trends reflects only a surface-level discussion of what types of needs may exist within the local community. Finally, it is important to recognize that the intention of this study was to address the general population of children birth to three. As a result, specific information pertaining to young children with challenging behavior was not available.

Together, these two initiatives - the EIPBS program, and the study conducted by Raffaele Mendez and Hess (2003) — have sharpened not only the community’s understanding of its children but the way services are delivered to young children with challenging behavior. Each project informed the community of the magnitude of its need to provide comprehensive services and supports to young children. However, it is clear 
that much work remains, particularly with respect to helping parents cope with the dayto-day challenges of raising a child with a disability and accessing services needed by the child and the family.

\section{Parent Perceptions and Experiences Associated with Their Child's Disability}

It is hard to imagine the experiences of parents learning for the first time that their child has a chronic medical condition, developmental delay, or developmental disability. As Rocco, Metzger, Zangerle, and Skouge (2002) suggested, "No one feels the pain of loss and broken dreams like a parent who has just learned that his or her child has a serious disability” (p. 79). Similarly, Scandariato (2002) commented, "I have heard that autism occurs in approximately four out of every 15,000 births. The fact is, this statistic means nothing unless your child is one of the four” (p. 245). While the impact of identifying a child has a disability is difficult enough, children and families with disabilities are more often subject to isolation, stigma, or discrimination (Goffman, 1963; Oliver, 1996; Susman, 1994), further exacerbating the difficulty of the situation. Therefore, it is important to consider issues of disability and to recognize some of the perceptions and experiences parents have reported as they attempt to cope with their child's disability. In the following sections, a review of the relevant literature on disability and social stigma was presented, followed by a summary and implications for young children in Hillsborough County, Florida.

The Concepts of "Disability" and "Stigma"

Often conceptualized as being limited solely to one’s biology, many have suggested that the term "disability” should be reconceptualized relative to a person's intellect, functional capacity, normality, and beauty (Link \& Phelan, 2001; Marks, 1999). 
It is estimated that nearly $20 \%$ of the entire population is disabled (Snow, 2003). As a result, the disability group has accounted for the largest and most inclusive minority group, crossing all cultures, races, and ethnicities (Green, in press). Representing more than physical attributes, stigma has been described as more of a social phenomenon, consisting of multiple interrelated factors that combine to form an individual's holistic experience (e.g., personal attributes, power, social status, identity, opportunities for inclusion; Goffman, 1963; Link \& Phelan, 2001; Marks, 1999). Similarly, some experts have suggested that the determination or assessment of one's disability is as dependent upon attitudinal and environmental factors as the impairment itself (Barnes, 1996).

Children and families with disabilities are burdened with the need not only to overcome the daily obstacles inherent to childhood but also are forced to overcome a host of additional obstacles, most of which pertain to social stigma and their ability to be included and integrated within society (Goffman, 1963; Marks, 1999). Defined as an adverse reaction to negatively evaluate those who are different from oneself (Goffman, 1963), "stigma” is comprised of the convergence of interrelated components, including labeling, stereotyping, separation, status loss, and discrimination together in a power situation that allows them manifest (Link \& Phelan, 2001). Stigma is contextuallydependent not only relative to individual differences but also to judgments of undesirable attributes, power and social status, and perceptions of identity (Goffman, 1963; Link \& Phelan, 2001).

It is not surprising that most people have considered a disability synonymously with a need for help and/or social support. American society has tended to oversimplify and marginalize disability as being solely biological and devoid of environmental or 
contextual factors (Priestley, 2003). To some degree, this explains why people with disabilities are often viewed as victims (Link \& Phelan, 2001) or associated with a label (Susman, 1994). However, it is equally clear that stigma is complex, existing along a continuum or spectrum. This means that the degree to which a person perpetuates a specific stigma (e.g., culture, disability) is dependent on the extent to which the stigma is perceived to be deviant from social norms (Link \& Phelan, 2001; Marks, 1999). Stigma is contextually-dependent—-that is, stigma is implicitly linked to perceptions of oneself and the groups who hold power and status within a society (Marks, 1999). As a result of this perception, the severity of one's stigma is largely dependent upon both the attributes of the individual rendering the judgment and the community's ability to respect and appreciate individual differences.

Relative to young children, the research on disability and stigma has had important implications for young children with disabilities and their families. There is consensus agreement among experts that disability is not solely limited to one's physical attributes or impairment. Rather, disability is reported to be a complex phenomenon whose definition is individually and contextually defined relative to one's perceptions of their body, identity, culture, and social norms (Priestley, 2003). Given the fact that there is a well-known relationship between rates of challenging behavior and perceptions of isolation, ostracism, and stigma, the impact of a child's disability on his/her family becomes not only an issue of concern but a potential standard by which an intervention is considered effective (Park, Turnbull, \& Turnbull, 2002; Turnbull, Turnbull, Wehmeyer, \& Park, 2003). As a result, this area of research has provided a meaningful contribution to the field in its firm assertion that the experiences and perceptions of parents of young 
children with disabilities are important. It is the perception of parents and the family that, in large part, dictate a family's acceptance of their child's disability, as well as their ability to build upon the strengths of both the child and entire family in order to achieve meaningful outcomes.

The Experiences and Perceptions of Parents of Young Children with Disabilities

Building upon such findings, research efforts have been undertaken to further understand the experiences and perceptions of parents of children with disabilities. A review of this body of literature indicated that a wide array of studies within the field of mental health have been conducted, each with the intention of better understanding the experiences and perceptions of parents of children with disabilities across a variety of contexts. For example, Abelson (1999) conducted a study addressing the impact of a child's disability upon the parents' ability to earn money. Questionnaires addressing experiences, feelings, and perceptions about respite care were administered to a sample of 574 parents of children with developmental disabilities. Chi-square tests were conducted, yielding statistically significant associations between: 1) The age of a child with a disability and parents refusing job opportunities or giving up a job in order to care for the child; and 2) the child's severity of disability and rates of parental absenteeism at work. (Abelson, 1999). The author reported that there was a relationship between a child's age, severity of disability, and their parent's ability to earn money. Not only did parents report missing hours of work, they also reported having to refuse opportunities to work due to their child's need for continued support and care, particularly for younger children and children with severe disabilities (p. 881). Such information only confirms the 
magnitude of stress that a child's disabling condition may have upon the entire family system.

In another study, Crossman and Adams (1980) conducted a study using a pretestposttest control group design assessing the degree to which preschool experience serves to negate the negative consequences of divorce and single-parent childrearing on children's social and cognitive development. A randomly selected sample of 23 children ages $3 \frac{1}{2}$ to 5 years participated in the investigation, which included two experimental groups-children from single-parent families $(\mathrm{N}=7)$ and intact nuclear families $(\mathrm{N}=8)$ receiving an 18-week preschool program, as well as a control group of children from intact nuclear families $(\mathrm{N}=8)$. Measured outcomes include estimates of cognitive development using subscales of the Wechsler Preschool and Primary Scale of Intelligence and the Locus of Control Measure for Preschool Children, as well as interviews and rating scales documenting parent perceptions of social adjustment and challenging behavior.

The authors conducted a series of one-way analyses of variance, with experimental and control group comparisons indicating children from single-parent families earned significantly higher scores on cognitive outcome measures after participating in the 18-week preschool program. Results indicated that divorced mothers were less tolerant of their child's challenging behavior, tend to engage in fewer interactions with their child and tend to report perceiving a greater degree of anger than representative comparison and control groups (p. 211). In spite of this data, however, the authors found that single parent mothers perceived themselves as being both involved and effective in supporting their child through incidents of challenging behavior. Though 
generalization beyond individual or groups of parents to others cannot be assumed, such studies suggest that the presence of a negative life event alone does not necessarily determine the nature or quality of parent-child interactions.

Similarly, Scorgie and Sobsey (2000) interviewed and surveyed 95 parents of children with disabilities in an investigation of "the transformations by parents of children with a variety of disabling conditions” (p. 198). The first phase of the study entailed conducting semi-structured interviews with 15 parents of children with disabilities. Interviews provided parents with opportunities to tell their own stories about an event and its impact on family life. In the second phase, 80 parents were asked to complete a 59-item Life Management Survey. In both cases, parents were selected by agency staff who perceived that they had successfully managed stressful life events.

Descriptive analyses were used to identify trends in both sets of data, with results indicating that "many parents are positively transformed by their relationship with their child who has a significant disability" (p. 204). Across both phases of the study, parents reported experiencing transformations in themselves (e.g., newly acquired roles and traits), their relationships (e.g., with family members, assuming roles as advocates, expanding networks of friends, attitudes toward people in general), and in the way that people view life (e.g., identifying what is truly valuable or important, accepting others, making the most of each day). Suggesting that "transformational outcomes may prove to be the key to understanding personal and family health in response to challenging life events," the authors found that "though the challenges in their lives have been great at times, parents have not only merely coped successfully with them, but have experienced positive or beneficial outcomes” (p. 198). 
While such outcomes vary, what is most important is recognition of the fact that some families derive strength from dealing with a child's disability rather than facing disability as if it were a traumatic loss. Some parents reported that "I’ve had opportunities I never would have dreamed possible, being asked to speak at different conferences and share our story," while others acknowledged that "My child helped me discover a side of myself I never knew existed. I might have never broadened my horizons without this experience" (pp. 200-201). Others remarked that "Success is not how we're perceived or how much we have, it's what we do with each day and with each person in our day" (p. 203). Such findings led the authors to conclude that "Parents and guardians are experiencing positive changes in their lives, changes many of them tell us would not have occurred apart from parenting a child with a disability” (p. 204).

Finally, it is important to recognize the growing accumulation of parents who have made the effort to share their experiences dealing with their child's disability. While some report that the experience of raising a child with a disability has had a positive, life-changing effect (e.g., Green, 2002; Turnbull, Turnbull, Wehmeyer, \& Park, 2003; Whaley, 2002), others have reported experiencing a much greater struggle, including marital stress, isolation from family and friends, changes in family demands, relentless demands, and despair when observing their child engage in self-injurious or dangerous behavior (e.g., Fox, Vaughn, Wyatte, \& Dunlap, 2002; Kayser, 2002; Markey, 2002; Maurice, 1993; Scandariato, 2002). Together, studies documenting the experiences and perceptions of parents of young children with disabilities yield an important conclusion in that a family or caregiver's overall experience is contextually dependent. While research has documented a host of factors that may place a family at risk for 
continued stress, many parents and caregivers also report positive experiences dealing with their child's disability. Thus, it is of paramount importance to consider the ecological factors (e.g., individual, micro-, exo-, and macrosystemic) that may impact a family’s ability to improve their child's quality of life.

Promoting parent involvement and collaboration. Within this body of literature, a growing body of evidence has emerged supporting the inclusion of parents as integral members of a child's support team, both relative to their perceptions and participation in their child's growth and development (Bailey, 2001; McConnell, 2001; Schwartz \& Rodriguez, 2001). Moving away from a medical model toward a collaborative problemsolving framework, parents and caregivers are more frequently considered “equals” or are recognized for the expertise they have acquired as parents and professionals. Adopting a similar philosophical viewpoint, Ferrell (1985) remarked:

Experience taught me many things, such as: 1) that parents know their children better than any professional does, and 2) that stock phrases of reassurance-_it will be okay,' 'it’s just a phase,' 'she'll grow out of it,' 'you're just going through shock/anger/guilt/grief'—really don't mean a whole lot; and 3) that it really isn't very difficult to make a supposedly intelligent person feel small and worthless and insignificant simply by what you say—or don’t say—-to them (p.203). Not surprisingly, Ferrell and others emerged calling for a greater degree of support for this approach. She concluded her discussion, arguing:

As teachers, you would not hesitate to share information with a colleague. That colleague may or may not read the article you give to him or her, but that doesn't keep you from sharing it. Well, parents are our colleagues too, or should be, if we 
really believe in parent involvement. They will decide when they are overwhelmed. They will decide what's interesting and valid to them. And believe it or not, they will read the article we copy, or not read the article, learn from it or not learn from it, accept the information or not accept it, grow from it or not—based on where they are and not where the expert is! (p. 204).

Similarly, Boulware, Schwartz, and McBride (1999) wrote in support of the use of the positive behavior support (PBS) model, largely due to the fact it incorporates a collaborative model that recognizes parents' skill and expertise. The authors' remarked: These strategies are not a simple cookbook - they do not tell you what to do for every child who has problems with transitions, for example, but they do offer a framework for working with families to help them solve the challenging behaviors they experience at home and in the community (p. 39).

Such findings were supported by the work of King, King, Rosenbaum, and Goffin (1999), who articulated a conceptual model of factors influencing psychosocial outcomes for parents of children with disabilities, designed to help identify parent perceptions of family-centered, professionally-provided caregiving relative to their own well-being. Evaluating a number of variables, including prognostic indices (i.e., demographic factors, disability parameters), professional caregiving, mediating variables (i.e., social-ecological factors, psychosocial life stressors, \& coping strategies), and outcomes (i.e., satisfaction with care, parent emotional well-being) (p. 43), the authors found that parents reported a greater level of well-being when services were delivered in a family-centered fashion and addressed issues such as the availability of social support, quality of life, and overall family functioning (p. 51). Similar findings were reported by other researchers (e.g., 
Fake, 2002; Fox, Benito, \& Dunlap, 2002; Palmer, Borthwick-Duffy, Widaman, \& Best, 1998; Peck, Carlson, \& Helmstetter, 1992; Rocco, Metzger, Zangerle, \& Skouge, 2002; Williams \& Hieneman, 2002), who found that parents of children with and without disabilities both reported positive perceptions of inclusive practices, particularly for children with mild to moderate disabilities.

In addition to documenting the need to foster a collaborative atmosphere between parents and professionals, research has also addressed communication, another critical component impacting a family's ability to cope with their child's disability. For example, Barry and Singer (2001) conducted a study on the grief responses of parents whose newborn infants were admitted into neonatal intensive care units (NICU).. Recognizing the stressful circumstances associated with NICU hospitalizations, the authors introduced a journal writing intervention for parents to use as a means of communicating their experiences. The results were encouraging-parents reported satisfaction with opportunities to engage in journal writing as they dealt with their child's traumatic events. Likewise, Singh (2003) interviewed a sample of 40 mothers of children with disabilities, finding that $75 \%$ preferred daily communication with their child's classroom teacher, with 70\% preferring it through the use of a written log (p. 171). Though both studies have entirely different foci, they illustrate an important point in that parents of children with disabilities may benefit from additional opportunities to communicate and share their experiences. Given the fact that parents have often reported difficulties coping with daily demands levied by their children (Rocco, Metzger, Zangerle, \& Skouge, 2002; Scandariato, 2002), communication is of the utmost importance in providing support to families of children with disabilities. 
In summary, a review of the relevant literature documenting the experiences and perceptions of parents of young children with disabilities was provided. The literature has shown that parents and families of young children with disabilities vary in the degree by which they accept and cope with their child's disability. However, it is also important to note that parents and families alike tend to report a preference for opportunities to engage in collaborative partnerships with professional caregivers, as well as having open lines of communication. In the case of these preferences, parents reported a greater degree of satisfaction and/or a more positive experience supporting their child with a disability when one or both components were available to the family.

Collectively, these studies provide an important contribution to the literature in that they together attest to the uniqueness of the parenting experience. While it appears that the experience of having a young child with a disability causes a predictable array of stressors (e.g., financial expenses, increased time demands, marital stress, social isolation), and that parents may report more positive experiences when given opportunities for both open communication and collaboration with professional caregivers, it is clear that each family context is unique, deserving its own exploration and inquiry.

\section{Summary}

The purpose of this literature review was to synthesize the relevant research pertaining to the purpose of this study. In this regard, information was presented illustrating the ecological theoretical framework, documenting the significance and longterm course of challenging behavior exhibited by young children, the systems of care (e.g., Medicaid, Part C) that serve children and families with challenging behavior, 
including local efforts to provide comprehensive behavior support services, and parent experiences and perceptions associated with the acceptance of a child's disability. Relative to these areas of research, a number of important points were identified. First, the ecological viewpoint (e.g., Bronfenbrenner, 1974) has provided an optimal theoretical framework by which it may be possible to better understand the greater context by which a family functions. Second, findings from the National Early Intervention Longitudinal Study (Hebbeler et al., 2001) documented that the majority of young children eligible for Part C services enter the program at one of two points: prior to 12 months and after 24 months of age. Hebbeler and colleagues (2001) reported that more than $38 \%$ of all children entering the Part $C$ program did so between birth and 12 months, while an additional 28\% entered after their second birthday (p. 5). Third, and perhaps more importantly, the authors found the age of the child at the point of their first family support plan varied depending upon their inferred reason for eligibility. On average, children considered at-risk of delay (8-9 months) and diagnosed with medical conditions typically received services at an earlier age (10-11 months) than children diagnosed with developmental delays (21 months) (pp. 9-11). Together, these data suggest that within the population of young children that require Part $C$ services, there are distinct differences between children depending upon the degree to which they are considered atrisk, disordered, or delayed.

Fourth, the recent study conducted by Raffaele Mendez and Hess (2003) identified a number of stressful circumstances specific to parents and caregivers of young children at the local level (i.e., Hillsborough County, Florida). In their study, the authors found that families reported that the following events or circumstances were stressful: 1) 
obtaining their child's initial diagnosis (as evidenced by reported fluctuations in the helpfulness of pediatricians); 2) acquiring accurate medical information relative to their child's disability or diagnosis; 3) learning about the local system of care and obtaining services for their child; 4) balancing the pressures of work and caring for their child; and 5) obtaining necessary parent or family support (p. 9-10).

Finally, the information conveyed in this literature review closely resembles many of the professional experiences of this researcher working within Hillsborough County, Florida. After working with children and families of Hillsborough County, it is the professional opinion of this researcher that there are appreciable differences between parent perceptions and experiences when they first enroll in the Part C program before 12 months of age versus those who enter it after 24 months of age. As a result, the purpose of this study was to document the experiences of both groups of parents with children in Hillsborough County who exhibit challenging behavior-those who first enrolled before 12 months of age and those who entered after 24 months.

\section{Qualitative Research Methods}

Qualitative research methodology was used to address the articulated purpose and corresponding research questions for this study. Though the specific methodology to be used has been presented at greater length in the next chapter, it is appropriate to review and summarize some of the literature on qualitative research methods.

The National Research Council's Committee on Scientific Principles for Education Research (Shavelson \& Towne, 2002) reported among its set of fundamental scientific principles that "methods are used that permit direct investigation of the question" and that one must "provide a coherent and explicit chain of reasoning” when 
conducting research (Shavelson \& Towne, 2002). In the case of a great many studies, a combined positivist/ postpositivist perspective and quantitative methodology is an appropriate match with the nature of a study's research questions. On other occasions, a more qualitative approach is necessary in order to further document and understand the experiences of others. Such an approach better allows the researcher to capture the individual's point of view, examine the constraints of everyday life, and secure rich descriptions of one’s experience (Denzin \& Lincoln, 2000).

Quantitative research has traditionally focused on the comparison of standardized scores, rating scales, and comparisons across participants with a focus on the representative sample and randomized selection of samples (Gall, Borg, \& Gall, 1996). Survey studies have also been a popular means of obtaining data on issues such as attitudes, prevalence, and satisfaction. Though these may be useful to assess such concerns, an individual's unique experiences cannot be captured using such methods, nor can it be inferred that experiences allow for comparison. Similarly, Marshall and Rossman (1989) suggested that the following types of research questions most often lend themselves to a qualitative methodology:

- $\quad$ Research that delves in depth into complexities and processes.

- Research on little-known phenomena or innovative systems.

- Research that seeks to explore where and why policy and local knowledge and practice are at odds.

- Research on informal and unstructured linkages and processes in organizations.

- Research on real, as opposed to stated, organizational goals.

- Research that cannot be done experimentally for practical or ethical reasons. 
- Research for which relevant variables have yet to be identified (p. 57).

Relative to this study, the research questions driving the study investigated the relationship between human actions and the setting or context by which they occur. Using a qualitative methodology, it becomes possible to obtain a much more detailed, indepth kind of analysis that would not otherwise be necessary using quantitative methods. Unfortunately, qualitative studies remain uncommon within the field of EI/ECSE (Sandall, Smith, McLean, \& Ramsey, 2002).

A phenomenological approach makes it possible to qualitatively study how one’s reality appears, rather than to objectively document the observable reality (Gall, Borg, \& Gall, 1996). Phenomenology does not entail the use of inductive reasoning; rather, phenomenological research involves the description and illustration of one's lived experience (Van Manen, 1990). Using this qualitative method, this researcher used a semi-structured phenomenological interviewing technique (Denzin \& Lincoln, 2000; Marshall \& Rossman, 1989) to facilitate the opportunity for parents of young children with challenging behavior to tell their story—-to share their experiences from the initial point where they learned their child was developing differently than other children to the present day. Phenomenology is "the study of lived experiences and the ways we understand those experiences to develop a worldview” (Marshall \& Rossman, 1989). The phenomenological approach assumes that an individual's experiences can be structured and narrated to others. Consequently, the purpose of the approach was to obtain an in-depth, explicit focus on the shared experiences of others.

Given the subjective nature of qualitative research, one must acknowledge the impact of the researcher as an active participant in the interview process. Following this 
logic and rationale, it was anticipated that this researcher would assume a passive role, where opportunities for interaction were minimized in favor of active listening and encouraging parents to tell their story—to "speak their voice" (Rogers, 1993). However, in recognition of the fact that one's own values may bias subsequent data analyses, an epoche was conducted (Gubrium \& Holstein, 1997). Using an epoche, it becomes possible for the researcher to identify his or her own philosophical orientation and acknowledge the experiences and values that are used to make judgments of one's own experience. In this exercise, this researcher provided a full written description of his personal experience relative to the research topic, thereby "bracketing” or containing personal experiences from interview and affording the researcher "to gain clarity from his own preconceptions” (Marshall \& Rossman, 1989). Such an exercise was conducted prior to the initiation of the study in order to acknowledge any predispositions and values that may influence subsequent data interpretation and analysis.

Upon completion of the interviews, data were organized and analyzed according to typically reported qualitative data analysis procedures, such as those outlined by Marshall and Rossman (1989): 1) organizing the data; 2) generating categories, themes, and patterns; 3) coding the data; 4) testing the emergent understandings; and 5) searching for alternative explanations (p. 152). Similarly, Frechtling \& Sharp (1997) offer a set of guiding questions for use in driving the analysis:

- What patterns and common themes emerge in responses dealing with specific items? How do these patterns (or lack thereof) help to illuminate the broader study questions? 
- Are there any deviations from these patterns? If yes, are there any factors that might explain these atypical responses?

- What interesting stories emerge from the responses? How can these stories help to illuminate the broader study questions? (p. 4-2).

It was anticipated that such guiding questions, posed in reference to the proposed research questions of the study, would contribute to the organizing and subsequent understanding of the experiences and perceptions of parents of young children with challenging behavior.

In summary, qualitative studies can be a rich source of information documenting how an individual understands and communicates his or her experience. The qualitative approach offers participants the opportunity to continue to add what they want to share over time, whereas quantitative methodology forces researchers to make inferences on their data at that moment in time. Perhaps most importantly, the qualitative approach offers the opportunity to further understand the experiences of families by seeking out themes for the specific population being studied instead of forcing specific themes that may not be relevant (Denzin \& Lincoln, 2000). Based upon such information, the researcher elected to use qualitative methodology in order to identify a number of themes that either expanded upon those identified by Raffaele Mendez and Hess (2003) or represented a new contribution to the local community. 
Chapter Three

Methodology

\section{Purpose}

The purpose of this study was to document the experiences of parents of young children with challenging behavior living in Hillsborough County, Florida. Using an ecological framework, emergent themes were reported, thereby allowing participating parents to both share their stories and to provide case illustrations about the obstacles and supports encountered in the process of navigating through the local system of care. The following research questions were proposed for this study:

1) What are the experiences of parents obtaining services for young children with challenging behavior living in Hillsborough County, Florida?

2) What types of protective factors (i.e., microsystemic, mesosystemic, exosystemic, macrosystemic, chronosystemic) are perceived by parents or guardians to positively influence the experiences of young children with challenging behavior living in Hillsborough County, Florida?

3) What types of risk factors (i.e., microsystemic, mesosystemic, exosystemic, macrosystemic, chronosystemic) are perceived by parents or guardians to negatively influence the experiences of young children with challenging behavior living in Hillsborough County, Florida? 


\section{Theoretical Framework}

A phenomenological approach (Seidman, 1998) was used to document and examine the experiences of the participants of this study. According to Gall, Borg, and Gall (1996), phenomenology is defined as ”the study of the world as it appears to individuals when they place themselves in a state of consciousness that reflects an effort to be free of everyday biases and beliefs” (p. 600). As noted by Marshall and Rossman (1989), the purpose of the phenomenological approach is to "describe the meaning of a concept or phenomenon that several individuals share” (p. 112). Using such a model, this researcher was able to learn more about each participant's past and present-day experiences as they are shared. While time consuming, the phenomenological approach offered the advantage of permitting both a focus of the researcher's personal experience, as well as the deep, lived meanings of the interview participants (p. 113).

\section{Measurement}

A semi-structured interview utilizing open-ended questioning was used in this study. Semi-structured interviewing involves “asking a series of structured questions and then probing more deeply using open-form questions to obtain additional information” (Gall, Borg, \& Gall, 1996). Using a semi-structured interview format, it was possible for this researcher to consistently pose a series of questions across participants while maintaining the ability to ask follow-up probe questions to allow for elaboration and content saturation. In the case of this study, a single, open-ended question was asked to parents, prompting them to "tell their story" to this researcher. Please see Appendix A for the specific interview protocol. 


\section{Procedure}

\section{Step 1: Participant Recruitment and Sampling}

The first step of this study was to recruit and obtain consent from participants selected for the study. Purposeful sampling procedures were utilized in this study (Sandelowski, 1995). According to Sandelowski (1995):

In qualitative research, events, incidents, and experiences, and not people per se, are typically the objects of purposeful sampling. People are certainly central in all kinds of inquiry approaches in the health sciences, but they enter qualitative studies primarily by virtue of having direct and personal knowledge of some event (e.g., illness, pregnancy, life transition) that they are able and willing to communicate to others and only secondarily by virtue of demographic characteristics (e.g., age, race, sex) (p. 180).

With respect to this study, Sandelowski's remarks are salient in that they provide an important differentiation between “convenience” and "purpose.” Participants were not selected merely due to convenient availability or willingness to participate. Likewise, parents or guardians were not asked to participate if their child does not have challenging behavior. Rather, parents or guardians were intentionally or purposefully selected based on the criteria that their child demonstrates challenging behavior and has obtained some sort of services and/or supports from the community.

From a conceptual standpoint, purposeful sampling allows one not to compare but to obtain a diversity of voice, the unit of analysis for this study. The use of the purposeful sampling procedure was to create a sample of information- 
rich cases described by parents of young children with challenging behavior, whose voices incorporated the racial, ethnic, and cultural diversity inherent to Hillsborough County, Florida. Combined with the inclusion of both parents or guardians of children with challenging behavior who initially obtain Part C services before 12 months and parents or guardians of young children with challenging behavior who obtain Part C services between the ages of 24-36 months, the purposeful sampling procedure provided a greater opportunity for this researcher to identify issues of central importance pertaining to the proposed research questions. Consequently, a sample size of 6 to 10 participants selected using purposeful sampling was anticipated in order to adequately sample a group of parents or guardians whose voice may be similar to other parents or guardians in Hillsborough County, Florida. A final sample of eight parent participants was obtained. Such a sample size allowed for adequate "saturation" of information, where repetitive themes are supported with interview information obtained across a diverse sample of participants (Seidman, 1998).

With respect to recruitment, participating parents or guardians were selected from three sources: 1) the entire sample of parents or guardians whose child was either enrolled in the EIPBS program or on its wait list; 2) parents or guardians whose child was receiving services and supports provided through the Infants and Young Children of West Central Florida (IYC); and 3) parents or guardians whose child was receiving services and supports through the Florida Diagnostic Learning Resources System (FDLRS). In addition to the latter two sources, the Early Intervention Positive Behavior Support (EIPBS) program is a unique resource for parents in Hillsborough County, Florida. 
Children eligible for Part C services who also presented with challenging behavior were also deemed eligible to receive comprehensive services and supports through the EIPBS program. Training, coaching, and technical assistance are provided to parents and caregivers with the goals of both enhancing the child's social and emotional skills and reducing rates of challenging behavior. The EIPBS program also features a parent education and support group, which provides an overview of the positive behavior support (PBS) process and teaches many of the specific skills required to successfully implement PBS intervention plans.

Written contact. Initial contact for prospective participants in the EIPBS program was established in writing, through a flyer disseminated to all parents or guardians. In order to ensure confidentiality, copies of the flyer were mailed by the EIPBS director. With respect to both IYC and FDLRS, contact was established either by disseminating the flyer through IYC’s Family Resource Specialists/ FDLRS' Parent Liason Coordinator or through personal contact by this examiner with parents or guardians attending the IYC/FDLRS-sponsored “New Star Training” sessions. Please refer to Appendix B for the flyer for participant recruitment.

Telephone contact. Interested parents or guardians voluntarily contacted this researcher to further discuss their participation in this study. During this contact, the researcher explained the study's consent, confidentiality, financial incentives, and data collection procedures to each potential participant in greater detail (e.g., number of interviews, anticipated interview duration of 45 to 60 minutes, the use of audio taping and transcription). In addition, this contact provided this researcher with the opportunity to ask questions linked to several screening criteria. Using these criteria, this researcher 
was able to purposefully refine the sample of potential participants into the final sample of eight parents or guardians. Criteria for the study were assessed using a family demographic data form (Appendix C).

The first criterion involved the participant's primary language. Given the fact that this researcher is a mono-lingual English speaking individual, selection was limited to participants fluent in English. The second and third criteria involved the age of the child and the presence of challenging behavior. Participating families were required to have a young child age three who demonstrates challenging behavior (i.e., up to three years, 11 months, 30 days). Similarly, the young child had to demonstrate a level of challenging behavior that was perceived by parents or guardians to "interfere with or is at risk of interfering with optimal learning or engagement in prosocial interactions with peers and adults” (Powell, Fixsen, \& Dunlap, 2003). However, parents or guardians who were either receiving or on the wait-list to receive EIPBS services and supports automatically met these two criteria, based on the program's own inclusion criteria.

The fourth criterion pertained to history of previous contact with this researcher. During the previous year (i.e., July 2003 to July 2004), this researcher served as an evaluator in the Tampa Regional Early Intervention Program, and in this capacity, both determined Part C program eligibility and referred families to the EIPBS program for services and supports. In the event that a parent or guardian had previous professional contact with this researcher prior to the initiation of this study, efforts were made to ensure their exclusion as a matter of both avoiding a potential conflict of interest and maintaining objective data collection. 
The final set of inclusion criteria pertained to demographic characteristics of the interested parents or guardians. In order to obtain a diversity of voice consistent with the residents of Hillsborough County, Florida, individual participants were selected for inclusion using purposeful sampling. Asking parents a list of demographic questions during their telephone contact, this researcher intentionally selected a set of participating parents or guardians who varied in their racial, ethnic, cultural, and demographic characteristics but shared the commonality of caring for young children who have challenging behavior. In addition to these criteria, participants were only considered eligible if they were a resident of Hillsborough County, Florida for over 12 months. The latter criterion enhanced the likelihood that the experiences reported reflected the experiences of families living within the same geographic region.

Participants who met the study's criteria were asked to provide verbal commitment to participate in two interview contacts, the first of which were scheduled at that time at a location of the participating parent/guardian's convenience. Participating families were also invited to meet at the University of South Florida College of Education in the event that a location conducive to interviewing was not identified. In the event that the number of interested families exceeded the sample of this study, the first 10 families who met the eligibility requirements of this research study were selected for participation. Those who did not meet this study's criteria were thanked for their time. Please refer to Appendix D for a copy of the informed consent.

Participation Stipends. Given the fact that parents/guardians volunteering to participate in this study were asked to both share personal information and make arrangements to spend time with this researcher, participating parents/guardians were 
provided with a $\$ 50$ cash stipend as a token of appreciation. Funding of up to $\$ 500$ was secured via the Family Involvement Funds Plan of the Tampa Area Infants and Toddlers Early Intervention Program. Funded through the state of Florida's Children’s Medical Services Early Intervention Program Office, the Family Involvement Funds Plan is designed to provide a wide variety of opportunities for families to attend and participate in trainings, meetings, and other activities to enhance the EIP experience for families in the program and also for other families who may benefit indirectly. Administered by Infants and Young Children of West Central Florida, Inc., the funds available through this plan were used solely for the purpose of compensating parents/guardians who participate in this study.

\section{Step 2: Bracketing Interview}

Before data collection was initiated, this researcher conducted a bracketing interview (i.e., epoche). According to Marshall and Rossman (1989), phenomenological researchers are required to write an a priori description of their own experiences, thereby allowing them to "bracket" their experiences from those of the study's participants. The authors noted that "the purpose of this self-examination is for the researcher to gain clarity from his own preconceptions, and it is part of the 'ongoing process rather than a single fixed event'” (p. 113). In support of this need, Janesick (2000) offered a model for bracketing that was used in this study. The following steps were recommended for use in the process of bracketing:

1. Locate within the personal experience or self-story, key phrases and statements that speak directly to the phenomenon in question;

2. Interpret the meanings of these phrases as an informed reader; 
3. Obtain the participants' interpretation of these findings, if possible;

4. Inspect these meanings for what they reveal about the essential, recurring features of the phenomenon being studied;

5. Offer a tentative statement or definition of the phenomenon in terms of the essential recurring features identified in Step 4 (p. 390).

The bracketing interview is located in Appendix E.

\section{Step 3: Interview Data Collection}

Consent. Prior to engaging in the interview process, interested participants were required to sign a University of South Florida Institutional Review Board informed consent form (see Appendix D) as well as provide verbal commitment to participate in a second interview contact. Participants were informed that data collection would consist of semi-structured interviews, but were also invited to share any written information (e.g., pertinent reports and medical records) they felt would potentially add to the data collection. Participants were likewise informed that all written information and interview transcripts were coded by number and stored in a locked filing cabinet as an additional measure of protecting confidentiality. Per the participant's preference, signed copies of informed consents were either mailed or provided at the time of the second interview contact.

Interviews. Using the interview protocol located in Appendix A, this researcher conducted a semi-structured interview with each participant using open-ended questioning. While the interview was conducted, this researcher also completed a checklist of topic domains discussed by each participant (e.g., diagnosis; pregnancy, labor, and neonatal course; stressors associated with obtaining support; impact on family 
members; Part C services and supports; preschool or daycare experiences). The specific content included in the checklist was determined by participant responses from the pilot study, which has been described in the next section. Upon completion of the interview, a second follow-up interview was scheduled with each participant. Each initial interview lasted an average of 67 minutes, with follow-ups lasting an average of 48 minutes. The average total length of the two interviews combined was 116 minutes.

Interviews were audio taped and transcribed using a procedure called “shadowing” (Newman, 2002). Using this procedure, this researcher played back a segment of the audio taped interview, paused the tape, and then dictated the text verbatim into a computer using Dragon NaturallySpeaking $6{ }^{\circledR}$ voice recognition software. Dictating each interview in its entirety consequently allowed this researcher to create a series of unabridged transcripts.

At the beginning of the second meetings, audio taping and timing resumed. Following a specific theme verification interview protocol (Appendix F), this researcher began by presenting a sample of representative transcript segments from the transcript of the interview. The participant was asked to review the quotes and make any changes they wish. Upon completion of that task, this researcher presented the checklist of topic domains completed during the interview, showing the participant the list of the specific discussion topics addressed previously. At that time, the participant was provided the opportunity to discuss any topic that was not discussed during the previous interview. Once again, this researcher completed the checklist of topic domains over the course of the meeting. Upon completion, the participant was thanked for their time and received a financial incentive of $\$ 50$ for their participation. 
Using the same transcription procedure, this researcher transcribed the second meeting. The transcript from the second interview was attached to the transcript of the interview, thereby creating a "master" unabridged transcript for the participant that was subsequently analyzed relative to the stated research questions. This process was conducted with each participant in the study.

\section{Step 4: Credibility}

Upon completion of each interview, the researcher read each transcript in its entirety and identified salient themes that are reported. Following the recommendation of Patton (1990), a “chain of evidence” was maintained with each transcript segment, so that evidence could be traced back to the specific participant, transcript page, paragraph, and line in which it appeared. Following such a procedure, it was possible for the researcher to select transcript segments representing emergent themes from each transcript. Representative transcript segments were presented to each participant in a second meeting with the researcher to verify each transcript's accuracy. At that time, participants were encouraged to make any additions, changes, or deletions to their transcripts in order to ensure that their experiences are told with as high a degree of integrity and free of the researcher's bias as possible.

Following the second meeting, the researcher made changes to each transcript exactly as indicated by the participant. This process was held constant across participants, thus enhancing the study's overall credibility and structure. Lists of thematic assumptions and subcategories are located in Appendix I.

Pilot Study. Prior to engaging in the proposed data collection and credibility procedures, it was necessary to first conduct a brief pilot study in order to ensure both the 
integrity of the data collection process, as well as the credibility of the resulting data. Following this rationale, a set of interviewing procedures were pilot tested on the first three participants. Using the same selection and credibility procedures as stated previously, this researcher conducted audio taped interviews in the accompaniment of a member of his doctoral committee who has extensive experience conducting qualitative research (i.e., Dr. Nesman). This researcher and the doctoral committee member collaboratively developed an interview protocol for use in this study, which is located in Appendix A.

Using the "shadowing" transcription procedure, this researcher transcribed each interview in its entirety and reviewed the resulting transcript with Dr. Nesman. Together, this researcher and Dr. Nesman assessed the average length of the interviews, and evaluated the wording of the interview protocol relative to the information provided in the transcript. In addition, this researcher and Dr. Nesman created a checklist of topic domains from the three sets of transcripts obtained in the pilot study (e.g., diagnosis; pregnancy, labor, and neonatal course; stressors associated with obtaining support; impact on family members; Part C services and supports; preschool or daycare experiences). Upon approval of the doctoral co-chairs, the resulting checklist was used with all remaining participants to further identify themes emerging from the data collection process.

At the beginning of the second interview, audio taping and timing resumed. This researcher began by presenting a sample of representative transcript segments identified in collaboration with Dr. Nesman. This researcher and Dr. Nesman asked the participant to review the quotes and make any changes they wished. Once again, the same interview 
procedures were followed as stated previously. Upon completion of the interview, the participant was thanked for their time and received a financial incentive of $\$ 50$ for their participation.

This researcher transcribed audiotapes from the second interview and presented the results of the pilot study to both the doctoral committee co-chairs (i.e., Drs. Keller and Raffaele Mendez) and Dr. Nesman, which included the interview protocols, transcripts, samples of representative quotes, and duration measurements of each interview for each participant (i.e., first and second interviews). Together, the team made necessary changes to the interview protocol and data collection procedures before the remaining data was collected, and decided whether the data obtained in the pilot phase of the study would be included within the final sample. Based on a combination of faculty observations of this researcher's performance, the degree that data collection was kept consistent, and that the information obtained appeared relevant to the study's research questions, the doctoral committee elected to include the data from the pilot study in the final sample of this research study.

Saturation. In addition to discussing the pilot study data, this researcher also consulted both the doctoral committee co-chairs (i.e., Drs. Keller and Raffaele Mendez) and Dr. Nesman regarding saturation. Saturation refers to the point in data collection in which new themes are no longer reported by parent participants (Denzin \& Lincoln, 2000; Strauss \& Corbin, 1990). With this concept in mind, this researcher continued collecting data until responses from parent participants were judged to reach saturation. This researcher estimated that saturation had been achieved after interviewing eight parents of seven children. At that point, this researcher consulted with Drs. Keller, 
Raffaele Mendez, and Nesman, providing complete transcripts for each participant and sharing specific quotes to illustrate commonality and similarity across participant reports. Discussing these data further, the team agreed that data collection reached a point where subsequent interviews were estimated to add little additional information to the data which had already been collected.

Step 5: Data Analysis

Unabridged transcripts were analyzed in a systematic, sequential, and verifiable process (Krueger \& Casey, 2000). Systematization was ensured through the use of a sequential data analysis process that was both documented and clearly stated. Likewise, data analysis was verifiable through a clear "chain of evidence” (Patton, 1990) that could be traced back to its original transcript location.

In order to facilitate this goal, analysis strategies outlined by Krueger and Casey (2000) were followed. All transcripts included the participant's initials, date, and page numbers such that each segment of text could be verified. Two copies of each transcript were kept, one intact, and a second for organizing into thematic categories (pp. 132-137). With respect to the latter, transcripts were also color coded with markers to facilitate identification of each specific transcript. Coding was ensured through the use of multiple color-coded vertical lines drawn down the left margin of the paper. This allowed the researcher to cut individual segments of text from its original transcript when creating thematic categories.

Thematic categories were created using flipchart paper and individual segments of text cut from transcripts. Cut segments were anchored onto individual sheets of flipchart paper, each sheet representing a separate category corresponding to systems articulated in 
Bronfenbrenner’s ecological theory (1979, 1986; microsystemic, mesosystemic, exosystemic, macrosystemic, chronosystemic). In addition, categories were coded relative to whether or not segments represent either risk or protective factors perceived by parents or guardians. Transcript segments were coded as risk or protective factors as well as to their respective ecological level, both as reported by experts in the field (i.e., Huffman et al., 2001). Once transcript segments were organized into their respective categories, the researcher wrote descriptive summaries of each category, describing what was reported by the participants.

In addition, a second person (i.e., a graduate student trained in qualitative research methodology) also analyzed the data as described above, serving to cross-check and validate the categories identified by this researcher. In the event of a disagreement, this researcher and the graduate student traced back the segment of text to its original transcript and determined the appropriate category after conducting a more thorough review of the transcript and context in which the comment was made. This additional procedure was selected as an additional means of ensuring the rigor of the methods used in this study.

Finally, the findings of each participant interview were summarized and described. Efforts were made to present each participant's comments in as simple a manner as possible in order to accurately communicate each parent's voice. In other words, quotes were not framed with value-laden judgments (e.g., "(Participant) described her experiences with a provider who appeared to be acting in a rude and unprofessional manner. She got upset, yelled at him, and said...”). Individual quotes were intentionally 
reported in as simple a fashion as possible (e.g., (Participant) described her experiences with (provider). She reported...”).

Once described, the data were summarized and described for the entire group of participants. Analyses were conducted using the model of analysis supported by LeCompte (1999). LeCompte offered a four-tier model of analysis: 1) item-level; 2) pattern-level; 3) structural-level; and 4) interpretation. For the purpose of this study, item-level analysis pertained to the three research questions posited by this researcher, while pattern-level analysis described trends and linkages identified across participants relative to each research question. Structural-level analyses addressed patterns of relationships across participants into groups of risk and protective factors, whereas interpretation focused upon describing the structures within the ecological paradigm. Analyzing the data in this fashion allowed this researcher to test emergent understandings and search for alternative explanations, while taking personal biases documented in the bracketing interview into account. 


\section{Chapter Four}

\section{Results}

The results of this study have been presented in terms of the themes, risk factors, and protective factors that emerged from the analysis of participant interview transcripts. Data were analyzed relative to Bronfenbrenner’s ecological framework (1986; 1999).

\section{Participant Demographic Information}

A total of eight parents participated in interviews discussing seven children. Demographic information describing each family participant and child are presented in Appendix G. A participant sample was obtained using the purposeful sampling procedures and inclusion/exclusion criteria discussed in Chapter Three. Using these procedures, a sample of parents were obtained with the intention of reflecting the diversity of voices existing within Hillsborough County, Florida. Parents volunteering to participate in this study differed relative to their relationship to the child, race/ethnicity, educational background, occupation, and SES (estimated by zip code). Similarly, child participants differed relative to the age at the time of the interview, the age when concerns were first noted, the age at the time of eligibility evaluation, gender, race/ethnicity, medical/developmental concerns, types of challenging behavior, and services received. With respect to the parent participants, eight people were interviewed — six mothers, one father, and one grandmother. Five of eight parents were married (63\%), and three reported that they were single (37\%). Four (50\%) parents 
characterized their race/ethnicity as African American, whereas the other four (50\%) described themselves as Caucasian. The average educational attainment of the parent participants was 14 years (range $=12-18$ years). Likewise, occupations ranged from paraprofessional to professional. One parent reported that she was disabled at the time of the interview. Families also varied relative to socioeconomic status. Six different zip codes were represented in the final sample of seven families.

Five boys (71\%) and two girls (29\%) were discussed in this study. The average age at the time of the interview was 36 (range $=25-43$ months). Similarly, concerns were first identified at an average age of 15 months (range $=0$-36 months), whereas the average age at which the children were evaluated was 32 months (range $=20-39$ months). With respect to specific diagnoses, a wide degree of variability was reported, including both medical (e.g., asthma, bronchitis, otitis media, eczema, ventricular septal defects, gastro esophageal reflux) and developmental diagnoses (e.g., developmental delay, speech delay, developmental language disorder, Williams Syndrome, pervasive developmental disorder—not otherwise specified). In addition, each child exhibited a wide array of challenging behaviors including: self-injury, noncompliance, tantrums, excessive crying, feeding difficulties, property destruction, biting, screaming, hitting, stuttering, scratching, throwing objects, dropping to the floor, and jumping off high platforms.

The seven children in this study received a variety of services and supports. Specific services and supports reportedly included speech therapy $(n=3 ; 43 \%)$, occupational therapy $(\mathrm{n}=1 ; 14 \%)$, physical therapy $(\mathrm{n}=1 ; 14 \%)$, early intervention $(\mathrm{n}=$ 2; 29\%), pharmacotherapy ( $\mathrm{n}=4$; 57\%), and a behaviorally-oriented parent support 
group $(\mathrm{n}=1 ; 14 \%)$. In addition to these services, one child was on a waitlist for an eligibility evaluation for preschool exceptional student education services ( $\mathrm{n}=1 ; 14 \%)$, one awaited an appointment for a speech therapy evaluation $(n=1 ; 14 \%)$, and one was on a waitlist of services provided by the Early Intervention Positive Behavior Support (EIPBS) program $(\mathrm{n}=1 ; 14 \%)$.

\section{Participant Descriptions}

The seven children who participated in this study have been individually described below. The pseudonyms used to protect the children's identities were personally selected by their parent(s).

Participant One: Bri

Bri is a 39 month-old girl of African American ethnicity diagnosed with speech and developmental delays and asthma. According to Bri’s mother, Bri was the product of a high risk pregnancy (maternal hypertension). Bri was born five to six weeks early via C-section and was diagnosed with asthma at approximately six months of age. At 18 months, Bri’s mother reported that "her language stopped," and at 24 months, she seemed to have “stopped learning." Enrolled in daycare, Bri’s mother reported that she began to withdraw and avoid socializing with other kids. Bri’s behavior soon deteriorated (e.g., noncompliance, self-injury, tantrums, excessive crying). Finally, Bri received a speechlanguage therapy evaluation, with results indicating that Bri was functioning at the level of an eight month-old (at approximately 36 months). Shortly after, Bri visited a neurologist to rule out the presence of seizures (results pending). A behavioral intervention specialist suggested Bri might have autism, and doctors provided conflicting opinions as to whether or not she may have attention-deficit-hyperactivity disorder 
(ADHD). Compounding the issue further, Bri required treatment for both allergies and asthma. According to Bri's mother, she cannot spend time either outdoors or in the public without risking allergic reactions. Despite such uncertainty, Bri has been determined eligible to receive services provided through the School District of Hillsborough County's Early Exceptional Learning Program (EELP). At the time of evaluation, Bri earned test scores suggesting that she was developing at a 24-month level at 36 months of age.

Bri’s medical and developmental concerns have placed a great deal of stress upon her family. Bri's father reportedly paid child support but did not spend any time with her, placing further stress on both her mother and maternal grandparents. Forced to prioritize Bri’s needs over work demands, Bri’s mother experienced difficulties obtaining promotions and has been penalized for taking too much time off from work (including maternity leave). As a result, Bri's mother was been forced to rely on the support of her parents, who themselves raised a child with special needs. Financially, Bri’s mother acknowledged that she is a single parent and has struggled with the many expenses inherent to raising a young child with challenging behavior. Bri’s mother reported concerns with obtaining health insurance for her, finding high-quality and affordable daycare, balancing her career as an administrative assistant, and planning to someday return to school.

Despite such difficulties, Bri’s mother was able to get help for her. Bri has received supports provided by a behavior specialist in the community. Bri's mother reported that this was very helpful, as the professional provided a wealth of ideas, made accommodations to visit the family on the weekend, and offered to help select 
developmentally-appropriate books and toys. Combined with the help of the behavior specialist and upcoming enrollment in the EELP program, Bri's mother is optimistic and committed to help her daughter continue to grow.

\section{Participant Two: Grace}

Grace is a 35 month-old girl of Caucasian ethnicity diagnosed with Williams Syndrome. According to her mother, Grace had experienced a number of medical concerns at a very young age. Grace was the product of a complicated pregnancy, labor, and neonatal course. Her parents had reportedly experienced fertility issues and several miscarriages prior to Grace’s birth. Grace’s mother was induced, and after a painful delivery, Grace was born weighing 5 pounds, 13.4 ounces. Her parents were soon notified that Grace had two ventricular septal defects (i.e., small holes in her heart), as well as an elevated billirubin count, requiring an extended stay in the neonatal intensive care unit (NICU). At their first checkup, Grace’s parents found out that she had a problem with her hip sockets, and was hospitalized for six days with a kidney infection soon after. Grace's parents reported that she was colicky and they suspected concerns with her development well before 12 months of age. Grace's mother claimed that, "none of the books were helpful...none of it was her, and I kept reading the same chapter over and over—waiting for her to get to the next chapter and nothing happened.”

After a second kidney infection, Grace’s parents elected to take their daughter to a geneticist and were abruptly told that she had Williams Syndrome. According to Grace's parents, the way by which both the evaluation was conducted and the diagnosis was rendered was irresponsible. The doctor reportedly diagnosed Grace based upon her physical characteristics alone rather than asking questions of her parents. The geneticist 
then reportedly told Grace’s parents that she would have limited intellectual functioning. Leaving the appointment with a diagnosis that was yet to be formally confirmed with the genetic panels that were ordered, Grace's parents requested additional information on Williams Syndrome, only to receive an illegible portion of an article in the mail weeks later. Approximately three weeks later, Grace’s parents received a telephone call from the geneticist's assistant to confirm that the diagnosis was positive—Grace had Williams Syndrome. In addition to the associated physical symptoms inherent to Williams Syndrome, Grace also exhibited several challenging behaviors, including feeding difficulties, self-injury, property destruction, biting, tantrums, and screaming.

Grace's parents primarily learned about their daughter's genetic condition through a combination of internet research and direct experience with Grace. Grace’s parents commented that they typically knew more about their daughter's condition than the pediatricians that saw Grace for routine pediatric care. After repeating the same information over and over again, Grace’s mother created a sheet of paper containing all of Grace's essential medical and developmental information on it, which was subsequently provided to every medical professional that the family came into contact.

Grace's parents have faced a number of challenges obtaining services and supports for Grace (e.g., oral motor feeding therapy, physical therapy, speech-language therapy, and early intervention). Despite her eligibility for such services through the early intervention program, Grace’s parents reported experiencing continual difficulties obtaining proper authorizations for services, requiring her mother to adopt an advocacy role for her daughter's well-being. Grace continued to receive services through the early 
intervention program at the time in which her mother was interviewed. Grace also attends preschool in a facility located at her mother's place of employment.

Compounding the difficulties associated with raising Grace was the fact that Grace’s mother reportedly has Dissociative Identity Disorder, and requires a considerable amount of time and therapy to help manage her own needs (e.g., sleep deprivation, therapy appointments), particularly in times of stress. Despite such difficulties, Grace's mother reported that she feels supported by her husband and extended family (i.e., maternal and paternal grandparents). Now that Grace and her family have connected with the Williams Syndrome Association, the family reported that they feel a sense of community with other families, and have remained focused upon their daughter's many strengths.

Participant Three: Darnell

Darnell is a 39 month-old boy of African American ethnicity who has been both diagnosed with eczema and suspected delays with his speech and language. Darnell was reportedly diagnosed with severe and chronic eczema at 10 months of age, of which the symptoms were exacerbated after moving to the Florida climate. According to Darnell's mother, he routinely experienced pain so intense that he would cry, try to speak, and eventually stammer while screaming. Darnell's skin color has reportedly changed as the result of frequent and severe episodes of scratching and itching. A host of medications were attempted, many of which were either very expensive to adequately manage Darnell's condition or became weaker due to repeated use. Darnell's mother continues to struggle to find medical treatment for her son. For example, Darnell's mother had reportedly received conflicting medical information and advice, and her son's 
pediatrician has shied away from discussing whether the severity of his dermatologic condition may have led to subsequent delays with his speech and language development.

Darnell's mother indicated that her son's chronic needs have placed a great deal of stress upon her family. Darnell often becomes so frustrated that he frequently engages in challenging behavior (e.g., tantrums, screaming, hitting, noncompliance, property destruction, withdrawal). The family was already under a great deal of stress, as her husband was laid off and forced to move to Florida to take a job at a lower salary. The family continues to rely on one income, despite the fact that they are a family of five (i.e., mother, father, Darnell, older sister, younger sister) and have several routine appointments to coordinate to support their children's needs. The family is also isolated (i.e., Darnell's mother does not drive), and his needs have reportedly had an impact upon the entire household. Darnell's needs had become so chronic, intense, and expensive that he has limited exposure to the outdoors, requiring his mother's constant attention, and likewise preventing her from enrolling both her son and older daughter in daycare, furthering her education (i.e., she had hoped to take courses at the local university), or from working to help supplement her husband's salary.

Looking toward the public school system for assistance, Darnell's parents recently took him to a developmental screening. Despite the fact that a screening represents a preliminary step towards obtaining services, Darnell's family was under the impression that he might become eligible at the time of the appointment, and therefore, receive services shortly thereafter. Not only was it a surprise to them when the process was clarified at the screening's exit interview, but they were not satisfied with the quality of the screening process itself, and faced another potentially lengthy delay in obtaining 
services for Darnell. In light of these challenges, Darnell's mother remains dedicated to her son, trying to both treat his medical condition and provide the enrichment necessary to optimize his growth and development.

\section{Participant Four: DJ}

DJ is a 33 month-old boy of African American ethnicity who has been diagnosed with gastroesophageal reflux and ventricular septal defects. He presently lives with his maternal grandmother, who was his primary caregiver since birth. DJ's grandmother reported suspecting that he had advanced abilities since six weeks of age and raised him with his older cousin. She consistently reported that DJ's rate of developmental milestone attainment exceeded age-level expectancies, but indicated that he engaged in a number of challenging behaviors (e.g., hitting, self-injury, noncompliance, property destruction, tantrums, screaming, scratching, throwing objects, dropping to the floor).

DJ's grandmother reported that despite the fact that his behavior was challenging, it appeared to serve the function of communication. His family struggled to identify what it was that DJ wanted or needed. They decided to try to control his diet despite its high expense, reporting that decreasing sugar and increasing lean meat, fresh fruits, and fresh vegetables appeared to help. Likewise, DJ's grandmother indicated that his behavior improved once he was given daily opportunities for exercise. Once DJ's language improved and his grandmother reported that he became quite articulate (e.g., an expanded vocabulary, pronoun usage, using logic and reasoning in arguments with adults).

DJ's behavior reportedly worsened after 18 months of age. According to DJ's grandmother, his pediatrician dismissed his challenging behavior, claiming that "If he's aggressive, it’s just that he's very intelligent.” DJ's grandmother reportedly did not 
receive any practical advice; she was told to simply wait. Though he was evaluated at the early intervention program at both 14 and 26 months of age, he was twice determined ineligible due to reports that he was developmentally advanced (i.e., scoring consistently at the 38-40 month level at 26 months of age). The only reported concern was difficulties with articulation of speech sounds, which makes it difficult for others to understand what DJ is trying to communicate. DJ was then enrolled in daycare, but soon experienced difficulties in that setting, as he reportedly wanted to engage in different activities that were suited for older children (e.g., reading books, watching movies, playing games, practicing writing). Facing expulsion from preschool for consistent noncompliance and task refusal, and consistent difficulties with tantrums in public settings (e.g., restaurants, the mall), DJ's family (e.g., grandmother, mother, uncles) elected to try to enhance the structure and predictability of the family's routines (e.g., dinner times, mother's work schedule). DJ's grandmother also reportedly tried to promote consistent parenting practices, suggesting that his mother refrain from spanking and using coercive discipline practices. DJ and his family remain on the EIPBS program waitlist and his language remains difficult to understand at times. Regardless, DJ's grandmother reported that the family intends to continue to build on his strengths and to work together to minimize the obstacles that may adversely impact his development.

Participant Five: Andrew

Andrew is a 38 month-old Caucasian boy diagnosed with both otitis media and pervasive developmental disorder, not otherwise specified (PDD-NOS). Born face-down, without oxygen, and his cord wrapped around his neck, Andrew was the product of a difficult labor. Andrew is an only child. At six months of age, Andrew's mother began 
to observe signs of challenging behavior (e.g., intense head banging, night terrors, aggression). Dismissed by his pediatrician as developmentally appropriate, Andrew’s mother soon noticed that the head banging had become increasingly intense over the next six months. Each of Andrew's developmental milestones reportedly occurred "on time," including sitting, crawling, walking, and talking. At 12 months of age, Andrew got an ear infection, which created speech problems according to his mother. After tympanostomy surgery, Andrew's mother reported that he would acquire language, but quickly lose it. Andrew's challenging behavior rapidly escalated, becoming both frequent and severe (e.g., hitting, biting, tantrumming, self-injury). Andrew "had no fear whatsoever.” Andrew's mother reported that doctors continued to dismiss her concerns at 18 months of age as developmentally appropriate, despite the positive history of autism spectrum disorders within her family. Andrew's mother continued to bring him in to the pediatrician, each time to no avail. Despite frequent visits to the pediatrician's office, Andrew did not receive a diagnosis or a referral for follow-up evaluation or service. At the same time, Andrew had become increasingly violent and aggressive, especially in public places (e.g., restaurant, grocery store). Both Andrew's family and his mother's friends had begun to limit the time they spent with him and his mother.

Following a divorce, Andrew's mother remarried and elected to take him to another state in which he might be more likely to receive services and supports. Days prior to the move to Minnesota, Andrew's mother allegedly convinced the pediatrician to consent to a referral to a neurologist. The neurologist confirmed his mother's suspicions that Andrew had PDD-NOS, and referred Andrew's mother to a developmental pediatrician so that he could obtain a formal diagnosis of autism. While in Minnesota, 
Andrew was determined eligible for special education services, and received a combination of occupational therapy, speech-language therapy, joint compression therapy, and desensitization therapy, in addition to pharmacotherapy (i.e., medication). Andrew's mother reported that these therapies were helpful, and that his therapists reported progress.

Shortly after the move to Minnesota, Andrew's biological father filed a lawsuit against his mother, claiming that Andrew moved to Minnesota against the state of Florida's approval (i.e., there was an alleged violation of a divorce-related statute of limitations). As a result of this lawsuit, Andrew and his mother were ordered by a court to return to Florida. Since then, Andrew's mother reported that she was unable to obtain the same services for her son as those that were provided on his individualized educational plan (IEP) in Minnesota. She indicated that the state of Florida required a formal diagnosis of autism before Andrew could be eligible for services in school, and that the state would not honor the same conditions as specified in the pre-existing IEP. In addition to these concerns, Andrew has been evaluated by a developmental pediatrician, who is in the process of ruling out the presence of a seizure disorder. Andrew and his mother currently live with her uncle, while the two attempt to take trips to Minnesota to see his step-father. Andrew's mother is presently unemployed and has been forced to move in with her uncle after Andrew's challenging behavior had become so intense that it had created a high degree of stress between Andrew, his mother, his maternal grandmother, and his maternal step-grandfather. Andrew's father reportedly has minimal involvement in his son's daily care, despite the pending lawsuit on his behalf. 
Andrew's mother continues to struggle to obtain services and supports for her son. The family is reportedly under a high degree of financial strain. Andrew's mother has spent considerable time researching intervention and legal options on the Internet. Andrew is presently taking homeopathic remedies, and his mother has faded him from gluten, casein, lactose, and foods with red dye. According to his mother, Andrew continues to await an evaluation provided by the local school district, and the legal concerns between both biological parents remain unresolved.

\section{Participant Six: Lenny}

Lenny is a 25 month-old boy of Caucasian ethnicity who has been diagnosed with developmental language disorder and otitis media. Lenny lives with his older brother and parents, both of whom participated in this interview. Lenny's parents described his pregnancy, labor, and neonatal course as unremarkable, and initially expressed concerns with his development at approximately 15 months of age, citing observations that he was not doing some of the things observed in younger children. Lenny's pediatrician reportedly dismissed concerns when they were first brought to attention, but gave him a diagnosis of developmental delay at 18 months of age (i.e., the next office visit). Lenny's parents reported that he was having difficulties communicating with others; rather than using age-appropriate forms of communication, Lenny was observed hitting, engaging in self-injury, tantrumming, biting, screaming, and throwing objects.

Lenny received a referral for a speech-language therapy assessment, and reportedly earned test scores falling well below the age level expectancies. His parents also reported that by that time, Lenny had undergone two tympanostomy surgeries as the result of chronic episodes of otitis media. Lenny then went to the early intervention 
program, where he received a diagnosis of developmental language disorder and a referral for both speech-language therapy and early intervention. The staff of the early intervention program recommended the latter, citing concerns with challenging behavior (e.g., biting, tantrumming, throwing objects, noncompliance).

According to his parents, Lenny's behavior created a great deal of stress across settings. Lenny's father reportedly became very stressed by episodes of challenging behavior out in the community (e.g., restaurant, movies), whereas his mother became more frustrated managing his behavior at home. Working together as supports for each other, particularly when the other is out of town on business travel, Lenny's parents acknowledged which person tends to be more successful in particular settings (e.g., mother in the community, father in the home). As a result, Lenny's mother and father reported a greater degree of success in supporting their son when spending time one-onone with their children. Despite such efforts, Lenny's parents reported a sense of isolation from their family and friends. Episodes of challenging behavior on play dates and trips to visit family (e.g., during the ride, while visiting) had become so severe at times that they haven't seen some of their friends in over a year.

Though Lenny's parents reported that the flexibility in their careers (e.g., both work from home) allows them to work around situations when their son demands their attention. Lenny is currently enrolled in a home-based daycare, which his parents find to be a good match for his needs. They hope to continue to teach him additional preacademic and social skills before he is evaluated for eligibility into the public school's Early Exceptional Learning Program (EELP). 


\section{Participant Seven: Tank}

Tank is a 43 month-old boy of African American ethnicity who has reportedly been diagnosed with asthma, bronchitis, and speech-language delays. He is the older child of a single mother, who also of a two month-old infant boy. Now that she has two children, Tank’s mother expressed difficulty managing the two children. In addition to the fact that she is presently on permanent disability from her daycare position, both children have asthma and receive breathing treatments via nebulizer twice per day. Tank’s mother relies on child support to help provide for her two children.

According to Tank’s mother, Tank exhibits a variety of challenging behaviors, including hitting, self-injury, noncompliance, tantrums, screaming, throwing objects, and jumping off of high platforms. Consequently, Tank's mother acknowledged that he is very demanding. Though she has tried a variety of behavior management techniques (e.g., spanking, redirection, ignoring, timeout), Tank’s mother reported that none has been very effective. Behavior management is particularly challenging for Tank's mother, as she reported having a "bad temper."

Tank’s behavior is particularly challenging in public, causing a degree of community isolation for Tank’s mother and other members of her family. However, Tank's mother reported that she is happy with the care her son has received through the pediatrician, and acknowledged that he is an important source of support that has been available at all hours of the day.

With respect to services and supports, Tank’s mother attended a behaviorallyfocused parent group when he was eligible for services through the early intervention program. Since then, Tank's two primary interventions have been daycare and 
pharmacotherapy (i.e., medication). Tank’s mother reported a high degree of satisfaction with the program. Though Tank was referred for a speech-language therapy evaluation, his mother has reportedly experienced difficulty in coordinating a scheduled appointment with the provider. Despite such difficulties, Tank's mother reported that she wants to teach her two sons how to interact with others and to treat people with respect. She indicated that she hoped to teach such skills to her children to help them cope with the type of exposure children now have to acts of violence.

\section{Research Questions}

Interview data obtained in this study were transcribed and analyzed relative to three research questions. Patterns and trends are discussed below, with sample quotes provided to illustrate specific experiences.

Question One: What are the experiences of parents obtaining services for young children with challenging behavior living in Hillsborough County, Florida?

In order to address this question, data were compared relative to both reported experiences and assumptions articulated by this researcher prior to data collection. The specific assumptions were: 1) parents of young children with challenging behavior will report difficulties obtaining accurate and useful information regarding their child's challenging behavior; 2) parents of young children with challenging behavior will report difficulties obtaining services and supports designed to reduce their child's rate of challenging behavior; 3) parents of young children with challenging behavior will report that their child's challenging behavior created financial stress; 4) parents of young children with challenging behavior will report experiencing stress among members of their family; and 5) parents of young children with challenging behavior will report that 
they experienced community isolation as a result of their child’s challenging behavior (i.e., decreased frequency and/or duration of interactions with friends, neighbors, community resources, religious services, and/or public transportation).

Assumption One: Parents of young children with challenging behavior will report difficulties obtaining accurate and useful information regarding their child's challenging behavior. Data obtained across participants yielded three different categories of responses pertaining to difficulties obtaining accurate information. First, parents reported that they did not always receive accurate and useful information about their child's behavior from their pediatrician. Several parents reported that their pediatrician quickly dismissed their concerns and was generally non-informative. For example, DJ's grandmother noted: “The doctor was like, ‘Don’t worry about it. If he’s aggressive, it’s just that he’s very intelligent.’

Similarly, Darnell's mother took her son to the pediatrician for treatment of eczema and reported:

Every time it got worse, we'd take him in to the pediatricians and complain to them about the new symptoms, remind them about the old symptoms, tell them, 'Look, what can it hurt to just have him tested?' Their thoughts were, 'There’s no point to having him tested. He’s too young. He’s still developing. Wait until he's done developing and then we'll see if there's a problem.'

Despite reports of his worsening skin condition, Darnell's parents continued to experience frustration obtaining more detailed information about his skin condition. Andrew's mother cited similar experiences coping with her son's pattern of severe head banging during bedtime. Andrew’s mother reported, 
We started talking to his pediatrician when the head banging got worse, and they kept telling us that it's not abnormal for a child to bang their head pretty hard to put themselves to sleep. So, they didn't have any concerns for him; they thought that he'd outgrow it. We told the pediatrician, 'This is ridiculous. He’s banging his head at night so severe, he has night terrors, he’s losing speech, he’s getting violent when I can’t understand him. I'm getting stressed not being able to understand him. I'm getting stressed not knowing how to deal with his violent temper tantrums. Please help me.' Once again, it was, 'He’s getting close to two, the terrible two's, he'll outgrow this.' They gave me a pamphlet on temper tantrums and how to handle them, and their idea of handling them was to pretend that they’re not happening, just ignore them.”

Similarly, Grace’s parents found that they knew more about their daughter's medical condition than the medical professionals responsible for her care. Grace’s mother reported:

Here's this resident who's reached the six to seven sentence paragraph in the medical textbook and doesn't know any more than that. We have had to educate everyone that we come into contact with, our pediatrician included. Even the attendings aren’t any more familiar with Williams Syndrome. For a parent, especially a first-time parent, that's incredibly frustrating, because you're so scared, and you want to talk to somebody who knows what the hell they're talking about. When they're telling you, 'Well, I’ve never heard of that, blah, blah, blah, blah,' you're thinking, 'How are you going to help me if you don't even know what my daughter has?' I mean, I know more than they know. 
While these pediatricians may have a very justifiable reasons for their actions or did not have experience working with children with genetic concerns, it appears that the impact these interactions had on parents was negative and stressful. Rather than providing specific information directly addressing their concerns, parents reported that their child's pediatrician tended to instead defer concerns for a future appointment or make frustrating, value-laden judgments (e.g., questioning Bri’s mother’s parenting skills instead of considering other medical explanations for her behavior, such as allergies). In contrast, two parents reported positive experiences with their child's pediatrician. When asked about her son's pediatrician, Tank's mother commented: My pediatrician was very good. He’s very, very good with Tank. Tank’s been going to him since he was two months old. I can’t say nothing bad about him because if I call, he calls back. If I call during the night at 2 or 3 o'clock in the morning, he calls back. What to do with Tank. 'Should I take him to the hospital? Should I give him more treatment and what medicine?’ He’s really good.

After switching pediatricians, Bri’s mother offered similar feedback:

When she saw Bri, she thought that she had allergies. She pointed out the darkened circles around her eyes. I have been satisfied with her, but we are still questioning what's happening. Dr. (provider) is very supportive and is concerned with labels. She told me to be very cautious about accepting any labels until they showed me evidence. Dr. (provider) said that she herself was labeled as a child. Dr. (provider) said that we need to rule out everything first. 
These circumstances differed from those reported by DJ, Andrew, and Darnell's parents. In contrast to their reports, Bri and Tank's parents provided indication that they were collaborating with their pediatricians. Tank's mother reported that her pediatrician calls back at any time of day or night, whereas Bri's mother said that “we are still questioning what's happening,” and that the doctor encouraged her to be cautious about accepting labels without reviewing the evidence. Such reports appear more indicative of a partnership between the parent and pediatrician than the non-informative and frustrating interactions previously reported by other participants in this study.

In addition to these experiences, seven parents reported that they experienced difficulties obtaining accurate medical/developmental diagnoses from their pediatrician, several of which were of a confrontational nature. Several parents reported that they had a sense something was wrong with their child before it was ever acknowledged by the pediatrician. For example, Lenny's father recalled a conversation with the pediatrician at his son's 15-month wellness check-up:

'He’s 15 months old and he has two words.' The doctor said, 'No, no big deal. We'll see you at 18 months. If he's still like that at 18 months, maybe we'll address it.' At that point, we were starting to get concerned. The doctors were not. She saw him at 19 months, and said, 'Yeah, okay. Now it's time.' Lenny's parents reported that they had an idea that their son was developing atypically before their pediatrician raised the concern. After years of discussion with her son's pediatrician about his severe challenging behavior, Andrew's mother reported a similar experience: 
We started preparing for the move, and during the preparation, and one of the pediatricians said that, 'The head banging, all along that we've been telling you was normal, now that you've had your husband confirm what you're telling us, we think it's a severe brain problem.' That was very frustrating for me, since I’ve been complaining about it since he was six months old and they've been telling me that it was normal, and now that I have somebody back me up, all of the sudden this is a serious problem.

Shortly thereafter, Andrew and his mother met with a neurologist to discuss Andrew's behavior. The neurologist confirmed her concerns. According to Andrew's mother: The neurologist was appalled. He could not believe it had taken two years for a pediatrician to finally realize that there was a problem and to recommend getting him in somewhere. He was very upset. He told me that my son was clearly and severely autistic.

Other parents discussed disagreements with their pediatrician. Bri's mother elected to change pediatricians after a discussion about her challenging behavior. She commented: I started with Dr. (provider). When Bri started to break out, he questioned me as a parent and whether I was properly caring for my daughter. I decided to find another doctor and found Dr. (provider). When she saw Bri, she thought that she had allergies. She pointed out the darkened circles around her eyes.

Bri's mother was insulted by the doctor, and after switching doctors, found a provider who not only identified her daughter's allergies, but established a supportive and collaborative relationship with her. Grace's mother also reported a number of difficulties 
as she and her husband learned more about her daughter's diagnosis of Williams Syndrome, a rare genetic disorder. Grace’s mother reported:

I told the pediatrician, 'Yes, well we're taking her to the geneticist in a month or so.’ He asked, ‘Are they looking for Williams?’ And I said, 'I don’t know, what is Williams?' And he says, 'Oh something they might be looking for’ and changed the subject. I was so mad. I mean, my God, you don’t just dump that on somebody and then send them on their way! Of course, I come home and the Internet being what it is, freak out and convince myself that information could not possibly be what's going on with my daughter.

Upon meeting with the geneticist, Grace's mother said:

The geneticist told us, 'Your daughter might, might be able to finish high school with help, and she'll never be able to go to college.' She made it a point to repeat the word, 'might.' I looked at her and said, 'My daughter is not even one year old and you cannot put her in a pigeon hole right now. I said, 'If I tell her my daughter every single day of her whole life that she can do whatever she wants to do if she wants it bad enough. How much will she be able to accomplish? But if I tell her every day, 'You might, might be able to finish high school with help, and you'll never be able to go to college, how much then will she accomplish?' After the doctor explained the symptoms and Grace's parents realized that she might actually have Williams Syndrome, Grace’s mother commented:

She started describing some of these things, which now, I'm familiar with and once she explained those things to me, I can see why she said what she said. However, she is a geneticist, and she is supposed to do this for a living. You 
would think that she would have a better way of explaining what leads her to that opinion rather than just stating her opinion and only justifying it if I yell at her. So at any rate, I said to her, 'If it’s not Williams, what else could it be?' She said, 'Oh well, we're pretty sure it’s Williams.' The way that she handled everything was just completely irresponsible. We asked her for information...she only copied like half of an article on something, and sent it with no cover letter. All of the information we found out, we found on our own, because we're smart enough—and sat there for hours on end on the Internet finding it ourselves. Although Grace did, in fact, meet the criteria for Williams Syndrome, the way in which this information was communicated angered her parents. Instead of relying upon and communicating with the geneticist, Grace's parents learned about their daughter's condition using the Internet. While accurate and useful information is readily available on the Internet for a variety of topics, Grace's parents chose to use it after they reported feeling insulted by their geneticist.

The final category of information obtained relative to this assumption pertained to parents' use of the Internet as a primary source of medical/developmental information. While the Internet is frequently used as an informational resource for parents, many parents reported that they learn more about their child's challenging behavior from the Internet than from a professional. One such example is Darnell's mother, who commented:

Yes, and I’ve learned those things pretty much through my own research. Just about eczema, that there are different foods and things, and particular environments. For example, being here in Florida is a problem. It gets swampy 
here and the heat causes it. It really puts him at that state, where he's (in pain) and we can't spend time outside. In less than 10 minutes and maybe 15 on a good day, he’s already starting to scratch and cry.

In the case of Darnell's mother, the Internet was used to learn more about the impact of heat and humidity upon her son's chronic skin condition. However, Andrew's mother reported using the Internet much more frequently, learning about a variety of topics related to her son's autism spectrum disorder.

It's all I do all day. I'm on the Internet 24-7. The fact of the matter is that I know in my lifetime, nor my son's lifetime, will there ever be a cure for it. But if I can find natural ways of making him at least live happy, then that's what I'll do, and the only way you can do it is to try to find what are all of the causes that they're looking at. I know now that MMR is a possibility, so that if I have another child, do you think I'm ever going to give him an MMR vaccine? No way. I'm never going to do that. And why? Because, 'What if?' It's just a matter of 'What if?' What if I held off, and because I held off, I might have a normal child now. As a parent, you have to your children every advantage in life.

Although both parents were able to use the Internet to supplement their understanding of their child's condition, Grace's mother acknowledged the limitations of relying on webbased information. Specifically, Grace’s mother remarked:

All of the information we found out, we found on our own, because we're smart enough—and sat there for hours on end on the Internet finding it ourselves. However, a lot of what's on the Internet is pretty extreme, because it's the people that are going through those extremes that are so determined to help other people 
who are going through the same thing. You don't see the average Joe putting up a website, because, why would he? You're seeing the ones that have had 20 heart surgeries and the ones that have died early because of going under with anesthesia. You see the similar facial characteristics, and as sad as it is to say, the extreme examples all look like they are mentally challenged. There is a blankness there that adults wouldn't have, but you're looking at the face of an adult. I think here's our daughter who took us 8 years to get, and you become afraid she's going to be living with us now the rest of our lives and never be able to have a family of her own, and it's beyond comprehension at that point.

In summary, multiple parent respondents shared several negative experiences with their pediatrician relative to both diagnosis and obtaining accurate and useful information to help support their child. In contrast, several parents acknowledged that they used the Internet as a primary source of information used to support their child. While the degree of Internet usage may vary across participants for reasons such as access to web-linked computer systems, an individual's ability to effectively research a topic of interest, and access to research databases (e.g., PsycInfo, the Educational Research and Information Clearinghouse), it also appears that parents differ relative to the degree of depth in which they research information (e.g., from obtaining simple descriptions to investigating medication side effects to reviewing research).

Assumption Two: Parents of young children with challenging behavior will report difficulties obtaining services and supports designed to reduce their child's rate of challenging behavior. Although parents provided a variety of responses to this assumption, each shared experiences of difficulties obtaining services for their child. The 
frequency, intensity, duration, and types of service varied widely across children. Consequently, the degree to which parents reported positive and negative experiences varied as well. For example, five parents described positive experiences with the professionals that provided support to their children. Lenny's parents described their experiences obtaining developmental evaluations for their child as satisfactory. They commented:

At the (clinic), I felt that I agreed with her assessment. He was not able to complete the task. I was not necessarily happy with his performance level, with what he did, but what she presented and what she asked him to do, I understand that he was not able to complete that. When we got to the one at the Early Intervention Program, it was the same situation there. They asked him to point to a number of pictures, point to the therapists. Despite the fact that your child can't do that within or doesn't do it in the prescribed time period, I feel that he is intelligent. I feel that he is, and I think that if he were more interested, in the material for starters, and perhaps an alternate way of getting to the same result, he might do better. But I think that for what they are and for being standardized as they are, I think that the environment was fine.

Both of Lenny's parents placed a high degree of value upon services for their children, and made plans to enroll him with a preferred teacher in daycare/preschool as early as they could. Lenny’s mother commented: "We were hoping all along for a slot in her classroom. It was like, 'Healthy delivery, and (teacher) has a slot.' That was the mantra at the beginning, as we were getting ready to have him. Plus, (brother) had been with her 
for a year or so at that point. What we would have done at that point was pull (brother) out so that (child) would have taken that slot.”

Other parents expressed satisfaction with specific service providers, especially those perceived by parents to be above and beyond the routine or required level. For example, Bri’s mother received behavior intervention services from a provider one weekend. After meeting with the professional, Bri’s mother remarked:

I was just excited that she would take the time on a Saturday to come out and spend time with us. I had met with her before, but this time, she gave up her own personal time at home and even offered to go to the mall with me. That says a lot about that she's definitely willing to help and that these people do exist, to try to help you get there.

Similarly, Grace's mother reflected upon the positive experiences she had with another provider who listened to her concerns and collaborated in exploring creative solutions: We got hooked up with (Provider) through (hospital). (Provider) is a miracle for us. She was the first person who was able to sit and talk to me and give me ideas about how to help get her to eat and different things I could do and told me different things she should be doing, how to make her do it, you know? She’s very clever and easy to talk to, and very creative. She had a lot of different methods that she tried with Grace. She started out doing signing with Grace, and that has been incredibly effective in helping her learn how to communicate.

In contrast to these experiences, parents also reported a host of negative experiences across services (e.g., medical, daycare/preschool, speech therapy, EIPBS parent group, the early intervention program). For example, Darnell's mother discussed her 
experiences obtaining medication to remedy her son's chronic eczema. Rather than describing a systematic or scientific process to remedy her son's concerns, Darnell’s mother reported experiences that seemed to be more hit or miss:

It was quite overwhelming, because none of the professionals that I had gone to for help were able to help, and it seemed like they started to really throwing things out there. Of course, the condition with Darnell scratching, he had damaged his first layer or so of skin. I noticed that when they started to throw stronger meds at him (since he was chronically scratching and breaking his skin), I would apply the topical meds, and they would burn him. As we speak right now, Darnell is discolored. His bottom half of his body is probably at least four shades darker than his face, if not more.

Not only did Darnell reportedly receive medications that did little to help him, Darnell’s mother was frustrated with the training of the professionals she met (i.e., training relative to understanding the illness, its causes, optimal forms of treatment, experience providing such treatment). She said:

I did not think she was really knowledgeable about eczema. What she advised me to use I found later was causing him to have bacterial infections from the wound. She was telling me to keep him heavily oiled with Vaseline and other things as such. However, I found that because of him scratching profusely and breaking skin, that was not allowing the wounds to breathe. It actually kept him infected. Other parents, such as Tank’s mother, reported having difficulties making appointments with local providers. Tank’s mother said, "It was hard trying to set up an appointment at (provider). Every time I would call, I would leave a message or they wouldn’t call.” In 
addition, Tank's mother commented that she received services that failed to meet expectations. As Tank’s mother described her experiences attending a behaviorallyoriented parent group, she reported:

She (facilitator) was just talking to you (i.e., parents). 'How you going to act with your kids? What's the outcome? How do they act when you try to get them to do something?' How to get them on a time schedule. Basically just read to your kids. It wasn’t bad. Everything that you get is good because even though you know something, it’s more than what you know. However, it really wasn’t about the behavior.

Despite the group’s reported focus, Tank’s mother claimed that the group was too general and did not address her concerns regarding strategies to help manage her son's challenging behavior. Other parents, such as DJ’s grandmother, also reported receiving services that did not meet their family's expectations. In DJ's case, the family experienced difficulties with daycare. Specifically, DJ's grandmother and family had become concerned about whether the staff of the daycare had enough training or experience to adequately support or manager DJ's behavior. According to DJ's grandmother:

We put him in daycare and we noticed that he was going through changes in daycare with behavior. He wanted to direct the class. She wanted them to write, he wanted to read. She wanted them to play with toys, he wanted to watch a movie, and he would disrupt the class because he wanted to do what he did, so he wanted to change the schedules at school. So we had threats of him being put out of school. No fighting, no hitting, no kicking. Just not being able to manage him 
with the other eight or 10 children in the class, so we had another challenge. He was going to be put out of school.

Although the news that DJ was advanced was certainly positive, the fact that the daycare staff were unable to handle him caused stress for the family. DJ's challenging behavior had reportedly become an obstacle keeping him from opportunities to enhance his growth and development. Similarly, Darnell's mother experienced communication difficulties as she attended a county-wide developmental screening. Expecting that she had brought Darnell to a location where he would receive an eligibility evaluation for exceptional student education services, Darnell's mother had been misinformed about the purpose of the developmental screening. She reported:

I was told zero to three could go to USF, which meant zero up to age four, not 36 months. She told me that I was incorrect and it was 36 months for children to go to USF. So I had been misinformed by the facilitator. That was pretty much what she pumped me with all throughout the screening. That was why I continued the process because I already looked into the fact that they had a developmental evaluation team. My intent when I went to Child Find was only to get their results, and to get a second opinion from USF. I didn't know the two were linked together. So I found out I was unable to do that and had been misinformed. That was a blow, and on top of that, I was misinformed again by a member of their staff.

As a result of this confusion, Darnell's mother learned that she would have to wait several months before her son could be evaluated by the school system. Whereas 
Darnell's mother thought she was at the point of arranging services for her child, she was surprised to find that she was only at the beginning of the process.

Grace's mother also became frustrated with the need to continually fight with the local early intervention program to obtain services for her child. She continually fought for services based on her own research and wrote letters or provided documentation to ensure that decisions made about her child actually met her needs. According to Grace's mother:

There was a lot of stress in yelling at my service coordinator...You know, looking back, I probably just should have gotten a new service coordinator, but I didn't. I managed to get everything we needed, but I had to fight for every freaking bit of it. So early intervention made my life more difficult, because instead of giving me the services that my daughter needed, every conversation with them was stressful. I had to do major research and major documentation in order to justify any decision. I had to write letter after letter and bring in mounds of paperwork to meetings to be able to prove that it was clear what she needed. So this agency that is supposed to help me, to help me define the needs of my child, did everything to prevent me from getting services for her, and it is a horrible shame that that agency makes the lives of parents more difficult than they have to be, when their job is to do precisely the opposite.

It is interesting to note that while these types of findings described negative experiences, parents reported taking on a greater role as advocates for their child, which can be considered a positive. In the case of Grace's mother, she recently accepted a position to sit on a committee affiliated with the local service system. As she remarked: 
I'm working with them to try to make that better. I heard the word, 'advocate,' but I never really knew what it was to be one until I had Grace. It's not just about Grace, it’s about every kid. It's about every kid, and about every parent, it’s about those parents that are uninformed, who don't know what to do, don't know who to call. I'm tenacious enough to figure it out or bug somebody until they tell me, but there's a lot of people that aren't, that take the word of their pediatrician or take the word of their specialist or who will listen to their service coordinator as if that person is God himself, and will say, 'Well, they don't think my child needs an hour of physical therapy, they think having therapy once a month for 10 minutes is going to help my child.' Not only do I not want to be that ignorant parent, I don't want that agency to get away with doing that to any parent. Although unanticipated, this finding is of particular importance. Not only does the response of Grace's mother serve the function of protecting her child, at the same time, she becomes a role model and support for others in similar situations.

Finally, Andrew's mother explained how she and her son were stuck in a legal dispute with his biological father. According to Andrew's mother, the legal dispute entailed keeping him in Florida so that he could live in close proximity to his father, and away from Minnesota, where Andrew and his mother had recently moved with her husband. As a result of this dispute, Andrew's mother was forced to keep him in Florida against her own will. Relative to services and supports, Andrew had an existing Individualized Educational Plan (IEP) from Minnesota that provided an array of comprehensive services. However, Florida has yet to agree to provide these services. According to Andrew's mother: 
What we're working on is working on forcing the state of Florida to honor the IEP that he already has in existence. The school is willing to give him the speech therapy and the occupational therapy there, but they're not willing to only let him go to school for two and a half hours per day. They want him going from open to close, five days a week. It's been deemed through his IEP that not only can he handle two and a half hours of that type of training, but he can only handle it four days a week. In Minnesota, they take a past opinion of the child and what they know about the child into heavy consideration, especially when they're scheduling the classes, whereas Florida is going to say, 'We know what's best, and we wants him to go five days a week, six hours a day. That's the beginning and the end of it.'

Complicating matters further, Andrew's mother reported that he is not eligible for the same services in Florida as he once was in Minnesota due to the fact that he is diagnosed with pervasive developmental disorder, not otherwise specified (PDD-NOS). She mentioned: Because Andrew is only diagnosed with PDD, and he’s not officially diagnosed with autism, he's not going to qualify for anything. The state of Florida just requires an official diagnosis. It doesn’t matter that PDD is a life-long developmental delay, that there is no cure for. They still insist that an official diagnosis of autism or Asperger's or any of those other different medical conditions be made. Until that happens, he's not going to qualify. Believe it or not, there is also such thing as being disabled, but not being disabled enough. When it comes to Florida's schools as well, until he is officially diagnosed with 
autism, they consider that he's not disabled enough. That's why they're having trouble with him.

While the accuracy of the statements made by Andrew's mother appears to conflict with policies and procedures articulated by the Florida Department of Education (Florida Department of Education, 1998), her statements nonetheless illustrate difficulties communicating with school staff and/or accessing accurate and useful information regarding the services and supports available to Andrew. Despite the precise reason, the experiences reported by Andrew's mother appear indicative of difficulties obtaining the services and supports Andrew needs.

In summary, each parent reported some degree of difficulty as they sought to obtain services and supports for their young child with challenging behavior. Though the needs and services provided to the children in the participant sample are diverse, the fact that each parent reported difficulties obtaining services is troubling. Knowing that services and supports consistently provided to young children with challenging behavior have the potential to make a difference (e.g., Dunlap \& Fox, 1996; National Research Council \& Institute of Medicine, 2000), these experiences are of particular concern. Assumption Three: Parents of young children with challenging behavior will report that their child's challenging behavior created financial stress. Though each parent varied relative to their type of employment and level of SES, each acknowledged a degree of financial strain resulting from their child's challenging behavior. Responses appeared to fit into two different categories, one representing financial expenses related to their child's challenging behavior (e.g., cost of medications, health insurance, gas, daycare, food) and the other reflecting stress associated with their career. In reference to 
the former, parents consistently reported that financial expenses associated with their child's behavior had been significant at times, so much that the cost had occasionally reduced the ability of some families to take care of needs in other areas. One such example pertains to reported concerns with health insurance. Six of eight parents interviewed described costs associated with healthcare expenses. For example, Andrew's mother reported:

His last surgery was two weeks ago. He had adenoids and his tonsils removed. That was a $\$ 7000$ surgery that insurance paid $85 \%$ of, so we were stuck with a $\$ 1,000$ bill. Over the last year, medical bills that have accumulated that health insurance is not responsible for comes to a total of $\$ 3,000$. That's after insurance's part. That doesn't include all of the prescriptions, monthly prescriptions. His monthly prescriptions total about $\$ 65$ a month. Out of pocket expense. Special dietary needs are about $\$ 100$ a week.

Similarly, Darnell's mother expressed concerns obtaining enough medication to treat her son's chronic eczema. She reported a wide discrepancy between what insurance deemed necessary for her son versus what she claimed to have needed:

I was only able to get the Elidel once every 30 days because when we first moved here, my husband was laid off in Georgia and was unemployed since we relocated here. Well, we were both unemployed obviously, and we were only able to get one every 30 days, and I was told by other physicians that she should be able to override Medicaid to get us what we needed to get through the month. The Elidel at $100 \mathrm{mg}$ would only get us through two days, maybe. 
Other parents reported similar concerns with the costs of therapies. For example, Lenny’s parents commented:

Our insurance does not cover developmental speech therapy. It covers speech therapy if somebody for instance, has a car accident and they used to be able to speak, and they lost that ability. That would be reparative. But because he never had the skill, it was not covered, and because of his age, we had to go through the EIP.

Andrew's mother also shared concerns with the cost of therapy, and coverage that she considers to be most important:

Andrew’s going to need 30-40 hours a week of ABA therapy at approximately $\$ 70$ an hour. That does not include getting him re-enrolled in his speech and occupational therapy. Health insurance usually pays full for those, so there is no out of pocket with those two therapies. My health insurance pays for all of that for him. I'm very blessed, but the ABA therapy is the most important therapy. It is the one that he gets the most of, and health insurance doesn't want to pay for that.

In addition to these concerns, parents also shared concerns relative to the affordability of co-payments for office visits relative to the child's frequency of need. Darnell's mother continued:

We've lost so much money, and with every time that Darnell needs to go to the doctor’s office-and he really needs to go quite often-I can’t take him because that's another $\$ 20+$ that needs to come with a co-pay. There were some times 
where I really needed to take him to the emergency room, but I thought I couldn’t take him, because that would cost us $\$ 100$.

Both Bri's mother and Grace's mother expressed similar concerns about the cumulative effect of frequent co-payments. According to Bri's mother:

I have Blue Cross/Blue Shield. It costs \$25 with a co-pay per prescription. \$25 for this medicine, $\$ 25$ for this medicine. It’s expensive. Financially it has been unbelievable. That's the sad part about it. My frustration's with health care in America today, period.

Grace’s mother commiserated:

We have insurance, but it’s a $\$ 25$ co-pay every time you walk through somebody's door, and so we're on the "Visa health plan," along with our insurance, going quickly in debt.

Another common source of financial stress came from daycare or preschool. Parent respondents readily acknowledged the benefits of daycare/preschool, but cited financial constraints that limited their ability to either seek a better daycare/preschool setting or enroll their child for the entire week. For example, Grace’s mother discussed her experiences finding a preschool setting:

We can only afford to have her there Monday, Wednesday, and Friday. While I'd like to have her there Tuesday and Thursday, it’s just not feasible financially. So she's there Monday, Wednesday, and Friday. Tuesday and Thursday she stays with my mother in-law 9-1 p.m. (Husband)'s parents live 15 minutes away and they keep her for me while I work. I work now part-time, from 9-1 p.m. and up until recently, they watched her that whole time, Monday through Friday. 
Both Bri and Darnell's mothers also acknowledged the high cost of daycare. The issue is that the need for a daycare provider that can handle the child limits options, and often puts the burden on the extended family to reduce the burden because they are expected to handle the child no matter how difficult. There appears to be an implied expectation that more expensive daycare would be able to handle the child better. Bri’s mother reported: If you can afford good daycare, that's good. Before I had a child I had never thought about the cost. It's expensive. Her daycare is way across town, so I'm running over there everyday, so the gas is just outrageous. So I'm trying to work between the hours, and thank God that my cousin owns the daycare.

Similarly, Darnell's mother commented about her confidence in leaving her son in the care of another person:

I can't leave Darnell with anyone. Nobody is able to really give him the attention that he needs with this disorder. Nobody is able to get a handle on it or get it under control and it's still an issue as we speak. It's a lot more tolerable, but as a result, I cannot get any type of daycare for him, or any type of care. I can’t afford any type of special nurse, or any type of private nurse who could come in and sit with him, and that's something that's pretty overwhelming, because other than my husband and myself, nobody really knows how to treat him and nurture him back to a relaxed state. Not even my husband, who starts to get nervous when he starts to cry and he's obviously in a lot of pain. So, we have not been able to do daycare and we're definitely not able to do a preschool environment where he cannot eat a lot of the foods or participate in some of the activities. If Darnell 
becomes too stressed out or frustrated, or if he starts to sweat a little more than he needs to, then of course his condition just flares up.

In addition to the costs associated with health insurance, daycare/preschool, therapy, and medications, parents of young children with challenging behavior shared some additional concerns, including the costs of gas, training pants, and high-quality produce. For example, DJ's grandmother expressed a concern with her grandson's nutrition. She reported that he demonstrates less challenging behavior when he eats a balanced diet. In order to provide DJ with fresh produce, his grandmother commented:

We might have to go to two or three stores just to get a bargain price on highquality produce, which means we take all the ads and the sale papers to see who's got the best price for this, this week. So that's time consuming. Expensive for the gas, the prices are off the wall right now, but we do that. I mean, this is our baby, and he's gotta have his health.

Darnell's mother also commented on the expense of a high-quality diet. Bri's mother acknowledged that training pants represent a constant financial stress, and Grace’s mother summarized the financial strain that she and her family face as the result of the accumulation of financial expenses. She mentioned:

There's been a lot of times when we didn't know how we were going to take another step, how we were going to be able to pay for stuff. It has been such an overwhelming, massive, daunting task, and you just don't know how you're going to be able to face it, but the fact of the matter is that you wake up and there it is right there in front of you, and you've gotta do something, you know? 
With respect to the impact of raising a young child with challenging behavior upon one's career, some parents reported that raising their young child has impacted their career (e.g., reduced options for jobs or reduced opportunities for advancement). For example, Bri’s mother indicated that raising Bri has caused difficulties at work. She said:

It's been a problem. I've been trying to get promoted, but I have to take time off from work because of my daughter. Absenteeism for your daughter limits promotions, but you have to know where your priorities are. I'm being penalized for it; I’m not paid for being out for my daughter's sick time. I don’t get personal days; vacation days are the only option. Sometimes she's at the doctor maybe 2 or 5 times a week, and I have to change my schedule at work to accommodate the appointments.

Darnell’s mother also reported pressure to balance work with caring for her child. According to Darnell's mother, caring for her child and providing the necessary supervision limited the time that was available for her to work outside the home. She reported:

My husband and I were both planning to work. However, that did not happen whatsoever. Now my son needs special care. He needs special things that this program does not fund and most importantly, I'm not even getting the support from the physicians that I need.

On the other hand, some parents were able to find accommodations to their work schedule such that the difficulties balancing work with caring for their child were reduced. For example, both Lenny’s parents work from home. Lenny’s father reported: 
It's not as though there's a job or something that I have to do at a particular time, and I cannot leave. I have tremendous flexibility and I work from home. You're talking to two people who are not in traditional circumstances. We're both lucky to have the jobs that we do. Telecommuting-you have to set that as a strategy. Because if the school calls, if the child's sick, unlike many other parents, in most cases, one of us can be there in five minutes.

Similarly, Grace's mother was able to enroll her in the preschool affiliated with the church where she worked. This arrangement allowed her to balance work with the opportunity to be available to deal with problems with Grace as they arise. She commented:

The preschool is actually where I work. They are run independently, but I am able to peek out my door and hear her hollering, and if they're having issues, they can bring her to me. It works out really well, because, with my history, trust is very difficult. It took me that whole year to get me to let my mother in-law keep her all day long, let alone put her in preschool. So the fact that it's on the facility where I work is good, because that way she is able to be independent without me having a panic attack every time I pull away.

Unfortunately, flexible accommodations such as those were only reported by two sets of parents. However, it would appear that the inherent flexibility in each set of circumstances, and the physical proximity to their children throughout the day, helped reduce the strain associated with raising a young child with challenging behavior. 
Assumption Four: Parents of young children with challenging behavior will report experiencing stress among members of their family. Data obtained across participant interviews indicated that young children with challenging behavior may have a negative impact upon relationships among family members. Specific categories pertaining to these data include relationships between members of the child's immediate family, and relationships between members of the immediate and extended family.

With respect to the former, Lenny's father summarized the feeling that he experienced after managing his son’s intense and draining behavior: “If you've had a tantrum in the morning, it's just as though you've had a fight with your spouse.” Bri's mother reported that she lives with her parents for financial reasons and support raising Bri. However, she remarked feeling stressed about the situation, commenting that, "My father’s had quadruple bypass, and my mom has had back surgery, and like I said, they have a 14 year-old who has special needs too.” Darnell's mother also reported that his behavior has impacted other members of his family:

Darnell's condition affected everybody. When he's crying and waking up in the middle of the night at 3 or 4 o'clock in the morning and he's scratching and crying at the top of his lungs. My other children would wake up. My daughter's saying, 'Mommy, is Darnell okay? What's wrong?' We had to move Darnell out of their bedroom because it was affecting everyone.

On other occasions, it appeared that some family members clashed relative to the way in which children were disciplined or redirected. Andrew's mother mentioned that her son's challenging behavior caused a rift between her, Andrew, her mother, and her stepfather: 
Things that have been hard for my step-father and I. My step-father has never wanted kids in his life. He doesn't have any of his own. So not only can he not handle kids but the ones he now has all have issues. When we first came down here, we had to live with my parents for a short period and then we ended up coming here. My son created too many problems. He was up all night. My stepfather works construction in another city, so he has to get up at four o'clock in the morning. He tries to go to bed early, and my son's up all night, making loud noises. It’s very difficult to get him to sleep without him crying, so my father's up all night. My parents are considering a divorce right now because of everything. It's caused a lot of tension. My father and I no longer speak. I have had to cut off all contact with him. That's made it difficult for my mother, because when I cut off all contact with him, my son no longer sees him because he cannot control his attitude and his temper around my son. So in doing that, my mother went from being able to see my son whenever she wanted to once a week, if that.

In addition to the fact that Andrew's grandparents are considering divorce, it is also evident that Andrew's challenging behavior also reduced his access to his grandmother because of his grandfather's unwillingness to allow the child to visit According to Andrew's mother, his step-grandfather became agitated whenever he exhibited challenging behavior. Andrew's mother found her step-father was responding in a way that was counter-productive to Andrew's care, and commented:

He just started pitching a fit, and finally my father just turned around and told me to shut him up. You know, what do I do? If I discipline him, it’s going to make 
him get louder. If I ignore it, he's going get frustrated, and it's going to make him get louder. No matter what I do here, he’s going to get worse. So finally, I just took the route that you know, unless my father sees my discipline him, he’s going to think that I'm not doing anything and it's going to make my father worse. So I picked my son up, I spanked him, and I told him to sit on the couch. Screaming bloody murder, he went over to the couch. Screaming, screaming, screaming. My father got upset, turned around and said, 'Good going, you just make it worse.' Finally, I just got upset and said, 'You know what? If you think that you can do a better job, step in anytime. I am doing the best that I can. I am the one home with him 24-7. I am the one who has to deal with him all day, every day. I am the one who knows him best and knows how to handle him best. It doesn't make me perfect, but if you feel that you can do a better job, do it.'

Andrew's step-grandfather became upset whenever he became loud and disruptive. Though troubling to others in the family (e.g., Andrew’s mother, grandmother), the resulting marital tension between Andrew's grandparents and the tension between his mother and step-grandfather contributed to a greater degree of isolation between Andrew, his mother, and maternal grandmother.

In a similar vein, Lenny's parents mentioned that their son's challenging behavior has limited their access to family living a few hours away. Lenny's mother acknowledged:

We have family living in (location) and (location), which are only three and a half hours from here. We don't go. We used to go with (brother) as an infant. I used to take him nursing and everything else from the time he was 12 weeks old. By 
myself, no less. Okay, it was not a big deal. I think we’ve been down once, no, twice in the last two years. Very short visits. Every four weeks or every six weeks we used to go. So that's a radical change. Absolutely.

Lenny's mother continued, "Even going to Orlando. (Husband) has a sister living in Orlando and we used to go there much more often, but just an hour in the car. We used to go and walk into Thanksgiving dinner twitching." These data illustrate the types of tension that can arise within families as the result of a child's challenging behavior. The above examples illustrate the types of difficult interactions that can occur within either immediate and/or extended family. Not only do these types of interactions cause tension, but they also have the potential to isolate the child and immediate family from other members of the family (e.g., Lenny’s parents visiting family in Florida).

Assumption Five: Parents of young children with challenging behavior will report that they experience community isolation as a result of their child's challenging behavior (i.e., decreased frequency and/or duration of interactions with friends, neighbors, community resources, religious services, and/or public transportation). Relative to this assumption, multiple categories of information emerged. Though data clearly illustrate perceptions of community isolation, parents differed in the ways and degree to which such isolation occurred. Specific categories include: 1) limited access to friends; 2) limited access to community for social recreation; and 3) limited access to services and supports for parents.

Relative to the first category—access to friends—parents typically reported experiencing a degree of isolation from friends as a result of their child's challenging 
behavior. For example, Andrew’s mother reported that as a result of her son's severe disruptive behavior:

Friends didn't want to hang around me anymore because I have a child, and it's a package deal and he doesn’t do well at restaurants. Restaurants set him off. They make him violent. He throws big fits. A lot of public places will set him off. We haven't learned everything that does it. He could go to a grocery store and be just fine. Other times, he pitches a fit so bad that he throws himself out of the buggy and lands on concrete and it's a big ordeal.

Similarly, Lenny's parents shared a recent example of a difficult and embarrassing visit with friends and their children:

We had an episode where we went to a friend's house and it was several other people with their kids. All of their kids are more or less the same age, and we haven't seen them since. I was so mortified, and I sent her an e-mail and everything. I wouldn't' say that she's wrote us off, but I'm sure she’s busy. We're still twitching. We're still twitching. It was just that other kids have temper tantrums or what not, but they tend to calm down quicker or it's just not as disruptive, and because his are so violent and so much longer, it made everybody twitch.

In both cases, the presence of the child (and their challenging behavior) created difficult interactions for the other adults. Both parents indicated that they haven't seen their friends since. In contrast, Grace's parents appear to have found a way to adapt and still spend time with friends. Grace's mother mentioned: 
My husband is phenomenal. He is one of those rare men who will wash dishes, vacuum, and clean house and laundry, and all of this kind of stuff. I am always saying how fortunate I am. There's a lot of times on the weekend when he will keep her and my friend, Susan, and I will go to Wal-Mart or go shopping or just putter around for several hours. He'll kind of hold the fort down around here and he'll occasionally do that in the evening, too. I have to be able to get away and have some time.

Through the process of taking turns watching Grace, her parents were able to effectively create opportunities for them to spend time and stay connected with friends. Such a strategy was also reported by Lenny’s parents, who commented, "We both travel for work occasionally. There are things we do where it's like tag team. 'You're it, you're it.' That's our family.” In the case of both families, this appears to have been a successful strategy for families to both spend time engaging in preferred activities within the community and to manage their time.

The second category pertaining to community isolation pertained to access to the community for the purposes of social recreation. Seven of eight parents provided a response to this circumstance, particularly with respect to trips to the restaurant. For example, Lenny's parents commented:

It definitely inhibits our ability to go out into the community. Going out to the restaurant. Our restaurant menu at this point consists of Burger King, Wendy’s, or McDonald's. Any place where we can pay first and then leave. Any place that has a quick exit. That's our criteria. Lenny is unpredictable and he's destructive 
not only to our own family unit, but to people around him. Things like movies, and things like that, we cannot normally take him.

In fact, Lenny’s father learned that he became so embarrassed with his son’s behavior in public that on occasions when he is alone with the children:

I'm so scared of unsafe behavior in public, that all I do is bring them back here (points go the family room). Whatever that is, 40 square feet of family room, that is where I keep them. I play with them, I feel them, I bathe them, I entertain them. We wrestle of the floor, there's hugging, there's kissing, there's loving, but I can control that environment. Outside of here, there are times where it gets unpredictable. I guess I embarrass very easily. The child that's misbehaving is mine, and everybody is running and looking at you. We were parents at an older age by our own choice.

It would appear that the reactions of Lenny's father are not unique. According to Andrew's mother:

They see this child, and they see a spoiled rotten, undisciplined kid. They don't see a child who has a problem and is making all of this happen. You go in public and your child pitches a fit, and all you hear is, ‘Thank God my children don’t behave that way.' 'Oh that child just needs a good discipline. A good spanking. Take him out to the shed,' you know? That's all you hear. Consequently, Andrew’s mother acknowledged that, “We don’t sit at restaurants because it's an issue. We try to avoid all of the things we know that create issues.” It appeared that parent participants frequently cited concerns with embarrassment and the perceptions 
of others observing their child's lack of self-control in the community. Tank's mother reported similar circumstances:

He cuts up worse when we go out in public. He runs from you or if I tell him to stop doing something, he tell me to, 'Leave me alone...' He'll say that in front of people. They look at me. I have to pull him by the arm or something so that I can talk to him real mean. 'You understand me?' And it still don’t work. He still go out and do the same thing.

DJ's grandmother reported that that her grandson's curiosity led to difficult situations when shopping at the local mall:

He'd get in the mall and he's inquisitive, so he'd want to touch the mannequins, wanted to touch the clothes racks and stuff, and when he couldn't, he'd fall out on the floor in the mall. So we started not to take him.

While DJ's family reacted in a way they felt was in everyone's best interest, it is equally important to note that DJ's curiosity while out in the community led to the occurrence of challenging behavior. As a result of the fact that his family chose to escape a potentially difficult or embarrassing situation, DJ also lost the opportunity to practice appropriate behavior in a community setting.

Finally, Bri's mother commented:

We don't go out a lot. I can't be out too long; it depends on her allergies and asthma. She's not old enough for an inhaler; she uses a nebulizer. We still go out to the movies, it depends on her preferences. She loves the park, but can’t play in the sand/dirt. She loves the water, but it's the same thing. We have a pool, but she can't stay in too long. 
Across parent interview respondents, it was clear that community trips were times of intense stress and potential ostracism. Two of the eight parents interviewed commented on the typical reactions given by adult bystanders, but across each situation, parents elected to remove their child rather than keep them within their environment.

The third and final category pertaining to community isolation related to services and supports for parents within the community and knowing whom to contact for help. One out of eight parents interviewed discussed this issue. A parent of a child with Williams Syndrome, Grace's mother found herself assuming the role of an advocate, which reportedly helped reduce the family's degree of community isolation. She commented:

I heard the word, 'advocate,' but I never really knew what it was to be one until I had Grace. It's not just about Grace, it’s about every kid. It’s about every kid, and about every parent, it's about those parents that are uninformed, who don't know what to do, don't know who to call, you know? I'm tenacious enough to figure it out or bug somebody until they tell me, but there's a lot of people that aren't, that take the word of their pediatrician or take the word of their specialist or who will listen to their service coordinator as if that person is God himself, and will say, 'Well, they don't think my child needs an hour of physical therapy, they think having therapy once a month for 10 minutes is going to help my child.' Not only do I not want to be that ignorant parent, I don’t want that agency to get away with doing that to any parent.

Assuming such a role, Grace's mother has served on a committee for an agency affiliated with the local early intervention program. Reflecting back upon these experiences, 
Grace's mother commented upon the importance of such connections with other who understand her child and family's situation. She remarked:

We have met a lot of people that we would not have met otherwise, we've had the opportunity to learn and experience things that would never have been a part of our lives, and we have become a welcomed part of the special needs community—meeting incredible people and affecting change where we can. In the case of Grace's mother, she appears to have learned how to cope with her daughter's disability and to turn a negative situation into a positive one where she has experienced personal growth.

Question Two: What types of protective factors (i.e., microsystemic, mesosystemic, exosystemic, macrosystemic, chronosystemic) are perceived by parents to positively influence the experiences of young children with challenging behavior living in Hillsborough County, Florida?

The research by Huffman and her colleagues (2001) have identified protective factors within the individual, microsystem, and exosystem levels of Bronfenbrenner's model. Using this framework, the reported protective factors were presented and discussed, with sample quotes provided to substantiate the presence of perceived protective factors.

Individual Level. At the individual level, these factors include child selfconfidence, high cognitive functioning, easy temperament and personality, and early history of positive functioning. With respect to these factors, DJ's grandmother suggested that he is functioning above age level expectancies. Describing DJ further, his grandmother remarked: 
He is just a leader. He leads and directs the 10 year-old, and he says, 'No, we're going to do this now.' He understands this now and later, and he doesn’t procrastinate. It needs to be done now, and if you say we're going to do it tomorrow, his response is, 'Why tomorrow?' He says it exactly like that, 'Why tomorrow?' I said, 'Because today is not a good day.' He said, 'Why, then, is today not a good day." "He argues with logic.” "Definitely. But he understands if you explain it to him why you're going to do it tomorrow.

Beyond his grasp of logic and rationale, DJ's grandmother describes him as having an easy temperament and personality. For example:

DJ likes to be the leader and when you leave, he likes to give you a hug goodbye and asks when you'll come over because he likes to look forward to seeing whomever he parts company with. And he's never met a stranger; he thinks everybody he’s met is wonderful. He loves to give kisses or cuddle. When he’s angry, he will step away from you and think about whether he was right or wrong, and if he’s wrong, he'll come back, say, 'I’m sorry,' and give a hug, saying, 'I love you.'

In addition, DJ’s grandmother commented that he was observed in his preschool by a doctor, who reportedly found that his skills were advanced compared to other children of the same chronological age. She said:

The doctor reportedly made a decision that he should go to another program where the parents and staff could learn how to deal with DJ. Their findings were at that time too, that he was advanced. And when we got the letter in the mail and 
we talked to them again, they said that he scored out between 38 and 40 months at 26 months of age.

On the basis of this information alone, it would appear that DJ possesses multiple protective factors at this level.

With respect to other children in the participant sample, Grace’s mother described her easy going temperament and personality. She said:

Grace is a very inquisitive child, and altogether too clever, and one thing that has always struck me about her even before she was diagnosed is that she draws people to her. She is very happy all the time and friendly. We can be standing in the supermarket in the 10 items or less line and have 20 items with the old guy behind us who’s crotchety and is counting our items and doesn’t look like he's had a good day since 1909. By the time we're at the end of the line, he's making stupid faces at her, trying to make her smile. She has this way about her that like attracts people.

Similarly, Darnell's mother described her son as a self-confident leader. She reported: Yes, he’s a leader because I think he's confident, coupled with the fact that (her sister) emulates him and he realizes it. Whatever he says, she says, and so he realizes that somebody looks up to him, and he kind of manipulates her. Those are his strengths.

Likewise, Bri’s mother suggested that she also has an easy temperament and personality. She commented:

Bri is very willful. My purpose is to turn that into a positive. I hope it gives her ambition. She’s loving...her smile. She has a beautiful smile. She’s very easy 
going, she likes to go out and have fun. Everybody loves her. She'll hug and kiss people.

Lenny's parents also offered an equally positive description of their child. They reported, "He brings a lot of positive energy and laughter and things of that nature. He loves (brother) as a brother and has made him into a wonderful, caring big brother.” Finally, Tank's mother mentioned that he is a bright young boy. Ironically, it appeared that this strength also presented a challenge. Tank's inquisitiveness and curiosity may have contributed to the reported difficulties he had at daycare. His mother said:

I saw him trying to get the baby to eat chicken. I said that babies can’t eat that. He said, 'Why momma? Why?’ He’s very intelligent. He’s very smart. You tell him something one time and he won't forget it. He knows names. He want to spell his name and he's learning that a little bit. He knows his date of birth. He knows who his mom is. He knows his phone number. He knows my mom’s phone number.

Together, these data suggest that the child participants in this study possess at least one protective factor at the individual level of analysis. Not only were parents aware of their child's strengths, but they also tried to both enjoy and build upon then when selecting interventions.

Microsystem Level. At this level, Huffman and her colleagues (2000) suggest the presence of the following protective factors: Residence with both parents or remarriage after divorce; high level of maternal education; stable, organized and predictable family environment; cooperative parental coping; social support; secure attachment in early years; larger number of classroom friends; and high-quality child care at an early age (p. 
21). With respect to these factors, four of the seven children reside with parents who are married (Grace, Darnell, Andrew, and Lenny), the average age of maternal education is 14 years (range = 12-18 years; Lenny's mother highest), and five of eight children are presently enrolled in a daycare or preschool program (e.g., Bri, Grace, DJ, Lenny, and Tank). However, the degree to which these programs are considered "high quality" is unknown. In the event that these programs were accredited reflecting a standard of "high quality” (Bredekamp, 1991), daycare or preschool enrollment would serve as a protective factor. In addition, four of seven children (i.e., Bri, Grace, Lenny, Darnell) reside in a stable, predictable, and organized environment, as evidenced by observations and interview data. Finally, with respect to cooperative parental coping and social support, interview data revealed several examples. One of the most prominent examples was provided by Lenny's parents, who discussed their appreciation for each other's support: We thank God every day that we're a team, because we can't see how single parents do it. We can see how a single parent could handle one child, but being a single parent of more than one child, I don't know how they do it.

While Lenny’s parents expressed their appreciation for each other, Grace’s mother was happy about the relationships she had formed with others in the community. She commented:

We have met a lot of people that we would not have met otherwise, we've had the opportunity to learn and experience things that would never have been a part of our lives, and we have become a welcomed part of the special needs community—meeting incredible people and affecting change where we can. 
With respect to sources of support, several parents have discussed how they work as a team to get through the day (e.g., Darnell’s mother, Grace’s mother, Andrew's mother, Lenny's parents). One such example is Grace’s family:

I'll keep her or I'll take her with me with Susan and she'll go shopping with us, so he has some time by himself, too. We try to balance out giving each other time without being responsible for the baby. We found out really early that you need to tag-team it.

Grace's parents learned that each needs some time to themselves, and decided to make time over the course of the week where Grace would spend time with her mother so that her father can relax. Likewise, Grace's mother enjoyed opportunities to shop with her friends and take a break from her daily responsibilities. In either circumstance, Grace’s parents reported that they learned to rely on each other for support and some muchneeded time alone. Similarly, Lenny's parents, as noted above, also felt it was important to have more than one parent sharing the responsibilities of a child with this level of challenges. In addition, Bri’s family, DJ's family, and Tank's family are reportedly closely knit and provide support to each other as well.

Another central source of support for families is their religious faith. During interviews, Grace's mother commented that she relies on her faith for a sense of support and perspective. For example:

My dad is a Southern Baptist minister, so I was raised with a lot of faith, and that has helped me during the time that I was abused, growing up, etc. It helps me cope with difficulty. I feel like I've managed to be able to put things in perspective to know that life is not always going to be pleasant, and while things 
happen that are unfortunate, you just deal with what you've gotta deal with, and you move on.

Once again, a review of the data obtained in this study suggested that each of the children possessed at least one protective factor at the microsystem level. Protective factors help balance stress, time limitations, and financial limitations of caring for children through activities such as having fun, promoting caring relationships, and considering how strengths can be built upon to ensure a better future for their child.

Exosystem Level. Beyond the microsystemic level of analysis, Huffman and colleagues identified a single protective factor at the exosystem level (higher SES). Given the fact that zip codes were the lone indicator of SES for participants in this study, additional information would need to be collected to accurately determine SES.

Chronosystem Level. Huffman and colleagues did not discuss any specific protective factors at this level of the ecological model. By definition, the chronosystem refers to the sequence or pattern of events that impact a child's development (Berk, 2002). Following this definition, it would appear logical to argue that there are three scenarios by which the passage of time may serve as a protective factor: 1) the relative age at which the child's concerns are identified and diagnosed; 2) the time that passes between the point in which concerns are first identified to the time in which a diagnosis is rendered; and 3) the time that passes between the point in which a diagnosis is rendered to the time in which services are initiated. In the case of all three scenarios, one could argue that the earlier the age or the shorter the period of time that passes, the more likely the passage of time served as a protective factor for the child's well-being and conversely for children at risk. 
Relative to these three scenarios, it would appear that the relative age at which each of the children's behaviors were identified serves as a protective factor. Each child's concerns were identified during the preschool years, thereby presenting opportunities to obtain services and supports designed to effectively treat and prevent the occurrence of challenging behavior in the future. This is particularly true for Grace, DJ, and Lenny, the only children in the participant sample whose concerns were first diagnosed at before 36 months of age. Not only were these children identified and diagnosed earlier than the other five children (i.e., identified at ages birth and 14 months, diagnosed at 11 and 20 months, respectively) but they have also received the greatest amount of service in terms of different treatment modalities, and frequency/intensity of sessions provided. This is particularly true for Grace, who was first diagnosed before 12 months of age.

Although each parent reported that their child presented with a physical illness that may have had an impact upon their development and/or tendency to demonstrate challenging behavior, Grace was diagnosed earlier as a result of physical problems associated with her condition (e.g., ventricular septal defects, jaundice, orthopedic concerns). As a result of receiving medical attention early and early enrollment in the early intervention program, the time in which Grace was diagnosed served as a protective factor for her.

However, in the case of the five of the other six children presented with either otitis media (i.e., ear infections) or a speech delay, the time in which their concerns were identified appeared to serve as a risk factor for them. Research suggests that there is a relationship between chronic and severe bouts of otitis media, subsequent hearing loss, 
and resulting speech delays (Friel-Patti, 1990; Lonigan, Fischel, Whitehurst, Arnold, \& Valdez-Menchaca, 1992; Rvachew, Slawinski, Williams, \& Green, 1999; Teele, Klein, Chase, Menyuk, Rosner, Allen, Bratton, Fisch, Stringham, Starobin, \& Tarlin, 1990; Trivette, 1998). Such concerns are typically identified after 18-24 months of age, the time in which a child's language development enters a critical period of rapid growth and development (Berk, 2002). Given the fact that children are eligible for the early intervention program until 36 months of age, the duration of enrollment and access to available services is drastically reduced. Though services are available for children between three to five years of age, the model of service delivery and the frequency, intensity, and duration of its services are different and often less individualized (Bailey, 2000; Bredekamp, 1991; Carta, Schwartz, Atwater, \& McConnell, 1991; Florida Department of Education, 1998; Guralnick, 2000).

Compounding the matter further, the standard treatment for chronic and severe episodes of otitis media other than antibiotic medication is a surgical procedure called tympanostomy, where drainage tubes are inserted into the child's middle ear (Trivette, 1998). Unfortunately, access to this surgical procedure is not equal for all, as Kogan, Overpeck, Hoffman, and Casselbrant (2000) found a strong relationship between tympanostomy tube insertions and continuous health insurance coverage (p. 249). Therefore, it appears that the natural progression of child development, and to a lesser degree, continuous health insurance coverage may contribute to an explanation of why some children's concerns are identified earlier than others. This is particularly relevant to young children with challenging behavior, the function of whose behavior is often closely tied to communication (i.e., initiating or sustaining social interactions; requesting access 
to preferred persons, objects, activities; Carr, Levin, McConnachie, Carlson, Kemp, \& Smith, 1994; Dunlap \& Fox, 1996; Wetherby \& Prizant, 2000).

Question Three: What types of risk factors (i.e., microsystemic, mesosystemic, exosystemic, macrosystemic, chronosystemic) are perceived by parents to negatively influence the experiences of young children with challenging behavior living in Hillsborough County, Florida?

The research by Huffman and her colleagues (2001) identified risk factors within the individual, microsystem, and exosystem levels of Bronfenbrenner’s model. Using this framework, the reported risk factors were presented and discussed, with sample quotes provided to substantiate the presence of perceived risk factors.

Individual Level. At the individual level, risk factors include low birth weight and neurodevelopmental delay, medical problems, psychophysiological problems, early cognitive deficits, difficult temperament and personality (e.g., hyperactivity, aggression), and early behavior and adjustment problems. Given the fact that each child participant demonstrated challenging behavior as part of an inclusion criteria for this study, one could argue that each child possesses risk factors associated with early behavior and adjustment problems. Likewise, each child reportedly demonstrated aggression (including self-injury), thereby suggesting that they may have a difficult temperament or personality. In addition to these risk factors, two children were born prematurely at low birth weight (i.e., Bri, Grace), and one was born with a neurodevelopmental delay (i.e., Andrew, who has pervasive developmental disorder, not otherwise specified). To illustrate such risk factors, Andrew's mother shared this description of her son's repetitive and disruptive behavior: 
He had no fear whatsoever. When we were in the process of moving, we had an entertainment center that was a little shorter than the table and just as long. We had cleared the TV off of it, because we were getting rid of everything. He proceeded to take one of his riding toys, and put it on top of the entertainment center, climb up, get on it, and ride it right off. Completely scratched up himself, hurt himself real bad. Screaming, crying, and I picked him up, kissed his booboos, and told him not to do it again. Five seconds later, he was right back up on there.

Illustrating behavior problems as well, Lenny’s parents remarked:

Because he was behaving somewhat like a caveman, it was hard for him to get along with his brother. His brother would build a tower, and he'd come in like a caveman. And he's probably in his own language, probably trying to say, 'Hey, I'd like to play with you.' Instead, he'd swat down the tower, and then he bit (brother) in the middle of his back. There's no fat there on the back. He was truly like a wild animal.

Describing risk factors inherent to low birth weight and/or neurodevelopmental delay, Grace’s mother discussed her experiences as she attempted to take her daughter home from the hospital when she realized that there was something "wrong” with her daughter: We were set to go home and they were doing that final check they do right before they send the baby home and said that she has a heart murmur. That was the first indication that things weren't right. Actually she has two-two little VSDs, little holes in her heart. We finally got clearance to leave from the cardiologist and when they did the next "final check,” they said, 'oh, she’s yellow.' So then she 
was in the NICU for six days with jaundice. Her billirubin counts were like 22, and 25, I think, causes brain damage. They were really high. They didn’t have to do transfusions or anything, but they had her under five different sets of lights. So we went from almost going home to there's something wrong with our daughter to 'there's something else wrong with our daughter.'

In an example of difficult temperament or personality, Bri's mother offered this account of her daughter's language and social development:

We started to notice a change at 18 months. Her language stopped, she wasn’t speaking like other children her age. At 24 months, it seemed like she had stopped learning. She was attending daycare, but wasn't able to go all the time because she had eczema and allergies to mold and animals. Bri began to withdraw from others and wouldn't socialize with other kids.

It is important to note that while each child participant possesses at least two risk factors at the individual level (i.e., difficult temperament and personality, early behavior and adjustment problems), the children themselves vary widely in terms of their medical/developmental histories. While each child demonstrates risk factors associated with challenging behavior, they differ relative to the underlying reasons why these behaviors might occur (e.g., medical/developmental concerns, environmental factors).

Microsystem Level. At this level of Bronfenbrenner's model, several risk factors have been identified in the literature, including the following: family composition (e.g., divorce, remarriage), low level of maternal education, parental substance abuse, problematic maternal relationship history, parental psychological problems, poor parenting practices, maltreatment, insecure attachment in early years, difficulties with 
peer relationships, and child care by someone other than the mother (e.g., daycare/preschool). However, it is interesting to note that some factors, such as remarriage and daycare/preschool enrollment, may serve as a risk factor in some situations, and as a protective factor in others (Huffman et al., 2001). Given the fact that the U.S. Census Bureau indicated that approximately 50 percent of all marriages in the United States result in divorce, remarriage may reflect stability in some situations, and instability in others (U.S. Census Bureau, 2004). Likewise, research suggests that daycare/preschool enrollment is considered a risk factor, unless it is in a high quality program (Belsky, 1999; Huffman et al., 2001). Using these identified risk factors, each of the children possesses at least one risk factor at the microsystem level. Three of seven children (i.e., Bri, DJ, Andrew, Tank) reside in families with a single or remarried parent. Three of seven children could be characterized as being "at-risk" due to low maternal education (i.e., 13 years of schooling or less; Grace, DJ, Tank). All seven children have received child care by someone other than the mother (e.g., daycare/preschool).

Relative to the other identified risk factors, Bri's father reportedly had difficulties with substance abuse. Bri’s mother commented:

When I told him, I didn’t think he believed I was pregnant. I actually showed him the test in February and it had been in November. He had actually been in rehab at the time. That's exactly why I left. He was on drugs, and I couldn’t deal with it. I left and actually, he checked into rehab. I thank God that he did because he is now drug free, he's a very productive young man, and has his own business. Relative to parental psychological problems, Grace’s mother candidly shared her own medical/psychological history: 
I have Dissociative Identity Disorder. It's a very complicated thing, and has required a lot of time and therapy. I have been on and off meds, although I didn't take them the whole time I was pregnant with her, and that was, well, interesting. I nursed her for 6 months, so I didn’t take it for that 6 months. The sleep deprivation was just too much, though, so I had to go back on meds. I weaned her and put her on sippy cups and whatnot, so that I could go back on the meds. You know, you gotta do what you gotta do, and it was what I needed to do. I always do better on meds than when I'm off. I have a great therapist who I work with very closely, and I was actually integrated entirely once, but with that being my mind's default mechanism for stress, it wasn't very much time with everything we were going through, that I was having a lot of issues again.

With regard to problematic maternal relationship history, Tank’s mother shared experiences that could be considered a risk factor for her son's development. She explained:

I was in a violent relationship with their father. So I had been with his father five years and nothing but domestic violence. Three years before I got pregnant he used to beat me. When I got pregnant, in my fourth year with him, he beat me until I got separated. I don't want to teach my boys that. I don't want my boys to think that it's okay, that it's cool to hit a woman, because it's not. We don't have it in my home, so you know when kids get older, and they get in that stage, they will learn. And in school, they pick up a lot of stuff. Some things in school, you wouldn't believe what they learn, but they do. There's a lot of stuff they see, 
watching kids fight, kids shoot, all of that stuff. Just a lot of it in society. It's like, ‘I knew him, I knew him. Oh my God.

Although Tank's mother candidly acknowledged the fact that she had a temper and had been in a problematic relationship in the past, she expressed concern with its impact upon her son. After getting out of an allegedly abusive relationship, Tank’s mother indicated that she did not want her children to be exposed to such violence, despite her perception that violence is increasing in society. While his mother's awareness of these circumstances may help protect or shun his exposure to such circumstances, the fact that Tank's mother has had a problematic relationship and his father engaged in poor parenting practice serves as a risk factor for his development in the future.

Finally, several parents discussed situations that presented challenges to their existing set of parenting skills. Parents consistently expressed a desire for both additional strategies and support from others in learning how to effectively provide nonaversive discipline and structure for their child. For example, two of seven parents discussed occurrences of spanking. Tank's mother shared such a situation:

When I tell him something to do, he tell me, 'No' or he'd start biting. One time, he used to slap me and hit me. I had to put a stop to that. He knows that he can't hit me. I'm the momma. If there's anybody that's going to be doing the hitting, that's going to be me. And I don't hit him, I spank him when it's needed. You know, it used to be that I let him get away with a lot of stuff. But I mean, he’s still a child. Sometimes I think he’s picking up on what I do. And I have a bad temper. 
Similarly, DJ's maternal grandmother shared a story about her effort to dissuade her daughter from spanking DJ. DJ's grandmother made a decision to use a more prosocial strategy to help her grandson manage his behavior, and wanted to teach her daughter a set of more functional parenting strategies. She remarked:

DJ is in his formative years, where the stability and consistency is going to change his behavior for life. And the other part is she believes in spanking. She doesn’t spank abusively, like she'll take her hand and pop his butt, but he'll cry all of three minutes, and go back and throw the same thing on the floor. And I'm telling her, 'When are you going to get it? DJ's already understood that spanking's not going to change the way he thinks, but you haven't gotten it, so you're continuing to spank DJ. That's not working.' We had a discussion as recently as this morning about the spanking. Her whole attitude is that, 'He's two. I'm the mother and he's not going to run the house,' when the reality is that your two year-old runs your house, because you need to operate around your two year-old, and make things healthy and form his future.

Exosystem Level. While Huffman and her colleagues did not identify any risk or protective factors at the macrosystem level, they reported that immigrant status, minority status, and low SES represent risk factors at the exosystem level. Given the fact that zip codes were the sole indicator of SES for participants in this study, additional information would need to be collected to draw such conclusions. Relative to the other two risk factors, each child was born in the United States, and four of the seven child participants were of African American ethnicity. Therefore, four of the child participants in this study 
have a risk factor at the exosystem level due to how people are differentially served, perceived, received, and allowed access and opportunities.

Chronosystem Level. Huffman and colleagues did not discuss risk factors inherent to the chronosystem level. Given the fact that chronosystem refers to the sequence or pattern of events that impact a child's development (Berk, 2002), it would appear that there are three ways by which the passage of time may place a child at-risk: 1) the relative age at which the child's concerns are identified and diagnosed; 2) the time that passes between the point in which concerns are first identified to the time in which a diagnosis is rendered; and 3) the time that passes between the point in which a diagnosis is rendered to the time in which services are initiated.

With regard to the age at which the child participant's concerns were identified and diagnosed, four of the seven participants (i.e., Bri, Darnell, Andrew, Tank) were either first diagnosed or awaited an initial diagnosis after 36 months of age (average $=$ 36.75 months, range $=36-39$ months). Although the children are young, the average age at which concerns were first identified was 17.5 months (range $=6-36$ months).

Relative to the second scenario, six out of eight participants cited concerns with delays in receiving an accurate diagnosis for their child. For example, Andrew's mother discussed a conversation she had with her pediatrician while trying to obtain a formal diagnosis for her son:

(The pediatrician) finally decided that instead of sending him to a child development specialist with that waiting list, maybe he could see a neurologist. She notified me that the waiting list would be only two or three weeks, and it would be a lot easier. I asked her why she didn’t recommend that before. No 
response. So then, of course, I had to call and set that up. The pediatrician's office, we've always had problems. They never want to do any work. I didn't mind, I called to set the appointment up. Two days before we were leaving to go to Minnesota, we finally got in. I explained all of the problems that we were having with the pediatricians. The neurologist was appalled. He could not believe it had taken two years for a pediatrician to finally realize that there was a problem and to recommend getting him in somewhere. He was very upset. He told me that my son was clearly and severely autistic.

Similarly, Darnell's mother discussed her experiences and challenges trying to get her child's pediatrician to speak to her. In Darnell's case, his mother experienced frustration and difficulty while asking her pediatrician about whether Darnell's eczema could have led to subsequent developmental delays:

So I called recently to inquire about Darnell's history with her, if she thought I should get him screened (this was prior to the screening), if she thought that that condition may have caused any developmental delays. She didn't call me back. She had her medical assistant call me back, and I explained to her medical assistant, the patient, who I was, what the problem was, and if the doctor could return my call so that I could ask some questions regarding some developmental delays that he may have experienced as the result of the chronic eczema. I mentioned that at the time, she was his primary care. I asked if she would just touch bases with me; to tell me if that was even likely. I wanted to know if she thought eczema could have caused speech delays. She wouldn't call me back. She told her medical assistant that I would have to bring him in and I explained to 
her that I no longer lived in the area. I don’t drive. I wouldn’t be able to get in. I don't have car insurance, etc. She refused to even return my call. So it was then that I kind of went on my own. I started to call the university and some other places, mentioning that I had been referred by other professionals to the university because he was not engaging in any social activities, he was not talking, or using his skills. That was a critical time for him. It was a critical stage in his development.

The experiences of these two parents illustrate the fact that there was a delay in the time by which concerns were identified, diagnosed, and services were provided.

The following two quotes serve to illustrate the third scenario for a chronosystemic risk factor: The passage of time between the point of diagnosis to the time in which services are initiated. In the first example, Tank's mother discussed her experiences trying to set up appointments with her son's speech therapy provider, "It was hard trying to set up an appointment at (provider). Every time I would call, I would leave a message or they wouldn't call.” In the second example, DJ's grandmother discussed the possibility that her son would soon be included in a behaviorally-oriented parent support group:

It's been said that we would go for six weeks, for every Tuesday from 6-8 p.m. starting (date) where it would be other parents with somewhat the same type of background, like if we were all from up north. We're from New York, Brooklyn. They would try to use families that have the same type of backgrounds and cultures, somewhat close in age, to work together. They would discuss what their challenges have been with their children, and we would discuss our challenges 
with DJ, and we would get ideas. It would be based on backgrounds, cultures, ages, so that we would all be able to use that information that we pull together to help one another through the challenges of a child with behavior problems. That will be a wonderful thing, so we're hoping that will be something that we can take part in starting Tuesday evening. And we will do the whole six weeks, and other programs that come up. We want to be part of anything that's going to give us the support we need and the knowledge and skill for DJ's growth, but it will also be something that DJ can participate in, with children who are like him. Maybe eventually we'll be able to eventually find out what his IQ is, what things we would need to build on for him to achieve what we see as the direction that he is strong...We want to build on his strengths because he could go one way or the other. If he's a very intelligent child and he chooses evil per se—bad things—he could go as far as the east is from the west, so what we need to do is to continue to watch. Pay close attention so we can take those strengths and put them in good things, to help people, and share with people moral values and everything instead of that I can get over quickly because I am so smart and I can use people with weaker minds and get them to do what I want them to do. So that's going to be a challenge for us, but we need to get ahead of it so that we can know where to put him.

Though each parent's experience was distinctly different, both experienced frustration regarding the length of time that passed before services were provided. Tank's mother experienced difficulties scheduling speech therapy appointments with her son's speech therapy provider, whereas DJ's grandmother had been eagerly awaiting enrollment in a 
behaviorally-oriented parent support group. These illustrations underscore the importance of having resources to help parents and caregivers balance risk and protective factors at early stages of development, not just focusing solely upon medical issues.

\section{Summary of Questions Two and Three}

An analysis of the data obtained in this study revealed several risk and protective factors per child. Risk and protective factors were identified at the individual, microsystem, and chronosystem levels. In addition, demographic data may suggest the presence of exosystemic risk and/or protective factors associated with SES, although data collected at this time are inadequate to draw a more firm conclusion.

Across participants, a pattern was identified where children were subject to a greater number of risk factors than protective factors. However, each of the children were required to demonstrate challenging behavior as part of the inclusion criteria for this study. Consequently, the entire sample of children in this study can be considered "atrisk” as a result. In light of such concerns, as well as the fact that each individual's developmental history (i.e., medical, family, social, developmental) inevitably contributed to the manifestation of these behaviors, each of the seven children had been subjected to a greater number of risk factors. This finding is particularly important given the fact that the behavior of young children with challenging behavior is likely to be maintained by either increases in the number of risk factors and/or decreases in the number of protective factors.

In addition to these findings, it is important to acknowledge the contextual nature of risk and protective factors themselves. Considering each of these factors in isolation, it is possible for individual children to be considered both "protected" and "at-risk" for 
the same risk factor [(e.g., childcare provided by someone other than the mother vs. high quality child care); difficult temperament and personality (e.g., aggression, hyperactivity vs. easy temperament and personality)]. For example, a child who exhibits aggression in some situations (e.g., community outings) might be described as easy going and friendly in other situations (e.g., playing at home). As a result, one cannot simply compare and contrast lists of identified risk and protective factors; it is the ecological context in which they occur that meaningful conclusions can be drawn. The importance and implications of these findings and those of question one were subsequently addressed in the next chapter relative to both the needs of young children and their families (e.g., Hebbeler et al., 2001; Powell, Fixsen, \& Dunlap, 2003) and existing research on local service delivery system (Raffaele Mendez \& Hess, 2003). 


\section{Chapter Five}

\section{Discussion}

\section{Review of Research Questions}

The results of this study indicate that the sample of parents of young children with challenging behavior in Hillsborough County, Florida shared not only many similar experiences, but also reported comparable risk and protective factors impacting their child's behavior. In order to appreciate the findings of this study, however, it is first necessary to consider the research questions from which they were derived. Specific outcomes were linked to the research questions as they are presented. Findings for question one were both summarized and presented relative to each of the assumptions that were made by this researcher, while findings of questions two and three were presented together to facilitate discussion of the inter-relationships between the risk and protective factors reported in this study.

\section{Research Questions}

Research Question One: What are the experiences of parents obtaining services for young children with challenging behavior living in Hillsborough County, Florida?

The purpose of the first research question was to give voice to parents of young children with challenging behavior in Hillsborough County, Florida — to provide them with a venue in which to share their experiences raising their child. Data were compared 
relative to both reported experiences and assumptions articulated by this researcher prior to data collection in the bracketing interview. Relative to these assumptions, the findings are presented by category in Appendix I.

Parent interview data verified each of the five assumptions, indicating that parents of young children with challenging behavior share a number of common stressors. These stressors included obtaining accurate and useful information about their child, obtaining services and supports, managing financial stressors associated with their child's care, strained family relationships, and community isolation. At the pattern level of analysis (LeCompte, 1999), subcategories were identified for three of the five assumptions, whereas the other two consisted of a single category. Each is described below in further detail.

Obtaining information about challenging behavior. When asked about difficulties obtaining information about their child's challenging behavior, parents shared three different types of problems: 1) receiving accurate and useful information from their pediatrician about their child's behavior; 2) difficulties obtaining accurate medical/developmental diagnoses from their pediatrician; and 3) learning more about their child's challenging behavior from the Internet than from a medical professional. While medical professionals (e.g., physicians, physician’s assistants, nurse practitioners, nurses) are well-trained to treat pediatric medical and/or developmental conditions, they typically do not receive comprehensive training on their behavioral, educational, and psychological components (Power, Heathfield, McGoey, \& Blum, 1999; Roberts, 1995).

The findings of this study would appear consistent with such research. Parents consistently reported that their pediatrician did not provide adequate information about 
their child's challenging behavior. This contributed to two different categories of difficulty for parents—one associated with obtaining information for their own consumption and understanding, and another associated with the confidence of an accurate and timely diagnosis. Parents consistently identified concerns with their child's behavior that were typically formally diagnosed six to 12 months later. Though pediatricians provide care with the best practices in mind, it is also possible that the latency by which diagnoses are rendered may also be attributable to many other factors (e.g., gaps in the medical professional's training, difficulties in scheduling appointments). While it is neither possible nor appropriate to infer a more precise conclusion, it is reasonable to hypothesize that gaps in the medical professional's training may contribute to delays in a child's diagnosis and subsequent services. Parents of children with autism spectrum disorders often report such concerns, as exemplified by one of the participants in this study (i.e., Andrew's mother).

In addition to these concerns, the relative ease by which parents can access information also appears to serve as an area of concern. Although parents commonly reported using the Internet to research basic aspects of their child's care (e.g., side effects of prescribed medicines, parenting advice, symptoms of colds and other illnesses, condition-specific information), there is an inherent risk associated with a reliance upon such information. Whether the information relates to education, medicine, behavior, or another discipline, information obtained using the Internet is only as reliable as its source, and as a result, is best considered a supplement to professional advice. Given the fact that parents in this study reported difficulties not only with community isolation but also with accessing services and supports, it is not surprising that such a finding was obtained. 
In such circumstances, the Internet may serve as an even more important resource to parents and caregivers. However, the implications of such a finding are important to consider, especially in the event that a parent considers alternative treatments or medicines for a child who is already under the care of a physician or other professional (i.e., contraindications, medication or chemical interaction effects). While the Internet is an empowering resource for many parents, it also is replete with inaccurate or incomplete information. Such circumstances place an even greater value upon effective communication between parents and professionals, an important mesosystemic risk or protective factor.

Obtaining services and supports. Each of the parents interviewed in this study each reported difficulties obtaining services and supports for their children. Specifically, parents shared experiences relative to their difficulty identifying providers within the community, setting up appointments, receiving quality assessment and intervention services, and avoiding prolonged lengths of time with delays in service. These findings are similar to those reported by researchers at both the local and national levels (Bailey et al., 1998; Bailey, Scarborough, \& Hebbeler, 2003; Grosz et al., 2000; Powell, Fixsen, \& Dunlap, 2003; Raffaele Mendez \& Hess, 2003), as well as with individuals (e.g., Duda, Dunlap, Fox, Lentini, \& Clarke, 2004; Dunlap \& Fox, 1999; Fox, Benito, \& Dunlap, 2002). Relative to the local level, Raffaele Mendez and Hess (2003), reported that parents of children birth to age three residing in Hillsborough County, Florida experienced frustrations with both entering and navigating through the local service system. With respect to the service system for children birth to three at the national level, experts in the field reviewing the state of service delivery systems for young children 
with challenging behavior cited the following concerns: 1) screening and identification lacks an adequate empirical base; 2) existing referral systems need more effective linkages to available services in the community; 3) services and supports are provided on an inconsistent basis across the nation to children and families; and 4) federal- and statelevel policies are needed to regulate screening, identification, referral, and services for young children with challenging behavior (Powell, Fixsen, \& Dunlap, 2003). Consequently, difficulties reported by parents seeking services and supports for their young children in this study reflect not only risk factors at microsystem level of the ecological model but also at the mesosystem (e.g., quality of communication between the child's family and community providers and agencies), macrosystem (e.g., federal- and state-level policies), and chronosystem (e.g., the amount of time that passes between the time when concerns are identified, the child receives a diagnosis, and services are provided). Given the fact that these types of concerns have been acknowledged in the research literature on a conceptual basis and targeted for change through a familycentered model of service delivery, it would appear that the findings of this research study may be useful as a rationale for future applied research efforts at the local level, as well as program planning, adjustments to programs, and training efforts (e.g., Bailey et al., 1998, Guralnick, 2000; Smith \& Fox, 2003).

Financial stressors. Parents of young children with challenging behavior reported that their child's challenging behavior created two different types of financial stress, the first pertaining to financial expenses and the other reflecting stress associated with career. Parents consistently reported that their child required a number of costly products or services, including medications, health insurance, daycare or preschool, 
and/or high quality produce. In addition to these costs, parents often reported difficulties coping with the increasing cost of gasoline, as their child's needs often forced the parent to drive prolonged distances (e.g., to attend medical appointments, find stores with better prices, commute across the city to a more affordable daycare center). With regard to health insurance, parents reported not only having difficulties with insurance premiums and co-payments but also with affording expenses that are rejected by health insurance companies (e.g., speech-language therapy for children who have not yet learned to speak, applied behavior analysis). Given the fact that child care costs continue to increase, as do the relative cost of goods and services, it appears that the financial strain associated with such changes may be magnified for parents of young children with challenging behavior due to the fact that they require more care and support.

The second category associated with financial stress pertains to difficulties balancing one's career with the high demands of raising a child with challenging behavior. Although some parents interviewed in this study reported that they had a flexible work environment (e.g., parents who worked a portion of their day at home, parents who had an on-site daycare at their place of employment), others who did not have such accommodations reported feeling a high degree of stress associated with their child's needs. Bri's mother reported high rates of absenteeism or tardiness due to the need to take their child to medical appointments or to take care of their child when ill. Both Andrew and Darnell's mothers reported that in light of their desire to do so, they were unable to keep a job due to the high demands associated with their child's care. Although each of the children in this research study exhibited challenging behavior, each child either had reportedly experienced episodes in which they were chronically ill or 
exhibited challenging behavior secondary to a primary medical condition with a complex array of symptoms (e.g., Williams Syndrome, eczema, pervasive developmental disorder—not otherwise specified, asthma, otitis media, gastroesophageal reflux, bronchitis, ventricular septal defects). Given the fact that these children all required a greater frequency, intensity, and duration of treatment and professional support than peers their age, the parents who participated in this study often reported that their child's needs made it extremely difficult to effectively balance and manage their own careers.

The financial stressors reported by the parent participants of this study appear consistent with findings reported in the research literature. For example, Abelson (1999) reported that there was a relationship between a child's age, severity of disability, and their parent's ability to earn money. Not only did parents report missing hours of work, they also reported having to refuse opportunities to work due to their child's need for continued support and care, particularly for younger children and children with severe disabilities (p. 881). Data from both studies support the contention that parents of young children with challenging behavior are more likely to experience these types of financial stressors. Relative to the ecological model, these data would likely magnify the impact of exosystemic risk or protective factors associated with SES.

Strained family relationships. Data obtained relative to the fourth assumption reflect experiences of stress among family members resulting from the child's challenging behavior, a finding that has been consistently reported in the research literature (e.g., Huffman et al., 2001; Ingoldsby, Shaw, Owens, \& Winslow, 1999; Koegel, Koegel, \& Dunlap, 1996; Landy, 2002). Within the limits of this study, parents reported a variety of strained family relationships including sibling conflicts with the 
individual child participant in this study, marital conflicts between the child's parents, marital conflicts between the child's grandparents, and conflicts between the child's parents and grandparents. A microsystemic risk factor, it appears that families of young children with challenging behavior may be at an elevated risk of experiencing stress between family members. The most frequently reported type of strained relationship was between the child's mother and father. Parents varied relative to their current marital status (e.g., single, separated, divorced, remarried, married), and as a result, their experiences differed. Several mothers discussed the lack of support (e.g., financial, time spent with children) they received from their child's father. One parent discussed a complex legal struggle with her ex-husband, another shared that her ex-husband had been incarcerated and received treatment for substance abuse, while another mother disclosed the fact that she had been physically abused by her child's father. These experiences contrasted sharply with those reported by the parents in the study who were married. Not only did these parents report a greater degree of support for each other, but they also shared more examples of a more stable, organized and predictable home environment (e.g., predictable routines and schedules, consistent interaction styles with their children).

Community isolation. Parents of young children with challenging behavior reported experiencing two different forms of community isolation. The first category of isolation entails a parent's diminished access to friends as a result of their child's challenging behavior, whereas the second category refers to a parent's relative isolation from recreational activities and support services. While it is true that all parents lead busy and involved lives, young children with challenging behavior may exacerbate such circumstances. Young children who exhibit challenging behavior in community settings 
often draw attention from others, embarrassing parents as a result. Almost every parent reported experiences in which they felt either embarrassed or singled out by other children and adults when their child exhibited challenging behavior in the community (e.g., eating at a restaurant, grocery shopping, shopping at the mall).

In addition, six of eight parents reported a degree of isolation from the community as a result of the severity of their child's behavior or illness. Two parents reported that their child had been either kicked out or were at-risk for being kicked out of their daycare/preschool for exhibiting challenging behavior. Additionally, several parents reported that their friends either expressed interested in spending time with them away from their child or decreased the frequency of their contact with the parent altogether. Contrary to these types of experiences, researchers have suggested that inclusion, such as opportunities to form meaningful relationships with individuals, join and contribute to social groups, and opportunities for community integration are instrumental for family's quality of life (i.e., characteristics of well-being, positive social involvement, and opportunities to achieve personal potential) (Schalock, 1994; Turnbull, Turnbull, Wehmeyer, \& Park, 2003). In the case of parents participating in this study, family quality of life remains elusive, but no less important or worthy of achieving.

Summary. The findings obtained in this study suggest that parents of young children with challenging behavior share many similar stressful experiences. Parents of young children with challenging behavior reported difficulties obtaining accurate and useful information about their child (e.g., information about their child's behavior, diagnosis, information from the Internet), obtaining services and supports, managing financial stressors associated with their child's care (e.g., expenses related to their child's 
behavior, career-related stressors), strained family relationships, and community isolation (e.g., isolation from friends and neighbors, limited access to recreational activities and support resources). Although each parent's experience differed relative to each reported area of difficulty, the parents interviewed in this study reported a level of stress and difficulty that may exceed that which is typically reported among parents of young children who do not exhibit challenging behavior. Whether related to their child's behavior directly (e.g., services and supports, strained family relationships) or indirectly (e.g., career-related stressors, community isolation), the parents of young children with challenging behavior interviewed in this study were consistently faced with a barrage of stressors, each with a relatively high degree of intensity and impact on their family. Although similar findings have been reported elsewhere in the research literature (e.g., Fox, Vaughn, Wyatte, \& Dunlap, 2002), the findings of this research study are unique relative to the specific to age range of the children discussed in this study (i.e., Fox and her colleagues studied parental experiences raising children ages three to 12 years). Despite this difference, both studies acknowledged the value of receiving support from caregivers and professionals, as well as the persistent impact of their child's behavior upon the family's overall functioning (e.g., family relationships, access to the community, financial resources, social networks).

Research Question Two: What types of protective factors (i.e., microsystemic, mesosystemic, exosystemic, macrosystemic, chronosystemic) are perceived by parents to positively influence the experiences of young children with challenging behavior living in Hillsborough County, Florida? 
Research Question Three: What types of risk factors (i.e., microsystemic, mesosystemic, exosystemic, macrosystemic, chronosystemic) are perceived by parents to negatively influence the experiences of young children with challenging behavior living in Hillsborough County, Florida?

The data obtained in this study suggested that each family possessed multiple factors identified in the literature as being consistent with either reducing (i.e., protective factors) or increasing (i.e., risk factors) the frequency, duration, and/or intensity with which challenging behaviors are exhibited by young children. Such factors were reported at the individual, microsystemic, exosystemic, and chronosystemic levels of the ecological model. More specifically, data indicated that the families participating in this research possessed a greater number of risk factors than protective factors. Such findings were to be expected, in addition to the fact that an inclusion criterion for participation in this research study was that the child's challenging behavior was perceived by parents or guardians to "interfere with or is at risk of interfering with optimal learning or engagement in prosocial interactions with peers and adults” (Powell, Fixsen, \& Dunlap, 2003). While the entire sample of children in this study is considered "at-risk," the degree to which they are "at-risk" appeared to be exacerbated by the additional risk factors that have been reported within each individual family (e.g., family composition, parental substance abuse, poor parenting practices, childcare by someone other than the child's parents). As a result, it appears that once a child begins to consistently demonstrate challenging behavior, the more likely it is that additional risk factors impacting the family will contribute to further escalation in challenging behavior (e.g., ineffective or aversive parenting practices, problematic relationships, financial stressors). 
This circular relationship may, in part, offer an explanation as to why it is often so difficult for parents of young children with challenging behavior to effectively manage their child's behavior on a consistent basis. Additional research in this area may help clarify the relationship and interaction between such variables that have been discussed in this study and in others (e.g., Broidy et al., 2003; Huffman et al., 2001; Landy, 2002; Rutter et a., 1997).

Looking further at the relationship between risk and protective factors, it appears that the ecological context in which these factors occur is of equal importance to the specific risk or protective factors that are reported. Considering each of these factors in isolation, it is possible for individual children to be considered both "protected" and "atrisk" for the same risk factor [(e.g., childcare provided by someone other than the mother vs. high quality child care); difficult temperament and personality (e.g., aggression, hyperactivity vs. easy temperament and personality)]. For example, a child who exhibits aggression in some situations (e.g., community outings) might be described as easy going and friendly in other situations (e.g., playing at home). As a result, one cannot simply compare and contrast lists of identified risk and protective factors; it is the ecological context in which they occur that meaningful conclusions can be drawn. This is why professionals providing support to young children with challenging behavior using an ecological framework would be better able to pinpoint the specific instances in which a child or family would benefit from support (e.g., trips to a specific store or restaurant; providing coaching not only to a parent, but also to the child's grandmother; training professionals who conduct both developmental screenings and evaluations rather than simply focusing on the latter). Though generalization beyond the participants of this 
study is not advised, the practical utility and logic of such a finding may, in fact, support changes in the behavior of both individual providers and the local service system.

With regard to the local service system, the findings of this study strongly support those obtained by Raffaele Mendez and Hess (2003). In their analysis of communitybased services and supports for children and young adults with special needs in Hillsborough County, the authors reported that parents of children birth to three faced challenges with respect to: 1) proper diagnosis; 2) acquiring accurate medical information; 3) entering and navigating the system of care; 4) balancing work and care for the child; and 5) getting support for oneself (Raffaele Mendez \& Hess, 2003). The findings of this study not only confirmed Raffaele Mendez and Hess’s findings but obtained examples suggesting that these challenges may be magnified for families who have young children birth to three with challenging behavior.

These findings also corroborate with those reported at the national level. Powell, Fixsen, and Dunlap (2003) articulated concerns with the national system of care for young children with challenging behavior. The authors reported several important findings: 1) the health care system remains the primary gateway for identification, screening, referral, and access to services for young children with challenging behavior; 2) young children with challenging behavior tend to use services at a rate that is lower than the projected need; 3) service utilization for young children with challenging behavior is largely determined by medical professionals; 4) the availability of services for young children with challenging behavior is impacted by family factors, education, race/ethnicity, and socioeconomic status; and 5) family-centered practices and a broader approach to young children with challenging behavior is needed in preschool and daycare 
settings (Powell, Fixsen, \& Dunlap, 2003). Parents interviewed in this study reported experiences consistent with these trends in service delivery. All seven families relied upon their pediatrician and/or medical specialist as the primary source of information and point of access into the service delivery system. Parents also tended to follow their pediatrician’s recommendations for intervention (i.e., some parents also considered homeopathic or nutritional interventions), a decision which is largely dependent upon the pediatrician’s knowledge of both intervention options and available service providers. Similarly, parents consistently reported that they faced obstacles accessing available services for their children, albeit for financial reasons (e.g., the cost of medications, outof-pocket expenses for behavior analysis providers, insurance co-payments) or for reasons associated with service providers (e.g., lack of available providers, scheduling difficulties and waitlists for existing providers, preschool or daycare settings reporting that they are not capable of managing a young child with challenging behavior).

Considering the findings of this study relative to other areas within the existing literature base, it is clear that the process of identification, screening, assessment, diagnosis, referral, and intervention is not a static process. Researchers have argued that in the case of children birth to three, "one of the basic principles of early intervention is that 'earlier is better.”' (Dunlap \& Fox, 1996; Hebbeler et al., 2001; National Research Council \& Institute of Medicine, 2000). Given the strength of the available evidence within the literature base, it is reasonable to question whether the greatest type of risk or protective factor is the chronosystem itself. Referring to the passage of time, parents interviewed in this study appeared to have qualitatively different experiences and support systems when the chronosystem served a protective role (e.g., the length of time between 
the time in which parents identify concerns, the child receives a diagnosis, and services are initiated). While this is an area in which we may learn more with further research, further investigation into the chronosystem may help professionals understand the relationship between the passage of time and parent's experiences. For example, research may help clarify whether or not there are differences in the experiences and outcomes between parents of children birth to three whose services are initiated prior to 12 months than those whose services are initiated after 24 months of age (e.g., differentiating between delays in the time in which parents recognize concerns, delays in obtaining diagnoses and referrals targeting such concerns, delays in subsequent service delivery, and/or differences in both the type and clinical presentation of a child's disability or developmental delay over time).

\section{Limitations}

It is important to recognize the limitations inherent to this study. First, the study's generalizability, or the degree to which findings can be applied to others, is limited due to both the study's small sample size and the assumed influence of this researcher's role as an interviewer. While this researcher served to act as an "interested sponge,” the role of both the researcher and the context in which phenomenological research is conducted must be acknowledged. However, this researcher wrote an a priori description of his own experiences, thereby allowing him to "bracket” his experiences from those of the study's participants (Janesick, 2000; Marshall \& Rossman, 1989). As a result, the reader is able to compare and contrast this researcher's values and experiences directly to the stories of the parent participants. 
A second limitation pertains to the diversity of the sample obtained in this study. A total of four participants describing their race/ethnicity as "Caucasian" and four as “African American” were included in this study. In addition to these two racial/ethnic groups, the Hillsborough County region also includes many people who describe their race/ethnicity as "Hispanic." Participants in this study did not include this racial/ethnic group, which consequently, serves as a limitation to this study. However, this is not to say that this researcher did not seek out opportunities to reach out to parents of this racial/ethnic group; efforts were made to connect with these parents using purposeful sampling (e.g., asking referral sources if any of them knew of any families of a Hispanic ethnicity who also met the inclusion/exclusion criteria for the study who might be interested in participating, extending the window of time in which participants were screened for participation). Despite such efforts, researchers have reported similar challenges in obtaining the voice of people from specific racial/ethnic groups (King \& Goodwin, 2002). In the case of some families, extra effort is required in order to effectively reach out to some parents, including: 1) planning a series of parentprofessional seminars or team-building activities based on survey/interview findings; 2) using professionals proficient in multiple languages; and 3) generating multiple ways for parents to become informed about specific activities (e.g., television, radio, newspaper, flyers) (King \& Goodwin, 2002). Though such efforts are beyond the scope of this dissertation, it is possible that the findings of this study would have been enhanced had there been opportunities to include the voice of parents with a Hispanic racial/ethnic background. Given the fact that several families participating in this study experienced difficulties with interpersonal communication with other family members and/or 
providers in the community, it is reasonable to question whether the difficulties with interpersonal communication for families of minority racial/ethnic groups may be exacerbated further. Such difficulties may magnify or compound the challenges and difficulties associated with raising young children with challenging behavior.

Limitations also exist relative to errors associated with bias and subjectivity. As Stoecker (1991) suggests, "all research involves a creative leap from data to explanation” (p. 93). In this regard, this study is limited due to its subjectivity. However, it is equally important to acknowledge the fact that efforts were taken to ensure an adequate degree of rigor, precision, and credibility. In addition to the aforementioned bracketing interview, the following steps were taken to ensure rigor: the rationale for the study was anchored in a well-researched and empirically-supported theory of child development (i.e., Bronfenbrenner, 1986), a standardized data collection process was used across participants, a pilot study was conducted, transcripts of the first interview were presented to parents at the second interview to allow for reflections and subsequent revisions, data analysis findings were discussed with another doctoral candidate trained in qualitative research methods, and data analysis findings were presented and reviewed to members of the doctoral committee (e.g., Drs. Keller, Nesman, and Raffaele Mendez).

A number of issues pertaining to transcription and reduction also limit the findings of this study. First, interviews were audio taped and later transcribed for subsequent data analysis. Although it is likely to be small, one could argue that a small degree of error could be attributed to occasional deteriorations in the quality of audiotape playback (e.g., ambient background noise, presence of children and other adults in background). A second limitation pertains to the use of voice recognition computer 
software in this study. Using a procedure called "shadowing" (Newman, 2002), this researcher played back a segment of the audio taped interview, paused the tape, and then dictated the text verbatim into a computer using Dragon NaturallySpeaking 6® voice recognition software. Although an effective transcription procedure, some degree of error must be assumed as audio taped text is verbally dictated into the software program. In this regard, opportunities for error exist as the researcher both repeats the audiotape and the computer program interprets the researcher's language into typed text. While participants had an opportunity to review segments of their own transcript as a means of preserving the accuracy and credibility of their voice, it is possible that transcription errors could potentially change the meaning of a respondent's statements.

\section{Implications for Future Research and Practice}

In spite of its limitations, this study offers several contributions to research and practice within the field. From a research standpoint, the most important contribution is that it provided illustrations of the experiences of parents of young children with challenging behavior living in Hillsborough County, Florida. Prior to the initiation of this study, relatively little information was available documenting the experiences of these families (Brantlinger, Jimenez, Klingner, Pugach, \& Richardson, 2005). Likewise, the most important contribution toward future practice is the direct benefit to the parents and guardians who participated. Given the fact that one of the central themes identified in this study was that parents/guardians of young children with challenging behavior experienced a high degree of isolation, the opportunity alone for parents to share their experiences may be of direct benefit. Not only did several participants express interest in the results of this study, but one mother commented that "it will be interesting to know if 
other parents have had similar experiences as I have.” Many of the parents' experiences were, in fact, similar to others who participated in this study. As a result, this researcher will follow-up with parent participants upon completion of this study. Parents will receive both a copy of the presentation used at this researcher's dissertation defense, as well as a link to the study once it is published electronically by the University of South Florida. Such information may not only validate an individual parent's experiences but also has the potential to reduce the degree to which a parent feels a sense of community isolation.

In addition to providing parents with an opportunity to express their voice, other research-related benefits include both the potential expansion of categories of risk and protective factors (i.e., the assumptions and categories described in this study). Assumptions and their theoretical categories were verified over the course of the study that were driven by both the ecological framework and this researcher's own professional experiences (i.e., the bracketing interview). Given the many changes that occur in society, consideration of issues such as access to information from the Internet may not only help researchers expand the conceptualization and theoretical framework of risk and protective factors, but potentially drive future research efforts (Tzeng \& Kackson, 1990).

At the community level, the findings of this study can be seen as an extension or complement to research previously conducted by Raffaele Mendez and Hess (2003). The authors investigated community-based services and supports for children and young adults with special needs in Hillsborough County. In contrast to their study, which employed a mixed method research design to assess the system of care up to age 24 years, this study used qualitative methodology to provide a more detailed analysis of 
parents of children birth to age four with challenging behavior. Across the two studies, a number of similar findings were obtained (e.g., parents experienced stressors associated with obtaining a proper diagnosis, accurate and useful medical information, entering and navigating the system of care, balancing work and care for the child, and getting support for oneself), thereby enhancing the credibility of the findings for both studies and providing a more solid rationale for prevention-oriented systems change within the community. On other occasions, the findings of the study differed or were extended (e.g., difficulties obtaining services and supports, financial stressors, family stressors, community isolation, and risk/protective factors). Together, these studies offer parents, community providers, administrators, and policy makers specific information about a group of children and families within the county who traditionally tap a disproportionately higher portion of services and fiscal supports.

Similarly, the findings of this study may reflect a gap in the efficiency of the local service system. Parents interviewed in this study consistently reported that their pediatrician served as either their primary or sole entry point into the local service system. At the same time, parents also indicated that they were generally dissatisfied with the quality of the information they received regarding their child's challenging behavior at the point of either receiving general advice from their pediatrician or when a formal diagnosis was rendered. Although some researchers, particularly within schools, suggest that the school system is also an entry point into the service system for children and youth with chronic health problems (e.g., Power, Heathfield, McGoey, \& Blum, 1999), this appears to be less of the case for parents of young children with challenging behavior living in Hillsborough County, Florida. Consequently, providers and policy 
makers in the region may wish to consider these findings as evidence supporting the need to provide training in the assessment, diagnosis, treatment, and referral process for young children with challenging behavior. While it is certainly true that there are very high expectations placed upon pediatricians, it is the community's responsibility as well to both provide and support pediatricians and other medical professionals in tapping into the available research and clinical services that reflect best practices for young children with challenging behavior (e.g., Duda, Dunlap, Fox, Lentini, \& Clarke, 2004; Fox \& Dunlap, 2002; Powell, Fixsen, \& Dunlap, 2003).

Another important contribution to the field is that this study contributes to the small but growing literature base in the field of early intervention/early childhood special education. Though qualitative research studies are being conducted with increasing regularity within the field (Sandall, Smith, McLean, \& Ramsey, 2002), the findings of this study contribute to the growing qualitative literature base supporting family-based practices. More specifically, this study serves as a demonstration of the utility of the phenomenological interviewing technique as an optimal means of obtaining information not otherwise obtained using quantitative or single subject methods. Based on previous experience in the local Part C program, this researcher selected the phenomenological interview technique in order to provide parents with a venue by which to let others hear their voice and to share meaningful experiences of raising their young children. Parents were afforded the opportunity to both share their stories and to provide case illustrations about the obstacles and supports encountered in the process of navigating through the local service system. Though both phenomenological interviewing and other forms of data collection could be used to address similar questions (e.g., completing surveys or 
behavior checklists), the former offers a level of informational detail that may be difficult to obtain otherwise.

\section{Conclusions}

Parents of young children with challenging behavior face many obstacles and challenges. While many of these challenges may also be common to parents of young children who do not have challenging behavior, the degree and combination by which they occur can have a significant negative impact. Parents of young children with challenging behavior and their families possess many positive qualities. Although they need to continue to assume the role as the leader and strongest advocate for their child's care, they are not the sole persons responsible for their child's care and well-being. While the service system in Hillsborough County for young children birth to three is in its infancy, it also shares responsibility for the care of these children and is actively working to develop such a capacity by funding prevention services for young children with challenging behavior and their families, endorsing the use of evidence-based practices, supporting training and capacity building of local service providers, and advocating for policy and funding strategies designed to optimize the impact and utility of fiscal and human resources (Children’s Board of Hillsborough County, 2002). Based on the experiences of the families who elected to have their voices heard, it would appear that this will be time, effort, and money well spent. 


\section{References}

Abelson, A. G. (1999). Economic consequences and lack of respite care. Psychological Reports, 85, 880-882.

Achenbach, T. M., \& Edelbrock, C. S. (1981). Behavioral problems and competencies reported by parents of normal and disturbed children aged four through sixteen. Monographs of the Society for Research in Child Development, 46(1), Serial No. 188.

American Academy of Pediatrics Committee on Children with Disabilities. (2001). Policy Statement: Developmental surveillance and screening of infants and young children. Pediatrics, 108, 192-196.

Agency for Health Care Administration. (2003a). About Florida Medicaid. Retrieved April 20, 2004 from: http://www.fdhc.state.fl.us/Medicaid/index2.shtml.

Agency for Health Care Administration. (2003b). Florida Medicaid: Summary of services FY2003-2004. Tallahassee, FL: Author.

American Psychiatric Association. (1994). Diagnostic and statistical manual of mental disorders (4th ed.). Washington, DC: American Psychiatric Association.

Barry, L. M., \& Singer, G. H. (2001). Reducing maternal psychological distress after the NICU experience through journal writing. Journal of Early Intervention, 24(4), 287-297. 
Bailey, D. B., McWilliam, R. A., Darkes, L. A., Hebbeler, K., Simeonsson, R. J., Spiker, D., et al. (1998). Family outcomes in early intervention: A framework for program evaluation and efficacy research. Exceptional Children, 64(3), 313-328.

Bailey, D. B. (2000). The federal role in early intervention: Prospects for the future. Topics in Early Childhood Special Education, 20(2), 71-78.

Bailey, D. B. (2001). Evaluating parent involvement and family support in early intervention and preschool programs. Journal of Early Intervention, 24(1), 1-14.

Bailey, D. B., Scarborough, A., \& Hebbeler, K. (2003). Families’ first experiences with early intervention. Menlo Park, CA: SRI International.

Barnes, C. (1996). Theories of disability and the origins of the oppression of disabled people in western society. In L. Barton (Ed.)., Disability and society: Emerging issues and insights. New York: Longman Publishing.

Barnett, D. W., Bell, S. H., \& Carey, K. T. (1999). Designing preschool interventions: A practitioner's guide. New York, NY: Guilford Press.

Barnett, D. W, Pepiton, A. E., Bell, S. H., Gilkey C. M., Smith, J. J., Stone, C. M., et al. (1999). Evaluating early intervention: Accountability methods for service delivery innovations. Journal of Special Education, 33(3), 177-188.

Batsche, G. M. \& Knoff, H. M. (1994). Bullies and their victims: Understanding a pervasive problem in the schools. School Psychology Review, 23(2), 165-174.

Belsky, J. (1999). Quantity of nonmaternal care and boys’ problem behavior/adjustment at ages three and five: Exploring the mediating role of parenting. Psychiatry, 62(1), 1-20, 
Berk, L. E. (2002). Child Development (6 $6^{\text {th }}$ ed). Needham Heights, MA: Allyn \& Bacon.

Berson, I. R., Vargo, A. C., Dailey, K. A., Lemrow, N., \& Powell, D. (2003). A study of the integration of Part $C$ and Medicaid-funded behavioral health services for infants and toddlers: Concept paper. Tampa, FL: Louis de la Part Florida Mental Health Institute, University of South Florida.

Berson, I. R., Vargo, A. C., Dailey, K. A., Zheng, Z., \& Powell, D. (2003). An examination of Medicaid and Part C service funding mechanisms to support interventions for young children. Tampa, FL: Louis de la Part Florida Mental Health Institute, University of South Florida.

Bijou, S. W. (1975). Development in the preschool years: A functional analysis. American Psychologist, 30, 829-837.

Boulware, G. L., Schwartz, I., \& McBride, B. (1999). Addressing challenging behaviors at home: Working with families to find solutions. In S. Sandall \& M. Ostrosky (Eds.), Young Exceptional Children: Practical ideas for addressing challenging behaviors (pp. 29-40). Monograph Series.

Brantlinger, E., Jimenez, R., Klingner, J., Pugach, M., \& Richardson, V. (2005). Qualitative studies in special education. Exceptional Children, 71(2), 195-207. Bredekamp, S. (1991). Developmentally appropriate practice in early childhood programs serving children birth through 8. Washington, D. C.: National Association for the Education of Young Children.

Bricker, D. (1992). An activity based approach to early intervention. Baltimore, MD: Paul H. Brookes Publishing Co. 
Broidy, L. M., Nagin, D. S., Tremblay, R. E., Bates, J. E., Brame, B., Dodge, K., Fergusson, D., Horwood, J. L., Loeber, R., Laird, R., Lynam, D. R., Moffitt, T. E., Pettit, G. S., \& Vitaro, F. (2003). Developmental trajectories of childhood disruptive behaviors and adolescent delinquency: A six-site, cross-national study. Developmental Psychology, 39(2), 222-245.

Bronfenbrenner, U. (1979). The ecology of human development: Experiments by nature and design. Cambridge, MA: Harvard University Press.

Bronfenbrenner, U. (1986). Ecology of the family as a context for human development: Research perspectives. Developmental Psychology, 22(6), 723-742.

Bronfenbrenner, U. (1999). Environments in developmental perspective: Theoretical and operational models. In S. L. Friedman \& T. D. Wachs (Eds.), Measuring environment across the life span: Emerging methods and concepts (pp. 3-28), Ithaca, NY: Cornell University Department of Human Development \& Family Studies.

Brown, D., Pryzwansky, W. B., \& Schulte, A. C. (1998). Psychological consultation: Introduction to theory and practice. Boston, MA: Allyn \& Bacon.

Bubolz, M. M., \& Sontag, S. (1993). Human ecology theory. In P. Boss et al. (Eds.), Sourcebook of family theories and methods (pp. 419-448), New York: Plenum Press.

Cadoret, R. J., Winokur, G., Langbehn, D., Troughton, E., Yates, W. R., \& Stewart, M. A. (1996). Spectrum disease, I: The role of gene-environment interaction. American Journal of Psychiatry, 153(7), 892-899. 
Caldwell, B. M. (1970). The rationale for early intervention. Exceptional Children, 36, 717-726.

Campbell, S. B. (1994). Behavior problems in preschool children: A review of recent research. Journal of Child Clinical Psychology, 36(1), 113-149.

Campbell, S., B., \& Ewing, L. J. (1990). Follow-up of hard to manage preschoolers: Adjustment at age 9 and predictors of continuing symptoms. Journal of Child Psychology and Psychiatry, 31, 871-889.

Campbell, S., B., Pierce, E. W., Moore, G., Marakovitz, S., \& Newby, K. (1996). Boys' externalizing problems at elementary school age: Pathways from early behavior problems, maternal control, and family stress. Developmental Psychopathology, 8, 701-719.

Carr, E.G., Levin, L., McConnachie, G., Carlson, J. I., Kemp, D. C., \& Smith, C. E. 1994). Communication-based intervention for problem behavior: A user's guide for producing behavior change. Baltimore, MD: Paul H. Brookes Publishing Co.

Carta, J. J. (2002). An early childhood special education research agenda in a culture of accountability for results. Journal of Early Intervention, 25(2), 102-104.

Carta, J. J., Schwartz, I. S., Atwater, J. B., \& McConnell, S. R. (1991). Developmentally appropriate practice: Appraising its usefulness for young children with disabilities. Topics in Early Childhood Special Education, 11(1), 1-20.

Centers for Medicare and Medicaid Services. (2003a). Facts about the centers for Medicare and Medicaid services. Retrieved April 24, 2004 from: http://www.cms.hhs.gov/researchers/projects/APR/2003/facts.pdf. 
Centers for Medicare and Medicaid Services. (2003b). Medicaid: A brief summary. Retrieved April 24, 2004 from: http://www.cms.hhs.gov/publications/overviewmedicare-medicaid/default4.asp.

Chen, H. J. (2003). The realization between service utilization and Medicaid enrollee's trust in health care providers. Tampa, FL: Louis de la Part Florida Mental Health Institute, University of South Florida.

Children's Board of Hillsborough County. (2002). The 2012 Plan: The strategic plan of the Child's Board of Hillsborough County. Tampa, FL: Author.

Creps, C. L. \& Vernon-Feagans, L. (2000). Infant daycare and otitis media: Multiple influences on children's later development. Journal of Applied Developmental Psychology, 21(4), 357-378.

Crossman, S. M., \& Adams, G. R. (1980). Divorce, single parenting, and child development, Journal of Psychology, 106, 205-217.

Danaher, J., \& Armijo, C. (Eds.). (2003). Part C Updates: Fifth in a series of updates on selected aspects of the early intervention program for infants and toddlers with disabilities, (Part C) of IDEA. Chapel Hill, NC: University of North Carolina at Chapel Hill, National Early Childhood Technical Assistance Center, Office of Special Education Programs, U.S. Department of Education.

Denzin, N. K. \& Lincoln, Y. S. (2000). Handbook of qualitative research ( $2^{\text {nd }}$ ed.). Thousand Oaks, CA: Sage Publications.

Division for Early Childhood. (1999). DEC concept paper on the identification of and intervention with challenging behavior. Washington, D.C.: Author. 
Donenberg, G. R. (2001). Understanding AIDS-risk behavior among adolescents in psychiatric care: Links to psychopathology and peer relationships. Journal of American Academy of Child and Adolescent Psychiatry, 40(6), 642-653.

Duda, M., Dunlap, G., Fox, L., Lentini, R., \& Clarke, S. (2004). An experimental evaluation of positive behavior support in a community preschool program. Topics in Early Childhood Special Education, 24(3), 143-155.

Dunlap, G., \& Fox, L. (1996). Early intervention and serious behavior problems: A comprehensive approach. In L. K. Koegel, R. L. Koegel, \& G. Dunlap (Eds.) Positive behavioral support: Including people with difficult behavior in the community, (pp. 31-50). Baltimore, MD: Paul H. Brookes Publishing Co.

Dunlap, G., \& Fox, L. (1999). A demonstration of behavioral support for young children with autism. Journal of Positive Behavior Interventions, 1(2), 77-87.

English, K., Goldstein, H., Shafer, K., \& Kaczmarek, L. (1997). Promoting interactions among preschoolers with and without disabilities: Effects of a buddy skillstraining program. Exceptional Children, 63(2), 229-243.

Fake, S. (2002). Learning to collaborate as colleagues: Our key to success. In J. M. Lucyshyn, G. Dunlap, \& R. W. Albin (Eds.), Families and positive behavior support: Addressing problem behavior in family contexts, (pp. 209-218). Baltimore: Paul H. Brookes.

Ferrell, K. A. (1985). Parents as partners and advocates. Journal of Visual Impairment and Blindness, 79(5), 203-204. 
Florida Department of Education. (1998). Early intervention services for your young child with special needs. Carmy Greenwood (Ed.). Washington, DC: Division of Public Schools and Community Education, Bureau of Instructional Support and Community Services.

Florida Department of Education. (1998). Volume 1-B: Florida statutes and state board of education rules. Tallahassee, FL: Division of Public Schools and Community Education, Bureau of Instructional Support and Community Services.

Fox, L., Benito, N., \& Dunlap, G. (2002). Early intervention with families of young children with autism and behavior problems. In J. M. Lucyshyn, G. Dunlap, \& R. W. Albin (Eds.), Families and positive behavior support: Addressing problem behavior in family contexts, (pp. 251-270). Baltimore: Paul H. Brookes.

Fox, L., \& Dunlap, G. (2002). Addressing the effectiveness of early intervention services from a community mental health model for serious disruptive behaviors. Tampa, FL: Louis de la Parte Florida Mental Health Institute, University of South Florida.

Fox, L., Hanline, M. F., Vail, C. O., \& Galant, K. R. (1994). Developmentally appropriate practice: Applications for young children with disabilities. Journal of Early Intervention, 18(3), 243-257.

Fox, L., Vaughn, B. J., Wyatte, M. L., \& Dunlap, G. (2003). “We can’t expect other people to understand”: Family perspective on problem behavior. Exceptional Children, 68(4), 437-450.

Frechtling, J., \& Sharp, L. (1997). User-friendly handbook for mixed method evaluations. Washington, DC: National Science Foundation. 
Friel-Patti, S. (1990). Otitis media with effusion and the development of language: A review of the evidence. Topics in Language Disorders, 11(1), 11-22.

Gall, M. D., Borg, W. R., \& Gall, J. P. (1996). Educational research: An introduction. White Plains, NY: Longman Publishers.

Goffman, E. (1993). Stigma: Notes on the management of spoiled identity. New York: The Free Press.

Green, S. (in press). "What do you mean 'what's wrong with her"”: Stigma and the lives of families of children with disabilities. Social Science and Medicine.

Green, S. E. (2002). Mothering Amanda: Musings on the experience of raising a child with cerebral palsy. Journal of Loss and Trauma, 7, 21-34.

Grosz, P., Behal, R., Fernandez, R., Urueta-Mazilli, D., Graven, S. N., Boothby, L., et al. (2000). Neighborhood analysis of early intervention supports and services: Data from a grassroots perspective. Tampa, FL: The Children’s Board of Hillsborough County.

Gubrium, J. F., \& Holstein, J. A. (1997). The new language of qualitative method. New York: Oxford University Press.

Guralnick, M. J. (2000). An agenda for change in early childhood inclusion. Journal of Early Intervention, 23(4), 213-222.

Guralnick, M. J. \& Bennett, F. C. (1987). A framework for early intervention. In M. J. Guralnick \& F. C. Bennett (Eds.). The effectiveness of early intervention for atrisk and handicapped children (pp. 3-29). San Diego, CA: Academic Press, Inc. 
Guralnick, M. J., Kiser, K. E., Eaton, A. P., \& Bennett, F. C. (1998). Pediatricians' perceptions of the effectiveness of early intervention for at-risk and handicapped children. Journal of Developmental \& Behavioral Pediatrics, 9(1), 12-18.

Hart, B., \& Risley, T. R. (1975). Incidental teaching of language in the preschool. Journal of Applied Behavior Analysis, 8(4), 411-420.

Hart, B., \& Risley, T. R. (1999). The social world of children learning to talk. Baltimore, MD: Paul H. Brookes Publishing Co.

Hebbeler, K., Spiker, D., Mallik, S., Scarborough, A., \& Simeonsson, R. (2003). Demographic characteristics of children and families entering early intervention. Menlo Park, CA: SRI International.

Hebbeler, K., Spiker, D., Mallik, S., Scarborough, A., Simeonsson, R., \& Collier, M. (2001). A first look at the characteristics of children and families entering early intervention services. Menlo Park, CA: SRI International.

Hebbeler, K., Spiker, D., Wagner, M., Cameto, R., \& McKenna, P. (1999). State to state variations in early intervention systems. Menlo Park, CA: SRI International.

Hinshaw, S. P., \& Anderson, C. A. (1996). Conduct and oppositional defiant disorders. In E. J. Mash \& R. A. Barkley (Eds.). Child psychopathology. New York, NY: The Guilford Press, 113-149.

Huffman, L. C., Mehlinger, S. L., Kerivan, A. S., Cavanaugh, D. A., Lippitt, J., \& Moyo, O. (2001). Off to a Good Start: Research on the risk factors for early school problems and selected federal policies affecting children's social and emotional development and their readiness for school. Bethesda, MD: National Institute of Mental Health. 
Hughes, C., Hwang, B., Kim, J, Eisenman, L. T., \& Killian, D. J. (1995). Quality of life in applied research: A review and analysis of empirical measures. American Journal on Mental Retardation, 99(6), 623-641.

Ingoldsby, E. M,, Shaw, D. S, Owens, E. B., \& Winslow, E. B. (1999). A longitudinal study of interparental conflict, emotional and behavioral reactivity, and preschoolers’ adjustment problems among low-income families. Journal of Abnormal Child Psychology, 27(5), 343-356.

Jacob-Timm, S., \& Hartshorne, T. S. (1998). Ethics and law for school psychologists (3rd ed.). New York, NY: John Wiley \& Sons, Inc.

Janesick, V. J. (2000). The choreography of qualitative research design: Minuets, improvisations, and crystallization. In N. K. Denzin \& Y. S. Lincoln (Eds.), Handbook of qualitative research ( $2^{\text {nd }}$ ed.). Thousand Oaks, CA: Sage Publications, Inc.

Joint Commission on the Mental Health of Children. (1969). Crisis in child mental health. New York: Harper \& Row.

Kaiser, A. P, Hancock, T. B., Cai, X., Foster, E. M., \& Hester, P. P. (2000). Parentreported behavioral problems and language delays in boys and girls enrolled in Head Start classrooms. Behavioral Disorders, 26(1), 26-41.

Kaiser, A. P., \& Hester, P. P. (1997). Prevention of conduct disorder through early intervention: A social communicative perspective. Behavioral Disorders, 22(3), 117-130. 
Kayser, A. T. (2002). A mother's perspective on developing and implementing behavior support plans. In J. M. Lucyshyn, G. Dunlap, \& R. W. Albin (Eds.), Families and positive behavior support: Addressing problem behavior in family contexts, (pp. 93-96). Baltimore: Paul H. Brookes.

Keenan, K, \& Wakschlag, L. S. (2000). More than the terrible twos: The nature and severity of behavior problems in clinic-referred preschool children. Journal of Abnormal Child Psychology, 28(1), 33-46.

Kennedy, C. H., \& Meyer, K. A. (1998). The use of psychotropic medication for people with severe disabilities and challenging behavior: Current status and future directions. Journal of the Association for Persons with Severe Handicaps, 23(2), 83-97.

King, S. H., \& Goodwin, A. L. (2002). Culturally Responsive Parental Involvement: Concrete understandings and basic strategies. Washington, DC: American Association of Colleges for Teacher Education.

King, G., King, S., Rosenbaum, P., \& Goffin, R. (1999). Family-centered caregiving and well-being of parents of children with disabilities: Linking process with outcome. Journal of Pediatric Psychology, 24(1), 41-53.

Knitzer, J. (1982). Unclaimed children: The failure of public responsibility to children and adolescents in need of mental health services. Washington, DC: Children's Defense Fund. 
Knitzer, J. (2000). Using mental health strategies to move the early childhood agenda and promote school readiness. New York: National Center for Children in Poverty. Retrieved April 12, 2004 from http://www.nccp.org/media/mhsoo$\underline{\text { text.pdf. }}$

Koegel, L.K., Koegel, R.L., \& Dunlap, G. (Eds.) (1996). Positive behavioral support: Including people with difficult behavior in the community. Baltimore: Paul $\mathrm{H}$. Brookes.

Krueger, R. A., \& Casey, M. A. (2000). Focus Groups: A practical guide for applied research ( $3^{\text {rd }}$ ed.), Thousand Oaks, CA: Sage.

Lahey, B. B., \& Loeber, R. (1997). Attention-deficit/hyperactivity disorder, oppositional defiant disorder, conduct disorder, and adult antisocial behavior: A life span perspective. In D. M. Stoff \& J. Breiling (Eds.), Handbook of antisocial behavior (pp. 51-59). New York: John Wiley \& Sons, Inc.

Lahey, B. B., McBurnett, K., \& Loeber, R. (2000). Are attention-deficit/hyperactivity disorder and oppositional defiant disorder developmental precursors to conduct disorder? In A. J. Sameroff \& M. Lewis (Eds.), Handbook of developmental psychopathology ( $2^{\text {nd }}$ ed.) (pp. 431-446). Dordrecht, Netherlands: Kluwer Academic Publishers.

Landy, S. (2002). Pathways to competence: Encouraging health social and emotional development in young children. Baltimore, MD: Paul H. Brookes Publishing Co.

Link, B. G., \& Phelan, J. C. (2001). Conceptualizing stigma. Annual Review of Sociology, 27, 363-385. 
Loeber, R. \& Coie, J. (2001). Continuities and discontinuities of development, with particular emphasis on emotional and cognitive components of disruptive behavior. In J. Hill \& B. Maughan (Eds.), Conduct disorders in childhood and adolescence (pp. 379-407). New York: Cambridge University Press.

Lonigan, C. J., Fischel, J. E., Whitehurst, G. J., Arnold, D. S., \& Valdez-Menchaca, M. C. (1992). The role of otitis media in the development of expressive language disorder. Developmental Psychology, 28(3), 430-440.

Mangione, C., Landau, S., \& Pryor, J. B. (1998). HIV and AIDS (Pediatric and Adolescent). In L. Phelps (Ed.), Health-related disorders in children and adolescents: A guidebook for understanding and educating (pp. 328-336). Washington, DC: American Psychological Association.

Marks, D. (1999). Disability: Controversial debates and psychosocial perspectives. New York: Routledge.

Markey, U. A. (2002). A legacy of love: Our path to freedom through behavioral support. In J. M. Lucyshyn, G. Dunlap, \& R. W. Albin (Eds.), Families and positive behavior support: Addressing problem behavior in family contexts (pp. 341-348). Baltimore: Paul H. Brookes.

Marshall, C, \& Rossman, G. B. (1989). Designing qualitative research. Newbury Park, CA: Sage Publications, Inc.

Maurice, C. (1993). Let me hear your voice: A families' triumph over autism. New York: Ballantine Books. 
McConnell, S. (2001). Parent involvement and family support: Where do we want to go, and how will we know if we are headed there? Journal of Early Intervention, 24(1), 15-18.

McEvoy, M. \& Reichle, J. (1995). Developing and evaluating a model of inservice and technical assistance to prevent challenging behavior in preschoolers.

Minneapolis, MN: University of Minnesota, College of Education, Institute on Community Integration, Center for Early Education and Development.

Moffitt, T. (1990). Juvenile delinquency and attention deficit disorder: Boys’ developmental trajectories from age 3 to age 15. Child Development, 61, 893910.

National Research Council and Institute of Medicine. (2000). From neurons to neighborhoods: The science of early childhood development. Committee on Integrating the Science of Early Childhood Development. J. P. Shonkoff \& D. A. Phillips (Eds.). Board on Children, Youth, and Families, Commission on Behavioral and Social Sciences and Education. Washington, D.C.: National Academy Press.

Navon, M., Nelson, D., Pagano, M., \& Murphy, M. (2001). Use of the Pediatric Symptom Checklist in strategies to improve preventive behavioral health care. Psychiatric Services, 52(6), 800-804.

New Freedom Commission on Mental Health. (2003). Achieving the promise: Transforming mental health care in America. DHHS Pub. No. SMA-03-3832. Rockville, MD: Author. 
Newman, D. (2002). Dragon NaturallySpeaking 6® User’s Guide. Peabody, MA: ScanSoft, Inc.

Nuttall, E. V., Romero, I., \& Kalesnik, J. (1999). Assessing and screening preschoolers: Psychological and educational dimensions. Needham Heights, MA: Allyn \& Bacon.

O’Connor, T. G., Deater-Deckard, K., Fulker, D. W., Rutter, M., \& Plomin, R. (1998). Genotype-environment correlations in late childhood and early adolescence: Anti-social behavioral problems and coercive parenting. Developmental Psychology, 34, 970-981.

Odom, S. L. \& Strain, P. S. (2002). Evidence-based practice in early intervention/early childhood special education: Single-subject design research. Journal of Early Intervention, 25(2), 151-160.

Office of Special Education and Rehabilitation Services (1997). Individuals with Disabilities Education Act Amendments of 1997. Retrieved April 11, 2004 from http://www.ed.gov/offices/OSERS/Policy/IDEA/IDEA.pdf.

Oliver, M. (1996). A sociology of disability or a disabilist sociology? In L. Barton (Ed.). Disability and society: Emerging issues and insights (pp. 18-42). New York: Longman Publishing.

Palmer, D. S., Borthwick-Duffy, S. A., Widaman, K., \& Best, S. J. (1998). Influences on parent perceptions of inclusive practices for their children with mental retardation. American Journal on Mental Retardation, 103(3), 272-287.

Patton, M. Q. (1990). Qualitative evaluation and research methods (2 ${ }^{\text {nd }}$ ed). Newbury Park, CA: Sage. 
Patterson, G. R., DeBaryshe, B. D., \& Ramsey, E. (1989). A developmental perspective on antisocial behavior. American Psychologist, 44(2), 329-335.

Park, J., Turnbull, A. P., \& Turnbull III, H. R. (2002). Impacts of poverty on quality of life in families of children with disabilities. Exceptional Children, 68(2), 151170.

Peck, C. A., Carlson, P., \& Helmstetter, E. (1992). Parent and teacher perceptions of outcomes for typically developing children enrolled in integrated early childhood programs: A statewide survey. Journal of Early Intervention, 16(1), 53-63.

Pierce, E. W, Ewing, L. J., \& Campbell, S. B. (1999). Diagnostic status and symptomatic behavior of hard-to-manage preschool children in middle childhood and early adolescence. Journal of Clinical Child Psychology, 28(1), 44-57.

Plomin, R., Fulker, D. W., Corley, R., \& DeFries, J. C. (1997). Behavioral Genetics ( ${ }^{\text {rd }}$ ed). New York: W. H. Freeman and Company.

Powell, D. (2002). Social and emotional needs of young children and their families in Hillsborough County. Tampa, FL: The Children's Board of Hillsborough County.

Powell, D., Fixsen, F., \& Dunlap, G. (2003). Pathways to service utilization: A synthesis of evidence relevant to young children with challenging behavior. Tampa, FL: University of South Florida, Center for Evidence-Based Practice: Young Children with Challenging Behavior.

Power, T. J., Heathfield, L. T., McGoey, K. E., \& Blum, N. J. (1999). Managing and preventing chronic health problems in children and youth: School psychology's expanded mission. School Psychology Review, 28(2), 251-263. 
Priestley, M. (2003). Disability: A life course approach. Polity Press. Cambridge, United Kingdom.

Qi, C. \& Kaiser, A. P. (2003). Behavior problems of preschool children from lowincome families: Review of the literature. Topics in Early Childhood Special Education, 23(4), 188-216.

Raffaele-Mendez, L., \& Hess, J. (2003). An analysis of community-based services and supports for children and young adults with special needs in Hillsborough County: Research summary. Tampa, FL: The Children’s Board of Hillsborough County. Roberts, M. C. (1995). Handbook of pediatric psychology. New York, NY: Guilford Press.

Roberts, M.C. (Ed.). (1995). Handbook of pediatric psychology ( $2^{\text {nd }}$ ed.). New York: Guilford Press.

Rocco, S., Metzger, J., Zangerle, A., \& Skouge, J. R. (2002). Three families’ perspectives on assessment, intervention, and parent-professional partnerships. In J. M. Lucyshyn, G. Dunlap, \& R. W. Albin (Eds.), Families and positive behavior support: Addressing problem behavior in family contexts, (pp. 75-92). Baltimore: Paul H. Brookes.

Rutter, M., Dunn, J., Plomin, R., Simonoff, E., Pickes, A., Maughan, B, Ormel, J. Meyer, J., \& Eaves, L. J. (1997). Integrating nature and nurture: Implications of personenvironment correlations and interactions for developmental psychopathology. Development and Psychopathology, 9, 335-364. 
Rutter, M., Silberg, J. L., O’Connor, T. G., \& Simonoff, E. (1999). Genetics and child psychiatry: I. Advances in quantitative and molecular genetics. Journal of Child Psychology and Psychiatry, 40, 3-18.

Rvachew, S., Slawinski, E. B., Williams, M., \& Green, C. L. (1999). The impact of early onset otitis media on babbling and early language development. Journal of the Acoustic Society of America, 105(1), 467-475.

Sandall, S. R., Smith, B. J., McLean, M. E., \& Ramsey, A. B. (2002). Qualitative research in early intervention/early childhood special education. Journal of Early Intervention, 25(2), 129-136.

Sandelowski, M. (1995). Sample size in qualitative research. Research in Nursing \& Health, 18, 179-183.

Scarr, S. \& Arnett, J. (1987). Malleability: Lessons from intervention and family studies. In J. Gallagher \& C.T. Ramsey (Eds.). The malleability of children (pp. 72-84). Baltimore, MD: Paul H. Brookes Publishing Co.

Schalock, R. (1994). The concept of quality of life and its current applications in the field of mental retardation/developmental disabilities. In D. Goode (Ed.), Quality of life for persons with disabilities (pp. 266-284). Cambridge, MA: Brookline Books.

Scandariato, K. (2002). They're playing our song: Our family's involvement in the Individualized Support Project. In J. M. Lucyshyn, G. Dunlap, \& R. W. Albin (Eds.), Families and positive behavior support: Addressing problem behavior in family contexts, (pp. 243-250). Baltimore: Paul H. Brookes, 243-249. 
Schwartz, I. S., \& Rodriguez, P. B. (2001). A few issues to consider: The who, what, and where of family support. Journal of Early Intervention, 24(1), 19-21.

Scorgie, K., \& Sobsey, D. (2000). Transformational outcomes associated with parenting children who have disabilities. Mental Retardation, 38(3), 195-206.

Seidman, I. E. (1998). Interviewing as qualitative research: A guide for researchers in education and the social sciences ( $2^{\text {nd }}$ ed). New York: Teachers College Press.

Sexson, A. \& Madan-Swain, A. (1995). The chronically ill child in the school. School Psychology Quarterly, 10(4), 359-368.

Shavelson, R. J., \& Towne, L. (2002). Scientific research in education. Washington, DC: National Academy Press.

Shonkoff, J. P., \& Meisels, S. J. (Eds.) (2000). Handbook of early childhood intervention (2nd edition). New York, NY: Cambridge University Press.

Singh, D. K. (2003). Let us hear the parents. Journal of Instructional Psychology, 30(2), 169-172.

Smith, B. J., \& Fox, L. (2003). Systems of service delivery: A synthesis of evidence relevant to young children at risk of or who have challenging behavior. Tampa, FL: Center for Evidence-based Practice: Young children with challenging behavior.

Snow, K. (2003, March). People language first. Paper presented at the School Readiness Quality Initiative Conference: Guiding Our Course to Quality Infant and Toddler Care, Orlando, Florida.

Social Security Administration. (2003). The official website of the Social Security Administration. Retrieved April 21, 2004 from: http://www.ssa.gov. 
Stoecker, R. (1991). Evaluating and rethinking the case study. The Sociological Review, 39, 88-112.

Stormont, M. (2000). Early child risk factors for externalizing and internalizing behaviors: A 5-year follow-forward assessment. Journal of Early Intervention, 23(3), 180-190.

Strauss, A., \& Corbin, J. (1990). Basics of qualitative research: Grounded theory procedures and techniques. Thousand Oaks, CA: Sage Publications.

Stroul, B. A., \& Friedman, R. M. (1986). A system of care for children and youths with severe emotional disturbances. (Revised edition). Washington, DC: Georgetown University Child Development Center, CASSP Technical Assistance Center.

Susman, J. (1994). Disability, stigma, and deviance. Social Science Medicine, 38(1), $15-22$.

Teele, D. W., Klein, J. O., Chase, C., Menyuk, P., Rosner, B. A., Allen, C., Bratton, L., Fisch, G., Stringham, P., Starobin, S., \& Tarlin, L. (1990). Otitis media in infancy and intellectual ability, school achievement, speech, and language at seven years. Journal of Infectious Diseases, 162, 685-694.

Tolan, P. H., Guerra, N. G., \& Kendall, P. C. (1995). A developmental-ecological perspective on antisocial behavior in children and adolescents: Toward a unified risk and intervention framework. Journal of Consulting and Clinical Psychology, 63(4), 579-584.

Trivette, P. S. (1998). Otitis media (Ear infections). In L. Phelps (Ed.)., Health-related disorders in children and adolescents: A guidebook for understanding and educating. Washington, DC: American Psychological Association. 
Turnbull, H. R., \& Turnbull, A. P. (2000). Accountability: Who’s job is it anyway? Journal of Early Intervention, 23(4), 231-234.

Turnbull, III, H. R., Turnbull, A. P., Wehmeyer, M. L., \& Park, J. (2003). A quality of life framework for special education outcomes. Remedial and Special Education, 24(2), 67-74.

Tzeng, O. C., \& Jackson, J. W. (1990). Common methodological framework for theory construction and evaluation in the social and behavioral sciences. Genetic, Social, \& General Psychology Monographs, 117(1), 51-76.

University of Florida College of Medicine Perinatal Data/Research Center. (2000). Early intervention program (EIP) center 01-Tampa: Graphics \& trends (Report \#1). Gainesville, FL: University of Florida College of Medicine, Perinatal Data/Research Center.

U.S. Census Bureau. (2004). Statistical abstract of the United States. Washington, DC: U.S. Department of Commerce. Retrieved January 23, 2005 from http://www.census.gov/prod/2004pubs/03statab/vitstat.pdf.

U.S. Census Bureau. (1999, October). Current population survey. Washington, DC: U.S. Department of Commerce.

U. S. Department of Education. (2000). Twenty-second annual report to Congress on the implementation of The Individuals with Disabilities Education Act. Washington, DC: Author.

U.S. Department of Education. (2001). Overview of No Child Left Behind. Retrieved May 25, 2004 from http://www.ed.gov/nclb/overview/intro/presidentplan/index.html. 
U.S. Department of Health and Human Services. (2000). Healthy People 2010:

Understanding and improving health. 2nd ed. Washington, DC: U.S. Government Printing Office.

U. S. Public Health Service. (2000). Report on the Surgeon Generals' Conference on Children's Mental Health: A national action Agenda. Washington, DC: Author.

Van Manen, M. (1990). Researching lived experience: Human science for an action sensitive pedagogy. Albany, NY: State University of New York Press.

Vernon-Feagans, L., Manlove, E. E.; \& Volling, B. L. (1996). Otitis media and the social behavior of day-care-attending children. Child Development, 67(4), 15281539.

Wetherby, A. M., \& Prizant, B.M. (Eds.). (2000). Autism spectrum disorders: A transactional developmental perspective. Baltimore, MD: Paul H. Brookes Publishing Co.

Whaley, R. M. (2002). Finding positive behavior support one piece at a time: Living and growing with David. In J. M. Lucyshyn, G. Dunlap, \& R. W. Albin (Eds.), Families and positive behavior support: Addressing problem behavior in family contexts, (pp. 45-56). Baltimore: Paul H. Brookes.

Williams, T. \& Hieneman, M. (2002). Team-based training in positive behavior support: A parent's perspective on the process. In J. M. Lucyshyn, G. Dunlap, \& R. W. Albin (Eds.), Families and positive behavior support: Addressing problem behavior in family contexts, (pp. 305-308). Baltimore: Paul H. Brookes.

Wishmann, A. Kates, D., \& Kaufmann, R. (2001). Funding early childhood mental health services and supports. Washington, DC: Georgetown University Child 
Development Center. Retrieved April 12, 2003 from http://www.georgetown.edu/research/gucdc/fundingpub.html.

Zeanah, C. H., Boris, N. W., \& Larrieu, J. A. (1997). Infant development and developmental risk: A review of the past 10 years. Journal of the American Academy of Child and Adolescent Psychiatry, 36, 165-178.

Zigler, E. \& Freeman, J. (1987). Early Experience, Malleability, and Head Start. In J. Gallagher \& C. T. Ramsey (Eds.). The Malleability of Children (pp. 85-95). Baltimore, MD: Paul H. Brookes Publishing Co.

Zill, N., Collins, M., West, J., \& Hausken, E. G. (1995). Approaching Kindergarten: A look at preschoolers in the United States. Young Children, 51, 35-38.

Zito, J. M., Safer, D. J., dosReis, S., Gardner, J. F., Boles, M., \& Lynch, F. (2000). Trends in the prescribing of psychotropic medications to preschoolers. Journal of the American Medical Association, 283(8), 1025-1030. 
Appendices 
Appendix A

Interview Protocol

Interview Protocol

Participant

Opening

“Thanks for volunteering to participate in this research study today. The purpose of this interview is to help me understand the experiences that you and your family went through raising your child. The results of this study will potentially help other families and providers learn how to continue or improve on the manner in which current services are provided in Hillsborough County. You were selected for participation in this study because you are a resident of Hillsborough County, Florida who is also the parent/guardian of a child under age four who demonstrates challenging behavior.”

"Your story will be recorded in order for me to review at a later time to ensure that I am capturing what you are sharing in an accurate and representative manner. Keep in mind that there are no right or wrong answers; I am simply hoping to learn more about your experiences, particularly those related to obtaining services for your child in Hillsborough County.”

“Before we begin, let’s set a few ground rules. This interview will last up to 60 minutes. We will really try to respect these time limits. Also, I may say some things that sound repetitive, such as “tell me more about that” or simply repeating back what you said in order to ensure that I am really understanding your experiences. If at anytime you feel uncomfortable, please let me know, and we can move on to the next question or 


\section{Appendix A (Continued)}

reschedule the interview for a later time. Do you have any questions? If you're ready, let’s begin.”

\section{Question}

"Every parent has a story. Please tell me about your story and experiences as a parent of (child's name).”

The researcher will used a combination of clarification and paraphrasing in order to ensure accurate understanding of the parent's story. In addition to asking the primary research question, the researcher will ask the parent an open-ended follow-up question about topics specified below. For each area, the researcher will ask:

“Tell me more about ___ ”

or

"There are a couple of other things I was wondering about. Tell me more about__."

Topic Domains and Prompts

1. Pregnancy, labor, and neonatal course (including NICU)

- Identifying concerns

- Diagnosis

- Acquiring useful and accurate medical information from pediatrician

- Possible prompts:

o “Tell me about your child’s pregnancy.” 
Appendix A (Continued)

o "Tell me about when you first realized there was something wrong with your child.”

o “Tell me about your experiences with your child’s doctor when you realized that something was wrong with your child.”

2. Obtaining services for your child

- Stresses associated with coordination of care

- Daycare or preschool experiences

- Early Intervention/Early Steps Program eligibility evaluation

- Early Intervention/Early Steps Program services and supports

- Possible prompts:

o “Tell me about your child’s pregnancy.”

o “Tell me about your child’s experiences in daycare or preschool.”

o “Tell me about your experiences in the Early Intervention/Early Steps Program.”

o “Tell me about the services and supports your family received from the Early Intervention/Early Steps Program.”

\section{Impact on parents/family}

- Parents’ career(s)

- Financial stressors associated with child's disability

- Relationships with family members (including extended family)

- Possible prompts: 
Appendix A (Continued)

o "Tell me about your child's difficulties have impacted your career."

o “Tell me about how your child's difficulties have impacted your personal finances.”

o "Tell me about your opportunities to spend time with other members of your family.”

4. Access to community

- $\quad$ Obtaining support for self (if necessary)

- Relationships with friends, neighbors

- Access to the community, transportation, religious services

- Possible prompts:

o "Tell me about your opportunities to go out into the community."

o "Tell me about your opportunities to spend time with friends or your neighbors.”

o "Tell me about the opportunities you have to get support for yourself (if necessary).”

5. Positive experiences

- Advocacy efforts

- Lessons learned

- Good experiences

- Possible prompts:

o “How have you grown from your experiences raising ___?” 
Appendix A (Continued)

o “What are your child's greatest strengths?”

o "What are some of your most memorable experiences raising ?”

While the interview is being audio taped, the researcher will listen and take notes highlighting important statements and reflections.

\section{Closing}

"Thank you for participating in this portion of the study. As I had explained previously, I will transcribe the audiotape from this interview and share examples of your interview transcript when we meet next time. At that point, you will have a chance not only to expand on what you've already said, but also to add any additional information about your experiences. Once we finish that task, your role in this study will be completed and I will provide you with the stipend we had discussed previously. Thanks again.” 
Appendix B

Flyer for Participant Recruitment

Research Study Seeking Parent Participants

\section{Do You liawe A Child Under Age 4 With Challemging Behawors?}

This is a special opportunity to give parents/guardians their voice, and to help researchers understand parentalyuardian experiences navigating through our boal service systern.

If you have a young child with challenging behavior, have received any services, and have one or two hours of time that you can share, we need your help!

\section{Silpends of \$C0 will be purited for earh fantily who parlickpates.}
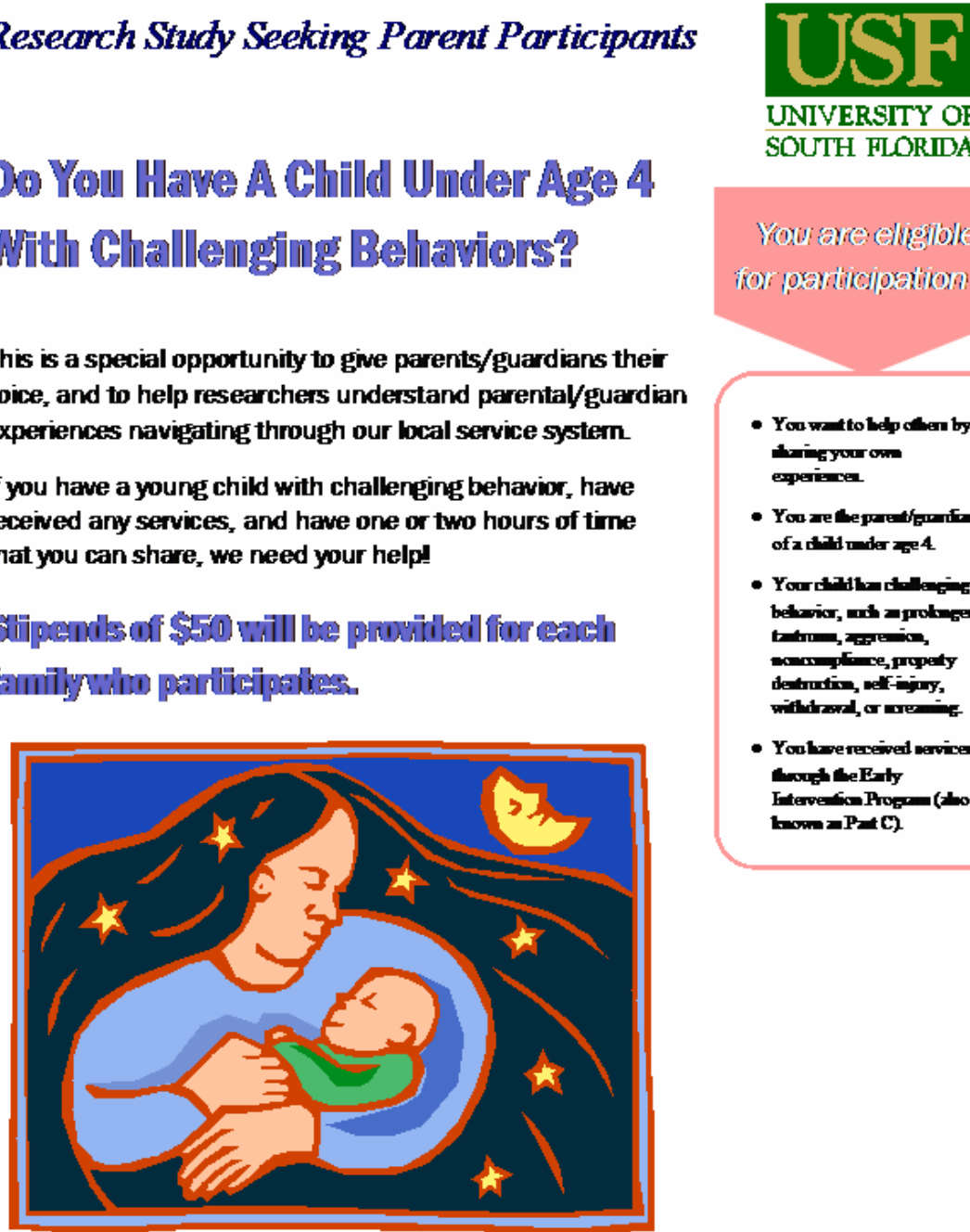

UNIVERSITY OF

SOUTH FLORIDA

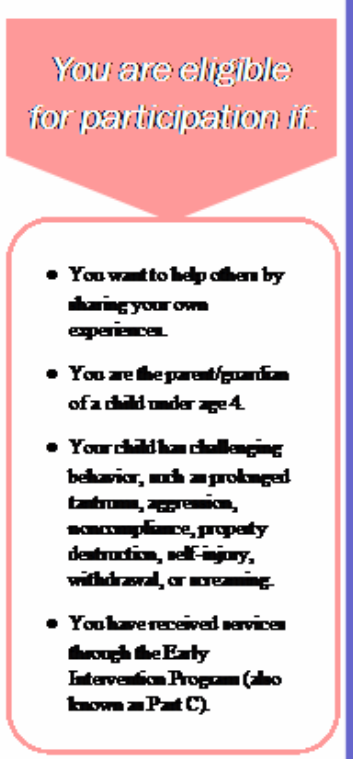

Participation involves one interview and one follow-sp meetong (1-2 hotas each) in your home or agned typon location.

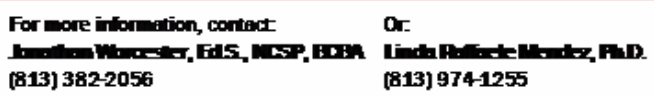




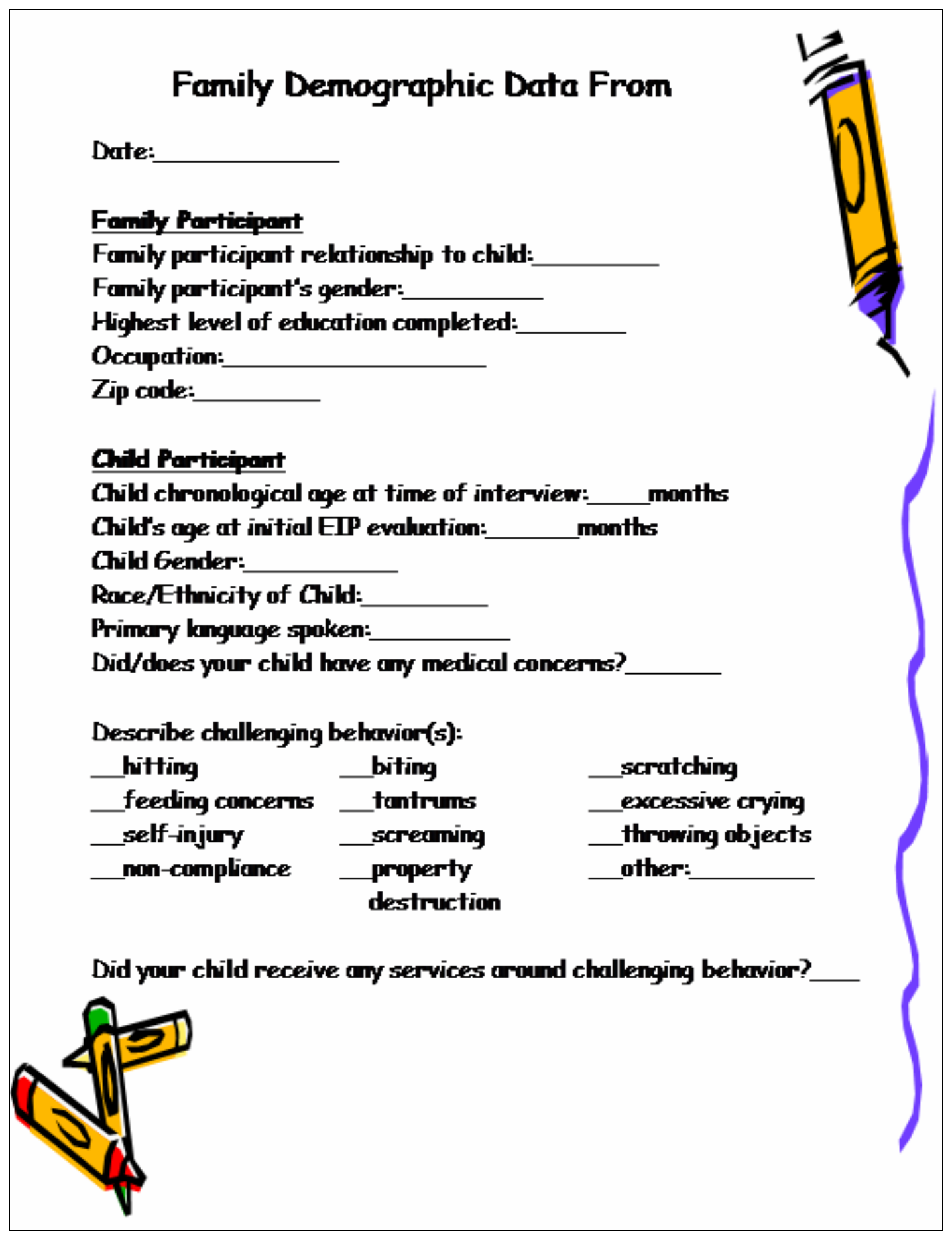


Appendix D

Informed Consent

\section{Informed Consent}

Social and Behavioral Sciences

University of South Florida

\section{Information for People Who Take Part in Research Studies}

The following information is being presented to help you decide whether or not you want to take part in a minimal risk research study. Please read this carefully. If you do not understand anything, ask the person in charge of the study.

Title of Study: Giving Voice To Parents Of Young Children With Challenging Behavior Principal Investigator: Jonathan Worcester, Ed.S., NCSP, BCBA

Study Location(s): Parent/Guardian's home, preferred community setting, or the University of South Florida College of Education.

You are being asked to participate because you are the parent/guardian of a child under age 4 who has challenging behavior, such as prolonged tantrums, aggression, noncompliance, property destruction, self-injury, withdrawal, or screaming. You have also received services for your child through the Early Steps Program (formerly known as the Early Intervention/Part C program) and have been a resident of Hillsborough County, Florida for over 12 months.

\section{General Information about the Research Study}

The purpose of this research study is to document the experiences of parents/guardians of young children with challenging behavior living in Hillsborough County, Florida. Parents/guardians will be given the opportunity to both share their stories and to provide illustrations about the obstacles and supports encountered in the process of obtaining services for their children.

\section{Plan of Study}

As a participant in this study, you will be asked to participate in two interviews. Each interview will focus on experiences raising your child and will be recorded via audiotape. It is anticipated that the first interview will last an average of 45-60 minutes. Upon completion of the first interview, a second follow-up interview will be conducted, where you will be provided the opportunity to review, expand, or make any changes to written transcript segments from the first interview. The follow-up interview will likely last between 30-45 minutes. 
Appendix D (Continued)

\section{Payment for Participation}

You will be provided with a $\$ 50$ cash stipend as a token of appreciation. These funds will not be withdrawn should you elect to voluntarily withdraw from this study.

\section{Benefits of Being a Part of this Research Study}

By taking part in this research study, you will have the opportunity to share your experiences raising your child. Through discussion of your stories and experiences, you may develop a greater understanding and appreciation for the magnitude and impact your child's behavior has upon your entire family. Findings may also help community providers improve the quality of services provided to children and families in Hillsborough County, Florida.

\section{Risks of Being a Part of this Research Study}

There are no anticipated risks to participation in this research study. You will control which topics you elect to discuss about your child, as well as how much information you share. You will also have the opportunity in a second interview to review information from the first interview, making any changes you would like in order to ensure its accuracy.

\section{Confidentiality of Your Records}

Your privacy and research records will be kept confidential to the extent of the law. Authorized research personnel, employees of the Department of Health and Human Services, and the USF Institutional Review Board and its staff, and any other individuals acting on behalf of USF, may inspect the records from this research project.

The results of this study may be published. However, the data obtained from you will be combined with data from others in the publication. The published results will not include your name or any other information that would personally identify you in any way.

The information you provide will be kept confidential using unidentifiable codes. All information will be stored in locked filing cabinets, and will not be discussed with anyone outside of the research team.

\section{Volunteering to Be Part of this Research Study}

Your decision to participate in this research study is completely voluntary. You are free to participate in this research study or to withdraw at any time. There will be no penalty or loss of the financial compensation you are entitled to receive if you stop taking part in the study. Your decision either to participate (or not to participate) will in no way affect the services received from either the Early Steps Program, the Early Intervention Positive 
Appendix D (Continued)

Behavior Support program (EIPBS), Infants and Young Children of West Central Florida (IYC), or through the Florida Diagnostic Learning Resources System (FDLRS).

\section{Questions and Contacts}

- If you have any questions about this research study, contact Jonathan Worcester at (813) 382-2056 or Dr. Linda Raffaele Mendez at (813) 974-1255.

- If you have questions about your rights as a person who is taking part in a research study, you may contact the Division of Research Compliance of the University of South Florida at (813) 974-5638.

\section{Consent to Take Part in This Research Study}

By signing this form I agree that:

- I have fully read or have had read and explained to me this informed consent form describing this research project.

- I have had the opportunity to question one of the persons in charge of this research and have received satisfactory answers.

- I understand that I am being asked to participate in research. I understand the risks and benefits, and I freely give my consent to participate in the research project outlined in this form, under the conditions indicated in it.

- I have been given a signed copy of this informed consent form, which is mine to keep.

Signature of Participant

$\overline{\text { Printed Name of Participant }}$

Date

\section{Investigator Statement:}

I certify that participants have been provided with an informed consent form that has been approved by the University of South Florida's Institutional Review Board and that explains the nature, demands, risks, and benefits involved in participating in this study. I further certify that a phone number has been provided in the event of additional questions.

Signature of Participant

$\overline{\text { Printed Name of Investigator }}$

Date 


\section{Appendix E}

\section{Bracketing Interview}

In order to acknowledge personal biases that may impact this researcher's objective investigation of the phenomenon in question, a bracketing interview was conducted. For the purpose of this interview, this researcher chose to refer to himself in the following section as "I," as a means of facilitating communication of personal experience.

"I am a 30 year-old Caucasian male living in Tampa, Florida. I have never married, nor do I have any children. I was born in Providence, Rhode Island, where I lived until age three. At that point, my family moved to Swansea, Massachusetts, where my family continues to reside. My immediate family is comprised of my parents and two younger sisters. Although I saw them only a few times each year, my maternal grandparents, maternal aunt and family, and paternal aunt and family all lived within few hours in New Hampshire. I am a family-oriented person and have close relationships with members of my family, in light of the fact that my parents divorced in the early 1990s.

I lived in Swansea until I graduated high school out of a class of 188 people. Swansea is a town of approximately 25,000 residents comprised mostly of Caucasian, middle to lower middle class families. Though geographically close to cultural centers such as Providence, Newport, Boston, and New York City, Swansea has been historically quite homogeneous. Most of the town's families were of Portuguese or Irish descent, and when I graduated in 1991, there was only one African American family who lived in my 


\section{Appendix E (Continued)}

town. As a result, I had largely been isolated in life, receiving little opportunity to engage and learn from diverse cultures and ethnic groups. While I was raised in an environment of acceptance and sharing, I was eager to learn more about individuals whose culture and ethnic background were different from my own.

"Education has always been a priority in my family. My mother is a special education teacher in the public schools and my father is a professor of journalism. Both hard work and academic achievement were held in highest of esteem by my parents, and early on in life, I knew that I wanted to go to college. This influence had a positive impact upon everyone in my family, and not surprisingly, my sisters and I have all gone to college and chosen similar professions as our parents: I am a school psychologist, my middle sister is an elementary school teacher, and my youngest sister is studying to become a nurse.

“After graduating with a Bachelor’s Degree in Psychology at the University of Connecticut, I moved back home to Massachusetts, where I worked for three years at the Brown University Medical School as a supervisor of an intensive behavioral treatment program for young children with autism. In this capacity, I enjoyed collaborating with a variety of professionals and families as I worked to provide comprehensive behavioral and educational support to children with chronic medical conditions and developmental disabilities. Though I thoroughly enjoyed working at Brown, I knew I wanted to go on to graduate school. I had a goal to become a child psychologist and I was determined to see it through. 


\section{Appendix E (Continued)}

"I am now in the process of earning a doctoral degree in school psychology at the University of South Florida. I have lived in Tampa, Florida since my initial enrollment in graduate school in 1998. In my second semester at the University of South Florida, I began working as an applied researcher/behavioral consultant at the Louis de la Parte Florida Mental Health Institute (FMHI). I worked at FMHI for the next three years, obtaining training and experience working with families of children with autism and other developmental disabilities.

"At FMHI, I was fortunate to receive training and mentorship from the staff of the Division of Applied Research and Educational Support (DARES), including Drs. Glen Dunlap, Lise Fox, Pamelazita Buschbacher, Bobbi Vaughn, Donald Kincaid, and Heather George. While at DARES, I was taught how to provide services and supports to children and families using positive behavior support (PBS). Positive behavior support is an evidence-based model of problem solving designed to enhance the capacities and skills of individuals and their families (Koegel, Koegel, \& Dunlap, 1996). Based on both empirical research and humanistic values, PBS offers a method for identifying the environmental events, circumstances, and the interactions that trigger or predict challenging behavior, the purpose of challenging behavior, and the development of support strategies for preventing challenging behavior and teaching new skills (Koegel, Koegel, \& Dunlap, 1996).

"As I learned about PBS, I came to appreciate and understand the need to provide services and supports that not only teach new skills, but actually lead to meaningful 


\section{Appendix E (Continued)}

changes in the child, family, or caregiver's quality of life. I was taught that research should be a collaborative process with parents and caregivers, with a shared vision driving the team process that reflects the values, beliefs, and goals of the child's family. The notion of collaboration was held in such high regard in DARES that both parents and teachers had been routinely asked to serve as authors on published research studies or to present at local, state, national, or international conferences. My colleagues at FMHI heavily reinforced the idea that parents and teachers are truly colleagues and equal partners in the process. This is a value that I practiced as I conducted my thesis research, which entailed developing, implementing, and evaluating the degree to which a comprehensive PBS intervention plan for a middle-school aged girl with multiple disabilities had positively impacted her quality of life in the school setting. Not only were we successful as a team of parents and professionals, but the teacher served as an author in the study's publication and a follow-up study was conducted in partnership with the school and family.

"In addition to learning how to facilitate, implement, and evaluate PBS intervention plans for both individuals and entire schools, I had developed a growing interest in working with preschool-aged children, particularly those with chronic medical conditions. Under the supervision of Dr. Kathleen Armstrong, I received training in preschool assessment and intervention, completing both an advanced practicum within the Division of Child Development and Neurology of the USF Department of Pediatrics, and a year-long assistantship serving as a behavioral consultant to a local community 


\section{Appendix E (Continued)}

preschool. At this time, I became familiar with the Early Intervention Program (EIP) and the larger service system for young children that was emerging within Hillsborough County, Florida. I soon developed a passion for working with young children and their families, learning first-hand that services and supports provided at an early age could result in significant and meaningful changes. I found that if identified properly and provided in a timely and consistent manner, the opportunity existed to affect long-lasting change - to literally rewire a child's brain and to provide much needed support to their families.

"Since that realization, I completed a doctoral internship working in both the School District of Hillsborough County and at FMHI. In the former role, I served as a school psychology intern for a local elementary school, while in the latter, I served as a consultant facilitating the implementation of school-wide positive behavior support in the same school. Shortly thereafter, I returned to the EIP, assuming a position as a developmental specialist in the Division of Child Development and Neurology of the USF Department of Pediatrics, where I continued to obtain experience providing assessment and intervention for young children and their families. In this capacity, I obtained first-hand experience in working with young children with challenging behavior.

“Though I have always been to some degree disadvantaged providing support to parents since I am not a parent myself, nowhere had this “gap” been more apparent than at the EIP. Yes, I did have the advantage of being a big brother who played a big part in 


\section{Appendix E (Continued)}

raising a sister 12 years my junior. Likewise, I understand what families go through when a divorce occurs, since my own parents divorced when I was a senior in high school. However, I still did not know what it is like to be a parent, let alone a parent of a young child with challenging behavior. I realized that I lacked the perspective of a parent.

"It was at this point in my career that I truly came to realize how much of my own professional development came directly from interacting with parents. Attuned more than ever to their own experiences, successes, and stressors, I found that by listening to them, I was able to learn as much, if not more, than what I could learn from observation. Consequently, I found myself becoming more effective, enhancing my collaboration with families, better understanding a child’s needs, and identifying additional services and supports that could help children and their families. Interestingly, I found that as I saw more and more children and families, that there seemed to be a difference between the needs of children who were initially eligible for Part C services prior to 12 months and after 30 months of age. While both groups of children presented with challenging behavior, it appeared to me that the quality of the overall experience shared by families appeared different relative to the information they received from their pediatrician, their experiences learning about their child's condition, the process by which they found and received supports, and the family's overall level of satisfaction in obtaining quality services for their children. 


\section{Appendix E (Continued)}

"Perhaps equally important as this realization was the discovery that parents reported dissatisfaction with the existing system of care in Hillsborough County. Parents frequently lamented about having difficulties finding service providers, quality childcare settings, or community support groups. Others reported that they did not know where to go for help, and expressed regret over bringing their child in at an older age. Given the recent interest within the county to dramatically enhance the quality of services and supports for young children (including those with challenging behavior), I became interested in learning more about parent experiences, wondering if not only had their voices been heard, but whether or not their experiences had been considered in the development and improvement of the local system of care. As I move closer to beginning this research study, I anticipate that the parents I interview will share several different themes, and based on my own experience and interactions with other parents in similar circumstances, I would expect that the following themes will emerge:

- Pregnancy and labor

- Neonatal course (including NICU)

- Identifying concerns

- Diagnosis

- Acquiring useful and accurate medical information from pediatrician

- Entering and navigating the system of care

- Stresses associated with coordination of care

- Parents’ job experiences 


\section{Appendix E (Continued)}

- Part C eligibility evaluation

- $\quad$ Part C services and supports

- $\quad$ Respite care services, obtaining support for self

- Financial stressors associated with child's disability

- Daycare or preschool experiences

- Family members

- Access to the community, transportation

- Friends of family

- Access to church/religious services

- Impact on neighbors

I certainly cannot predict which themes will emerge or whether or not these themes even accurately represent the concerns and experiences of the families I interview. However, what is of unquestionable value is that I will later be able to reflect upon these predispositions at the end of this study and evaluate the degree to which they matched the actual themes that emerged.

“In summary, I am a firm believer that all children can learn, particularly when parents provide modeling and nonaversive support. More specifically to young children, I have observed the potential change that can occur when comprehensive services and supports are provided at an early age in collaboration with their families. However, I have also come to develop a greater appreciation for the many stressors and difficulties inherent to parenting children, particularly those with challenging behavior. Though I am 


\section{Appendix E (Continued)}

not a parent, I can see how it is easier said than done. As a professional, I feel as though it is time for me to be the student—-to learn what families have to say, so that I may share their stories and perhaps inform those within our community of how we might be able to change the system of care to better achieve its purpose.” 
Appendix F

Theme Verification Protocol

After initial contact and the interview is conducted, the researcher will transcribe data and look for common themes within groups. Following this step, the researcher will follow the theme verification protocol stated below:

1. Make telephone contact with the participant and set up a meeting for 45 minutes (15 minutes for rapport and purpose, 30 minutes for theme verification).

2. The researcher will introduce up to five selected segments of the participant's interview transcript and ask the following questions for each segment:

a. "When I asked about (question), you mentioned (read transcript). Does this sound like what you meant to say?

b. Is there a way that I should modify the statement to reflect a more accurate portrayal of your experiences?

c. Are you pleased with/do you agree with this segment?

3. After each segment has been reviewed, the researcher will ask participants if there are any other questions, or if there is anything they forgot to mention during the initial interview.

4. Finally, the researcher will ask the family if he can contact them in the future if he has any questions, provide the $\$ 50$ stipend, and thank them for their time. 


\section{Appendix G}

\section{Participant Demographic Information}

\begin{tabular}{|c|c|c|c|c|c|c|c|c|}
\hline Number & $\begin{array}{c}\text { Age at } \\
\text { Interview } \\
\text { (Months) }\end{array}$ & $\begin{array}{c}\text { First } \\
\text { Concerned } \\
\text { (Months) }\end{array}$ & $\begin{array}{c}\text { Age at } \\
\text { Eligibility } \\
\text { (Months) }\end{array}$ & Gender & $\begin{array}{c}\text { Race / } \\
\text { Ethnicity }\end{array}$ & $\begin{array}{l}\text { Medical } \\
\text { Concerns }\end{array}$ & $\begin{array}{c}\text { Challenging } \\
\text { Behaviors }\end{array}$ & Services \\
\hline \multirow[t]{3}{*}{$\begin{array}{c}1 \\
\text { Bri }\end{array}$} & 39 & 18 & 36 & $\mathrm{~F}$ & $\begin{array}{c}\text { African } \\
\text { American }\end{array}$ & $\begin{array}{l}\text { Speech } \\
\text { delay, } \\
\text { develop- } \\
\text { mental } \\
\text { delay, } \\
\text { asthma, } \\
\text { otitis } \\
\text { media, } \\
\text { eczema }\end{array}$ & $\begin{array}{l}\text { Self-injury, } \\
\text { non- } \\
\text { compliant, } \\
\text { tantrums, } \\
\text { excessive } \\
\text { crying }\end{array}$ & $\begin{array}{c}\text { Speech } \\
\text { therapy } \\
\text { evaluation; } \\
\text { EELP } \\
\text { evaluation; } \\
\text { speech } \\
\text { therapy } \\
\text { 3x/wk } 30 \\
\text { min }\end{array}$ \\
\hline & $\begin{array}{l}\text { Relation } \\
\text { to Child }\end{array}$ & $\begin{array}{c}\text { Highest } \\
\text { Education } \\
\text { (Years) }\end{array}$ & Occupation & $\begin{array}{c}\text { Zip } \\
\text { Code }\end{array}$ & & & & \\
\hline & Mother & 14 & $\begin{array}{l}\text { Admin. } \\
\text { Assistant }\end{array}$ & 33647 & & & & \\
\hline
\end{tabular}


Appendix G (Continued)

\begin{tabular}{|c|c|c|c|c|c|c|c|c|}
\hline Number & $\begin{array}{c}\text { Age at } \\
\text { Interview } \\
\text { (Months) }\end{array}$ & $\begin{array}{c}\text { First } \\
\text { Concerned } \\
\text { (Months) }\end{array}$ & $\begin{array}{c}\text { Age at } \\
\text { Eligibility } \\
\text { (Months) }\end{array}$ & Gender & $\begin{array}{c}\text { Race / } \\
\text { Ethnicity }\end{array}$ & $\begin{array}{l}\text { Medical } \\
\text { Concerns }\end{array}$ & $\begin{array}{c}\text { Challenging } \\
\text { Behaviors }\end{array}$ & Services \\
\hline \multirow[t]{3}{*}{$\begin{array}{c}2 \\
\text { Grace }\end{array}$} & 35 & Birth & 11 & F & Caucasian & $\begin{array}{l}\text { Williams } \\
\text { Syndrome }\end{array}$ & $\begin{array}{l} \\
\text { Feeding } \\
\text { concerns, } \\
\text { self-injury, } \\
\text { property } \\
\text { destruction, } \\
\text { biting, } \\
\text { tantrums, } \\
\text { screaming, } \\
\text { sensory }\end{array}$ & $\begin{array}{l}\text { Occupational } \\
\text { therapy 2x } \\
30 \text { min; } \\
\text { physical } \\
\text { therapy 2x } \\
30 \text { min; } \\
\text { speech } \\
\text { therapy 2x } \\
30 \text { min; } \\
\text { early } \\
\text { intervention } \\
\text { 1x } 60 \text { min; } \\
\text { pharmaco- } \\
\text { therapy, }\end{array}$ \\
\hline & $\begin{array}{l}\text { Relation } \\
\text { to Child }\end{array}$ & $\begin{array}{c}\text { Highest } \\
\text { Education } \\
\text { (Years) }\end{array}$ & Occupation & $\begin{array}{c}\text { Zip } \\
\text { Code }\end{array}$ & & & & \\
\hline & Mother & 12 & $\begin{array}{l}\text { Admin. } \\
\text { Assistant }\end{array}$ & 33611 & & & & \\
\hline
\end{tabular}


Appendix G (Continued)

\begin{tabular}{|c|c|c|c|c|c|c|c|c|}
\hline Number & $\begin{array}{c}\text { Age at } \\
\text { Interview } \\
\text { (Months) }\end{array}$ & $\begin{array}{c}\text { First } \\
\text { Concerned } \\
\text { (Months) }\end{array}$ & $\begin{array}{c}\text { Age at } \\
\text { Eligibility } \\
\text { (Months) }\end{array}$ & Gender & $\begin{array}{c}\text { Race / } \\
\text { Ethnicity }\end{array}$ & $\begin{array}{l}\text { Medical } \\
\text { Concerns }\end{array}$ & $\begin{array}{c}\text { Challenging } \\
\text { Behaviors }\end{array}$ & Services \\
\hline \multirow[t]{3}{*}{$\begin{array}{c}3 \\
\text { Darnell }\end{array}$} & 39 & 10 & 39 & M & $\begin{array}{c}\text { African } \\
\text { American }\end{array}$ & $\begin{array}{l}\text { Eczema, } \\
\text { speech } \\
\text { delay }\end{array}$ & $\begin{array}{l}\text { Hitting, non- } \\
\text { compliant, } \\
\text { property } \\
\text { destruction, } \\
\text { tantrums, } \\
\text { screaming, } \\
\text { excessive } \\
\text { crying, } \\
\text { stuttering, } \\
\text { withdrawn, } \\
\text { sleep } \\
\text { deprivation }\end{array}$ & $\begin{array}{c}\text { Pharmaco- } \\
\text { therapy, } \\
\text { EELP } \\
\text { Waitlist }\end{array}$ \\
\hline & $\begin{array}{l}\text { Relation } \\
\text { to Child }\end{array}$ & $\begin{array}{c}\text { Highest } \\
\text { Education } \\
\text { (Years) }\end{array}$ & Occupation & $\begin{array}{l}\text { Zip } \\
\text { Code }\end{array}$ & & & & \\
\hline & Mother & 15 & Home Maker & 33647 & & & & \\
\hline
\end{tabular}


Appendix G (Continued)

\begin{tabular}{|c|c|c|c|c|c|c|c|c|}
\hline Number & $\begin{array}{c}\text { Age at } \\
\text { Interview } \\
\text { (Months) }\end{array}$ & $\begin{array}{c}\text { First } \\
\text { Concerned } \\
\text { (Months) }\end{array}$ & $\begin{array}{c}\text { Age at } \\
\text { Eligibility } \\
\text { (Months) }\end{array}$ & Gender & $\begin{array}{c}\text { Race / } \\
\text { Ethnicity }\end{array}$ & $\begin{array}{l}\text { Medical } \\
\text { Concerns }\end{array}$ & $\begin{array}{c}\text { Challenging } \\
\text { Behaviors }\end{array}$ & Services \\
\hline \multirow[t]{3}{*}{$\begin{array}{c}4 \\
\text { DJ }\end{array}$} & 33 & 9 & 14, 26 & M & $\begin{array}{c}\text { African } \\
\text { American }\end{array}$ & $\begin{array}{c}\text { Ventricular } \\
\text { septal } \\
\text { defects x2, } \\
\text { gastro- } \\
\text { esophageal } \\
\text { reflux }\end{array}$ & $\begin{array}{l}\text { Hitting, self- } \\
\text { injury, non- } \\
\text { compliant, } \\
\text { property } \\
\text { destruction, } \\
\text { tantrums, } \\
\text { screaming, } \\
\text { scratching, } \\
\text { throwing } \\
\text { objects, } \\
\text { dropping }\end{array}$ & $\begin{array}{l}\text { EIPBS } \\
\text { waitlist }\end{array}$ \\
\hline & $\begin{array}{l}\text { Relation } \\
\text { to Child }\end{array}$ & $\begin{array}{c}\text { Highest } \\
\text { Education } \\
\text { (Years) }\end{array}$ & Occupation & $\begin{array}{l}\text { Zip } \\
\text { Code }\end{array}$ & & & & \\
\hline & $\begin{array}{l}\text { Maternal } \\
\text { Grand- } \\
\text { mother }\end{array}$ & 13 & Disabled & 33614 & & & & \\
\hline
\end{tabular}


Appendix G (Continued)

\begin{tabular}{|c|c|c|c|c|c|c|c|c|}
\hline Number & $\begin{array}{c}\text { Age at } \\
\text { Interview } \\
\text { (Months) }\end{array}$ & $\begin{array}{c}\text { First } \\
\text { Concerned } \\
\text { (Months) }\end{array}$ & $\begin{array}{c}\text { Age at } \\
\text { Eligibility } \\
\text { (Months) }\end{array}$ & Gender & $\begin{array}{c}\text { Race / } \\
\text { Ethnicity }\end{array}$ & $\begin{array}{l}\text { Medical } \\
\text { Concerns }\end{array}$ & $\begin{array}{c}\text { Challenging } \\
\text { Behaviors }\end{array}$ & Services \\
\hline \multirow[t]{3}{*}{$\begin{array}{c}5 \\
\text { Andrew }\end{array}$} & 38 & 6 & 36 & M & Caucasian & $\begin{array}{c}\text { Pervasive } \\
\text { develop- } \\
\text { mental } \\
\text { disorder } \\
\text { (not } \\
\text { otherwise } \\
\text { specified), } \\
\text { otitis } \\
\text { media }\end{array}$ & $\begin{array}{c}\text { Hitting, } \\
\text { feeding } \\
\text { concerns, } \\
\text { self-injury, } \\
\text { non- } \\
\text { compliant, } \\
\text { property } \\
\text { destruction, } \\
\text { biting, } \\
\text { tantrums, } \\
\text { screaming, } \\
\text { scratching, } \\
\text { excessive } \\
\text { crying, } \\
\text { throwing } \\
\text { objects }\end{array}$ & $\begin{array}{l}\text { None; } \\
\text { history of } \\
\text { occupational } \\
\text { therapy, } \\
\text { speech } \\
\text { therapy; } \\
\text { history of } \\
\text { IEP (autism } \\
\text { spectrum } \\
\text { disorder } \\
\text { placement) } \\
\text { pharmaco- } \\
\text { therapy, }\end{array}$ \\
\hline & $\begin{array}{l}\text { Relation } \\
\text { to Child }\end{array}$ & $\begin{array}{c}\text { Highest } \\
\text { Education } \\
\text { (Years) }\end{array}$ & Occupation & $\begin{array}{c}\text { Zip } \\
\text { Code }\end{array}$ & & & & \\
\hline & Mother & 14 & Home Maker & 33569 & & & & \\
\hline
\end{tabular}


Appendix G (Continued)

\begin{tabular}{|c|c|c|c|c|c|c|c|c|}
\hline Number & $\begin{array}{c}\text { Age at } \\
\text { Interview } \\
\text { (Months) }\end{array}$ & $\begin{array}{c}\text { First } \\
\text { Concerned } \\
\text { (Months) }\end{array}$ & $\begin{array}{c}\text { Age at } \\
\text { Eligibility } \\
\text { (Months) }\end{array}$ & Gender & $\begin{array}{c}\text { Race / } \\
\text { Ethnicity }\end{array}$ & $\begin{array}{l}\text { Medical } \\
\text { Concerns }\end{array}$ & $\begin{array}{c}\text { Challenging } \\
\text { Behaviors }\end{array}$ & Services \\
\hline \multirow[t]{3}{*}{$\begin{array}{c}6 \\
\text { Lenny }\end{array}$} & 25 & 15 & 20 & M & Caucasian & $\begin{array}{c}\text { Develop- } \\
\text { mental } \\
\text { language } \\
\text { disorder, } \\
\text { otitis } \\
\text { media, } \\
\text { delayed } \\
\text { milestones, } \\
\text { behavior } \\
\text { concerns }\end{array}$ & $\begin{array}{l}\text { Hitting, self- } \\
\text { injury, non- } \\
\text { compliant, } \\
\text { biting, } \\
\text { tantrums, } \\
\text { screaming, } \\
\text { throwing } \\
\text { objects }\end{array}$ & $\begin{array}{c}\text { Speech } \\
\text { therapy 2x } \\
30 \text { min, } \\
\text { early } \\
\text { intervention } \\
\text { (behavior) } \\
\text { 2x } 30 \text { min }\end{array}$ \\
\hline & $\begin{array}{l}\text { Relation } \\
\text { to Child }\end{array}$ & $\begin{array}{c}\text { Highest } \\
\text { Education } \\
\text { (Years) }\end{array}$ & Occupation & $\begin{array}{c}\text { Zip } \\
\text { Code }\end{array}$ & & & & \\
\hline & $\begin{array}{c}\text { Mother \& } \\
\text { Father }\end{array}$ & 18,16 & $\begin{array}{c}\text { Accountant, } \\
\text { Professional } \\
\text { Speaker }\end{array}$ & 33556 & & & & \\
\hline
\end{tabular}


Appendix G (Continued)

\begin{tabular}{|c|c|c|c|c|c|c|c|c|}
\hline Number & $\begin{array}{c}\text { Age at } \\
\text { Interview } \\
\text { (Months) }\end{array}$ & $\begin{array}{c}\text { First } \\
\text { Concerned } \\
\text { (Months) }\end{array}$ & $\begin{array}{c}\text { Age at } \\
\text { Eligibility } \\
\text { (Months) }\end{array}$ & Gender & $\begin{array}{c}\text { Race / } \\
\text { Ethnicity }\end{array}$ & $\begin{array}{l}\text { Medical } \\
\text { Concerns }\end{array}$ & $\begin{array}{c}\text { Challenging } \\
\text { Behaviors }\end{array}$ & Services \\
\hline \multirow[t]{3}{*}{$\begin{array}{c}7 \\
\text { Tank }\end{array}$} & 43 & 36 & 36 & M & $\begin{array}{l}\text { African } \\
\text { American }\end{array}$ & $\begin{array}{l}\text { Speech } \\
\text { delay, } \\
\text { asthma, } \\
\text { bronchitis }\end{array}$ & $\begin{array}{l}\text { Hitting, self- } \\
\text { injury, non- } \\
\text { compliant, } \\
\text { tantrums, } \\
\text { screaming, } \\
\text { excessive } \\
\text { crying, } \\
\text { throwing } \\
\text { objects, } \\
\text { jumping off } \\
\text { high } \\
\text { platforms }\end{array}$ & $\begin{array}{c}\text { Speech } \\
\text { therapy } \\
\text { evaluation } \\
\text { pending; } \\
\text { EIPBS } \\
\text { parent } \\
\text { group; } \\
\text { pharmaco- } \\
\text { therapy, }\end{array}$ \\
\hline & $\begin{array}{l}\text { Relation } \\
\text { to Child }\end{array}$ & $\begin{array}{c}\text { Highest } \\
\text { Education } \\
\text { (Years) }\end{array}$ & Occupation & $\begin{array}{c}\text { Zip } \\
\text { Code }\end{array}$ & & & & \\
\hline & Mother & 13 & $\begin{array}{c}\text { Home } \\
\text { Maker/Child } \\
\text { Development } \\
\text { Associate }\end{array}$ & 33612 & & & & \\
\hline
\end{tabular}




\section{Appendix $\mathrm{H}$}

\section{Assumptions and Categories for Research Question One}

\begin{abstract}
1. Parents of young children with challenging behavior will report difficulties obtaining accurate and useful information regarding their child's challenging behavior
\end{abstract}

1A. Parents of young children with challenging behavior reported that they did not always receive accurate and useful information from their pediatrician about their child's behavior.

1B. Parents of young children with challenging behavior reported that they experienced difficulties obtaining accurate medical/developmental diagnoses from their pediatrician.

1C. Parents of young children with challenging behavior reported that they learned more about their child's challenging behavior from the Internet than from a medical professional.

2. Parents of young children with challenging behavior will report difficulties obtaining services and supports designed to reduce their child's rate of challenging behavior

3. Parents of young children with challenging behavior will report that their child's challenging behavior created financial stress

2A. Parents of young children with challenging behavior reported difficulties obtaining services and supports designed to reduce their child's rate of challenging behavior (e.g., identifying community providers, setting up appointments, receiving quality services, avoiding delays without services).

3A. Parents of young children with challenging behavior reported that their child's challenging behavior has created financial stress relative to financial expenses related to their child's challenging behavior (e.g., cost of medications, health insurance, gas, daycare, healthy foods).

3B. Parents of young children with challenging behavior reported that their child's challenging behavior has created financial stress associated with their career.

4A. Parents of young children with challenging behavior reported experiencing stress among members of their immediate and extended families

challenging behavior will report experiencing stress among members of their family

5. Parents of young children with challenging behavior will report that they experience community isolation as a result of their child's challenging behavior (i.e., decreased frequency and/or duration of interactions with friends, neighbors, community resources, religious services, and/or public transportation)

6. Parents of young children with challenging behavior will report difficulties obtaining accurate and useful information regarding their child's challenging behavior
5A. Parents of young children with challenging behavior reported experiencing a degree of isolation from friends as a result of their child's challenging behavior

5B. Parents of young children with challenging behavior experienced a degree of community isolation relative to both recreational activities and support services

6A. Parents of young children with challenging behavior reported that they did not always receive accurate and useful information from their pediatrician about their child's behavior. 


\begin{abstract}
About the Author
Jonathan Worcester received a Bachelor's Degree in Liberal Arts and Sciences (Psychology) at the University of Connecticut in 1995. He enrolled in the School Psychology Doctoral Program at the University of South Florida in 1998, and prior to earning the Doctoral Degree, earned both a Master of Arts Degree (Curriculum and Instruction) in 1999, and an Educational Specialist Degree (Curriculum and Instruction) in 2003.

Jonathan is dual-certified as both a Nationally Certified School Psychologist and as a Board Certified Behavior Analyst. He has extensive experience supporting preschool- and elementary-aged children and families with severe disabilities and has conducted research in the areas of positive behavior support, applied behavior analysis, early intervention, and family voice. Jonathan’s current research interests include early intervention, positive behavior support, child development, and pediatric school psychology. Jonathan is the author/co-author of several peer-reviewed articles and has presented/facilitated training ranging from the local to international level.
\end{abstract}

